\title{
ASSEMBLY AND PERFORMANCE MODELING OF PROTON EXCHANGE MEMBRANE FUEL CELLS
}

\author{
by \\ Yuanyuan Zhou \\ A dissertation submitted in partial fulfillment \\ of the requirements for the degree of \\ Doctor of Philosophy \\ (Mechanical Engineering) \\ in The University of Michigan \\ 2009
}

Doctoral Committee:

Professor Shixin Jack Hu, Co-Chair

Professor Albert J. Shih, Co-Chair

Professor James R. Barber

Professor Levi T. Thompson Jr. 
C $\quad \frac{\text { Yuanyuan Zhou }}{\text { All Rights Reserved }}$

2009 


\section{ACKNOWLEDGEMENTS}

I would never have been able to finish my dissertation without the guidance of my committee members, help from friends, and support from my parents and my fiancé.

First and foremost, my deepest gratitude is to my advisor, Professor S. Jack Hu for sharing with me his vast knowledge and great vision and providing me tremendous help and stimulating suggestions. I have been amazingly fortunate to have an advisor who gave me the freedom to explore on my own and at the same time the guidance to recover when my steps faltered. Professor Hu taught me how to think critically and express clearly. His patience and support helped me overcome many tough situations and finish this dissertation.

My co-advisor, Professor Albert Shih, is always willing to help me and give his best suggestions to me. I am deeply grateful to him for the long discussions that helped me sort out the technical details of my work and improve my papers. I am also thankful to him for commenting on my views and helping me understand and enrich my ideas. His enthusiasm in research has truly inspired me along the way. I greatly appreciate his great help and sincere advice on my future career development.

I would also like to extend my sincere gratitude to my other committee members, Professor James Barber and Levi Thompson for their constructive suggestions and valuable discussions along my studies. Professor Barber is one of the best teachers that I 
have had in my life. He sets high standards for his students and he encourages and guides them to meet those standards. He opened the door of contact mechanics to me and I greatly enjoyed and benefited through his teaching. I really appreciate Professor Thompson's insightful vision and knowledge on energy technology development.

Very special thanks go to Dr. Guosong Lin. Through the three years we worked together closely, he gave me numerous help and encouragement. I couldn't have finished my Ph.D project without his knowledge, help and support. I am deeply indebted to him.

I would like to thank my peers in the Hu Lab and many other friends for their unconditional supports and friendship.

I will forever be thankful to my former advisor at Tsinghua University in China, Professor Xiaofeng Peng. He is the one who firstly showed me the wonders and frustrations of scientific research. I truly appreciate his guidance and friendship. Without his sincere advice and encouragement, I would not have the chance and courage to pursue the doctoral degree. His dedications to research have inspired me for the past years and will inspire me forever.

Most importantly, none of this would have been possible without the love and support of my family. My parents whom this dissertation is dedicated to, have been a constant source of love, concern, support and strength all these years. I want to express my deep appreciation for their faith in me no matter what I have chosen to do. They are always supporting and providing the best they can do to enlarge my vision and enrich my life. 
Finally, I would like to thank my fiancé Han Zhang for his love, understanding, consistent support and kind indulgence for the past ten years. He is always there cheering me up and stands by me through all the excitements and frustrations.

I owe my gratitude to all those people who have made this dissertation possible and made my doctoral study experience enjoyable. 


\section{TABLE OF CONTENTS}

ACKNOWLEDGEMENTS ........................................................................................ ii

LIST OF FIGURES ............................................................................................... vii

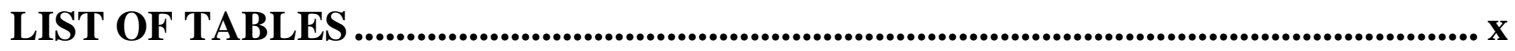

CHAPTER 1 INTRODUCTION ......................................................................... 1

1.1 Motivation......................................................................................... 1

1.2 Research objectives.......................................................................... 7

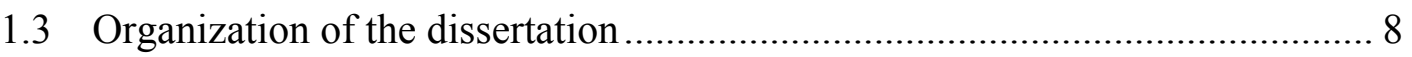

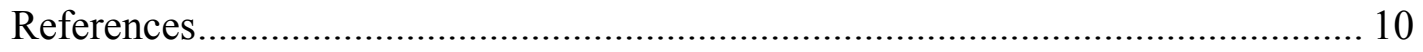

\section{CHAPTER 2 A MICRO-SCALE MODEL FOR PREDICTING CONTACT} RESISTANCE BETWEEN BIPOLAR PLATE AND GAS DIFFUSION LAYER IN PEM FUEL CELLS ................................... 11

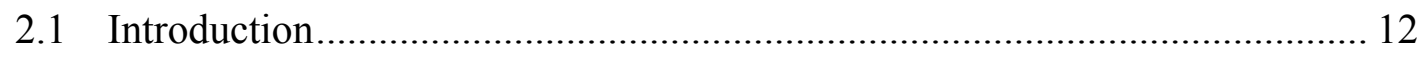

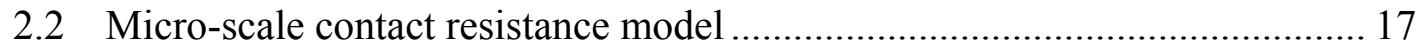

2.2.1 BPP surface topology simulation................................................ 18

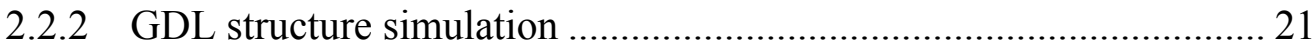

2.2.3 Contact resistance numerical model ............................................. 24

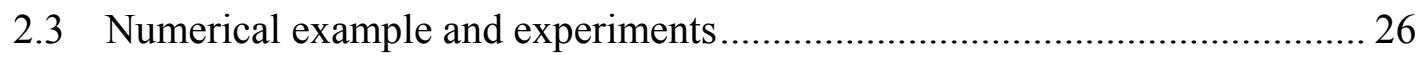

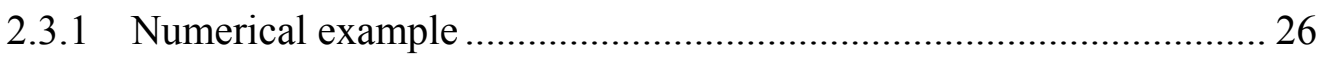

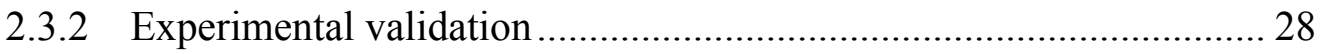

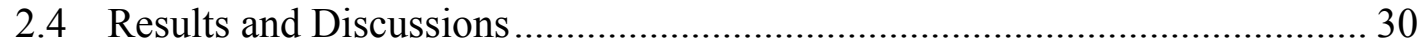

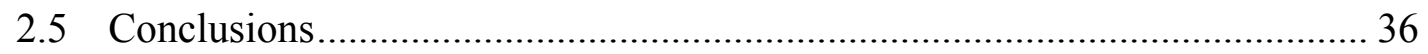

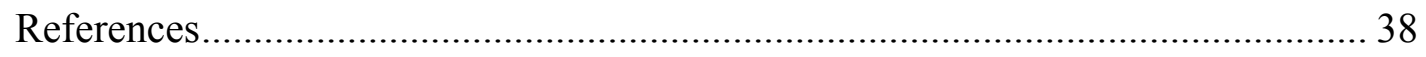

\section{CHAPTER 3 MULTI-PHYSICS MODELING OF ASSEMBLY PRESSURE} EFFECTS ON PEM FUEL CELL PERFORMANCE......................... 40

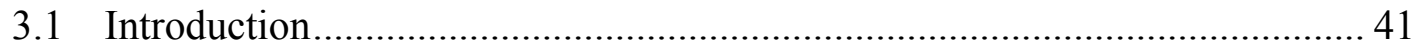




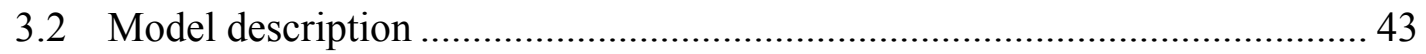

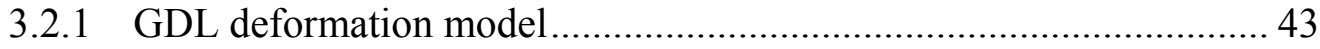

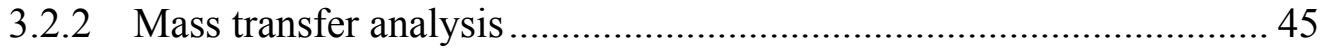

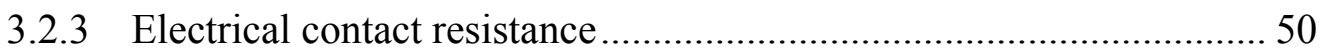

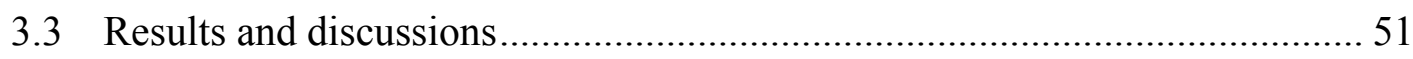

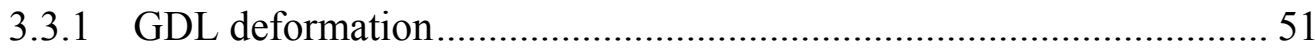

3.3.2 Assembly pressure effects on mass transfer ...................................... 53

3.3.3 Assembly pressure effects on electrical contact resistance.................. 55

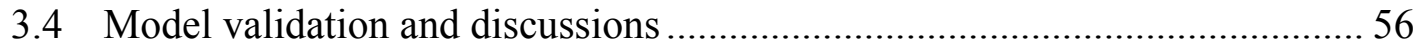

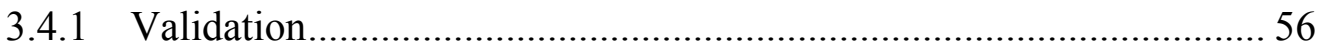

3.4.2 Assembly pressure effects on the overall PEM fuel cell performance 57

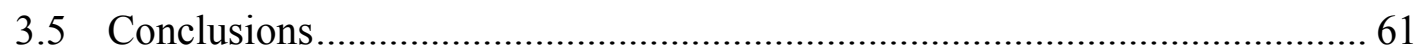

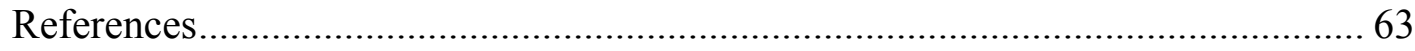

\section{CHAPTER 4 ASSEMBLY PRESSURE AND MEMBRANE SWELLING IN PEM} FUEL CELLS .......................................................................66

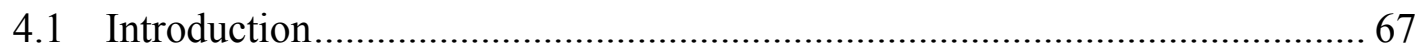

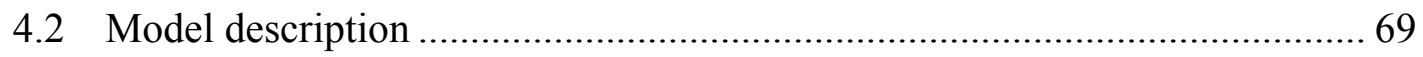

4.2.1 Stack deformation model under elevated temperature and humidity . 70

4.2.2 Contact resistance ........................................................................ 76

4.2.3 PEM fuel cell performance analysis .................................................. 77

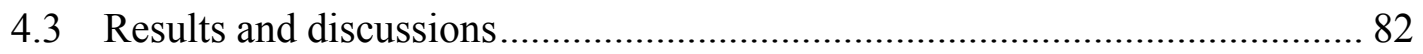

4.3.1 GDL and membrane deformation .................................................. 82

4.3.2 PEM fuel cell Performance .................................................................. 85

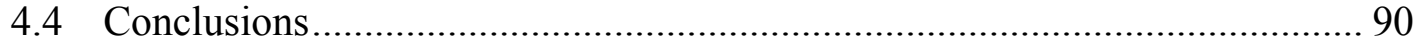

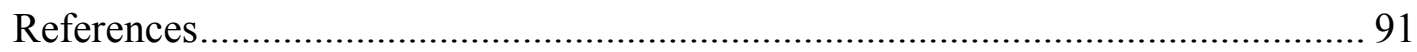

CHAPTER 5 CONCLUSIONS AND FUTURE WORK ................................................ 94

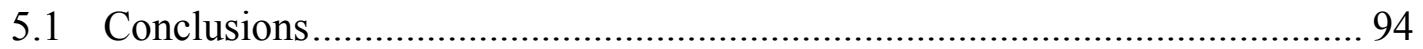

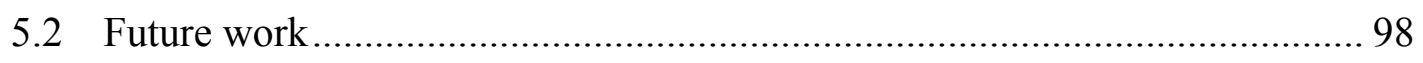




\section{LIST OF FIGURES}

Figure 1.1 Schematic of a PEM fuel cell stack [Costamagna and Srinivasan, 2001]...... 2

Figure 1.2 Typical performance curve for a fuel cell [Williams, 2000] .......................... 3

Figure 1.3 Schematic of stack assembly and membrane swelling ............................... 5

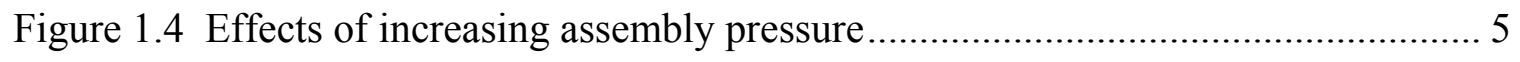

Figure 2.1 Schematic structure of a PEM fuel cell ................................................... 13

Figure 2.2 Schematic view of contact interface between BPP and GDL [Mishra et al.,

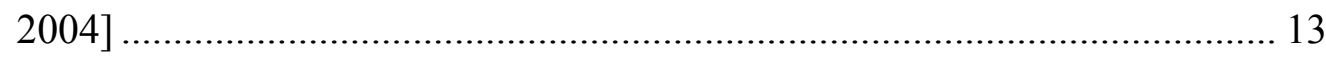

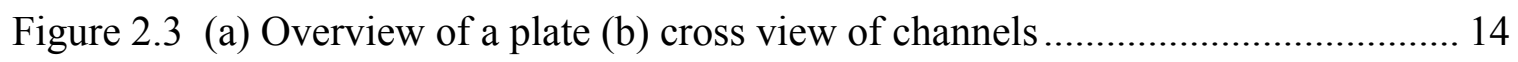

Figure 2.4 Two dimensional surface profile of bipolar plate from profilometer scans ... 19

Figure 2.5 Histogram of surface height distribution .............................................. 20

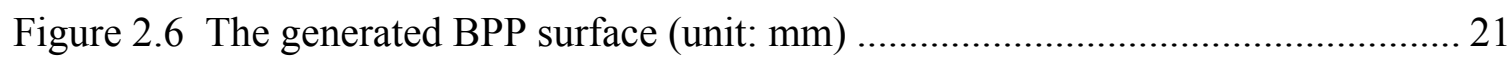

Figure 2.7 SEM micrographs of carbon fiber paper .............................................. 22

Figure 2.8 Simulation of one layer of carbon fiber in a GDL ..................................... 23

Figure 2.9 Two-dimensional illustration of the relative position between BPP asperities

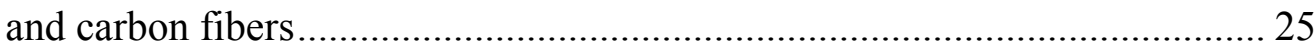

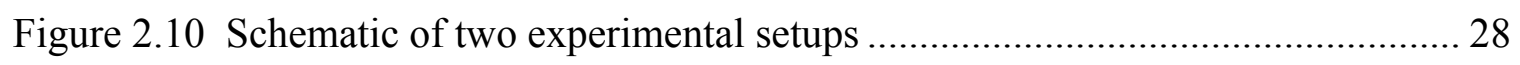

Figure 2.11 Experimental setup for contact resistance measurement ........................... 29

Figure 2.12 Comparison of experimental data with numerical prediction .................... 30

Figure 2.13 Influence of BPP summit density ..................................................... 32 
Figure 2.14 Influence of BPP summit radius.

Figure 2.15 Influence of BPP summit height standard deviation.....

Figure 2.16 The relationship between assembly pressure and the reciprocal of contact resistance at various BPP summit height standard deviations. 35

Figure 2.17 The relationship between $\mathrm{P}^{*} \mathrm{R}$ and BPP summit height standard deviation 36 Figure 3.1 Schematic of a PEM fuel cell: (a) cross section and (b) computational domain

Figure 3.2 Predicted contour of effective strain at $15 \mathrm{MPa}$ pressure 52

Figure 3.3 (a) Cell geometry before deformation and (b) deformed shapes of GDL under assembly pressures $0.1,1$ and $15 \mathrm{MPa}$ respectively 52

Figure 3.4 Compression ratio and porosity vs. assembly pressure 53

Figure 3.5 Assembly pressure effect on PEM fuel cell performance with only mass transfer resistance being considered 53

Figure 3.6 Simulated contact resistance vs. assembly pressure. 56

Figure 3.7 Polarization curves comparison between the modeling results with the experimental data under different assembly pressures.

Figure 3.8 Effect of assembly pressure on overall fuel cell performance: (a) polarization curves at different assembly pressures and (b) current density vs. assembly pressure at different cell voltages 58

Figure 3.9 Contours of current density at $0.58 \mathrm{~V}$ cell voltage and assembly pressure of:

(a) 0.6 MPa and (b) $15 \mathrm{MPa}$. 60

Figure $3.10 \mathrm{O}_{2}$ mass faction in GDL at channel outlet at assembly pressure: (a) $0.6 \mathrm{MPa}$ and (b) $15 \mathrm{MPa}$. 61 


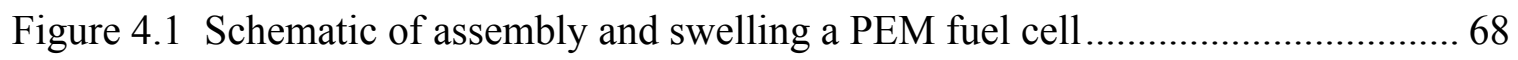

Figure 4.2 Swelling expansion as a function of humidity and temperature for Nafion ${ }^{\circledR} 112$

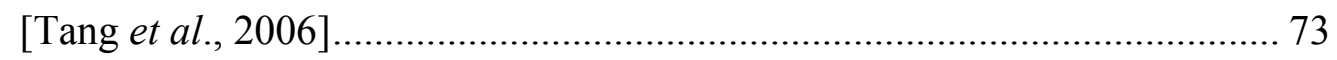

Figure 4.3 Finite element model for stack deformation analysis ............................... 73

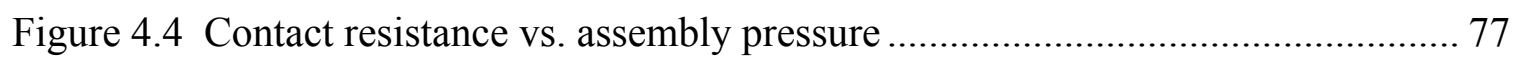

Figure 4.5 Computational domain for the base case............................................. 78

Figure 4.6 Predicted displacement contour at $Y$-direction under $3 \mathrm{MPa}$ assembly pressure

Figure 4.7 Deformed shape of GDL and membrane at various conditions ................... 83

Figure 4.8 Contact pressure and contact resistance at various operating conditions....... 84

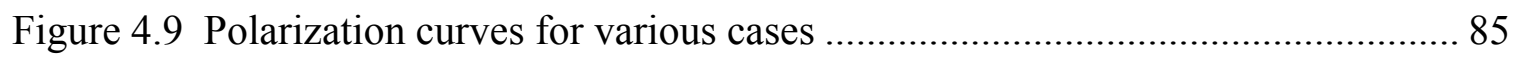

Figure 4.10 Current production rate profiles at the interface between CL and GDL for

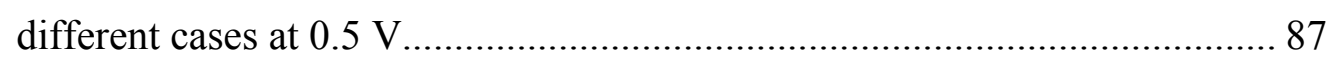

Figure 4.11 Current production rate profiles in the CL for different cases at $0.5 \mathrm{~V} \ldots \ldots .89$ 


\section{LIST OF TABLES}

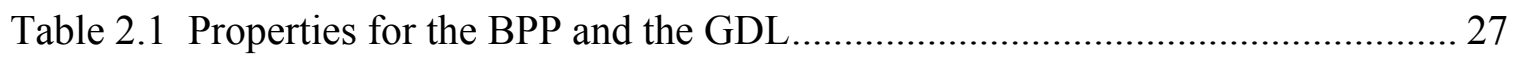

Table 2.2 Inputs parameters for the numerical contact model.................................... 27

Table 3.1 Geometric and physical parameters for the multi-physics performance model

Table 3.2 Binary diffusivities at reference temperatures and $1 \mathrm{~atm}$ [Inoue et al., 2006] 47

Table 3.3 Operating parameters for the multi-physics performance model .................. 49

Table 4.1 Geometric and physical parameters for the structural model and mass transfer analysis.

Table 4.2 Component material mechanical properties [Mathias et al., 2003; Kusoglu et al., 2006; Tang et al., 2006].

Table 4.3 Young's modulus (MPa) at various temperature and humidity for Nafion ${ }^{\circledR} 112$

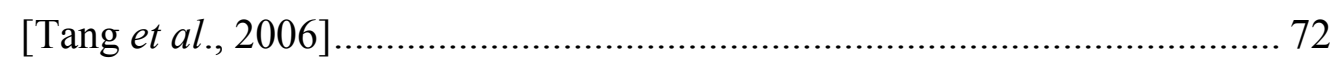

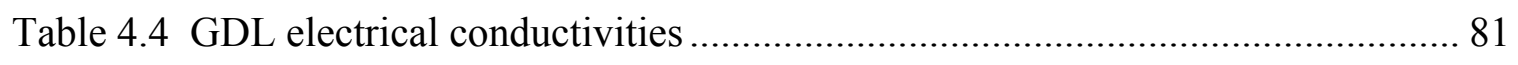




\section{CHAPTER 1}

\section{INTRODUCTION}

\subsection{Motivation}

Fuel cells are electrochemical devices that directly convert the chemical energy of reactions into electrical energy. Fuel cells and the associated hydrogen economy have been recognized as a key element of the future energy infrastructure beyond the current fossil-fuel based energy systems, owing to their merits of theoretically high efficiency and environment friendliness. In particular, proton exchange membrane (PEM) fuel cells have received broad attentions due to their low operation temperature, low emission and quick startup. They are ideally suited for transportation, small stationary and portable power applications. Commercialization of PEM fuel cell technologies depends on achieving a high specific power for a given cost, performance and durability. However, there have been questions on the performance robustness of fuel cells and the cost of manufacturing in addition to the need of a hydrogen support infrastructure. Even though fuel cell technology is more than 100 years old, research into design and manufacturing technologies that enable affordable production is just at its infancy. Cost, performance robustness and hydrogen infrastructure have been the key technical barriers to the broad adaptation and commercialization of PEM fuel cells. 
A typical PEM fuel cell consists of a cell stack, water and thermal management modules, hydrogen and oxygen management modules, and a power conditioning and system control module. A cell stack is an assembly of membranes, catalysts layers, gas diffusion layers (GDL), bipolar plates (BPP) and seals as shown in Fig.1.1. The PEM fuel cell stack is a combination of several flow systems, i.e., electrical, chemical, fluid and heat flows; therefore, it is the heart of the whole fuel cell system. The stack is sized to generate the designed power output. PEM fuel cells show some losses of efficiency and power density with the scale up when the number of cells and their areas increase in a stack. PEM fuel cell stack assembly process, component quality, contact status between components, etc. may contribute to performance degradation.

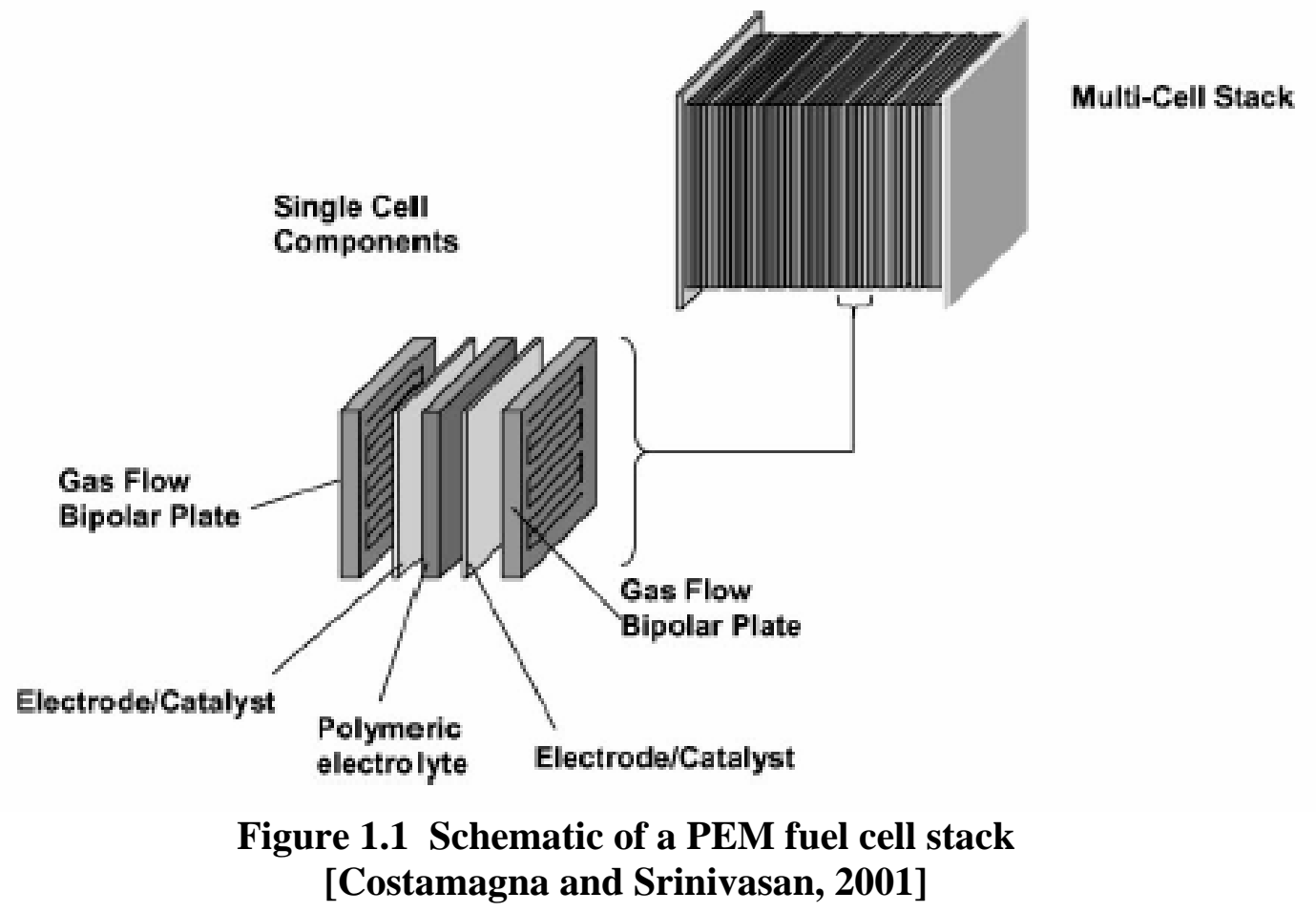

A standard criterion for fuel cell performance evaluations is the performance curve, as shown in Fig. 1.2. Electrical energy is obtained from a fuel cell only when a 
reasonably current is drawn, but the actual cell potential is decreased from its equilibrium potential because of irreversible losses caused by activation polarization, ohmic polarization and concentration polarization.

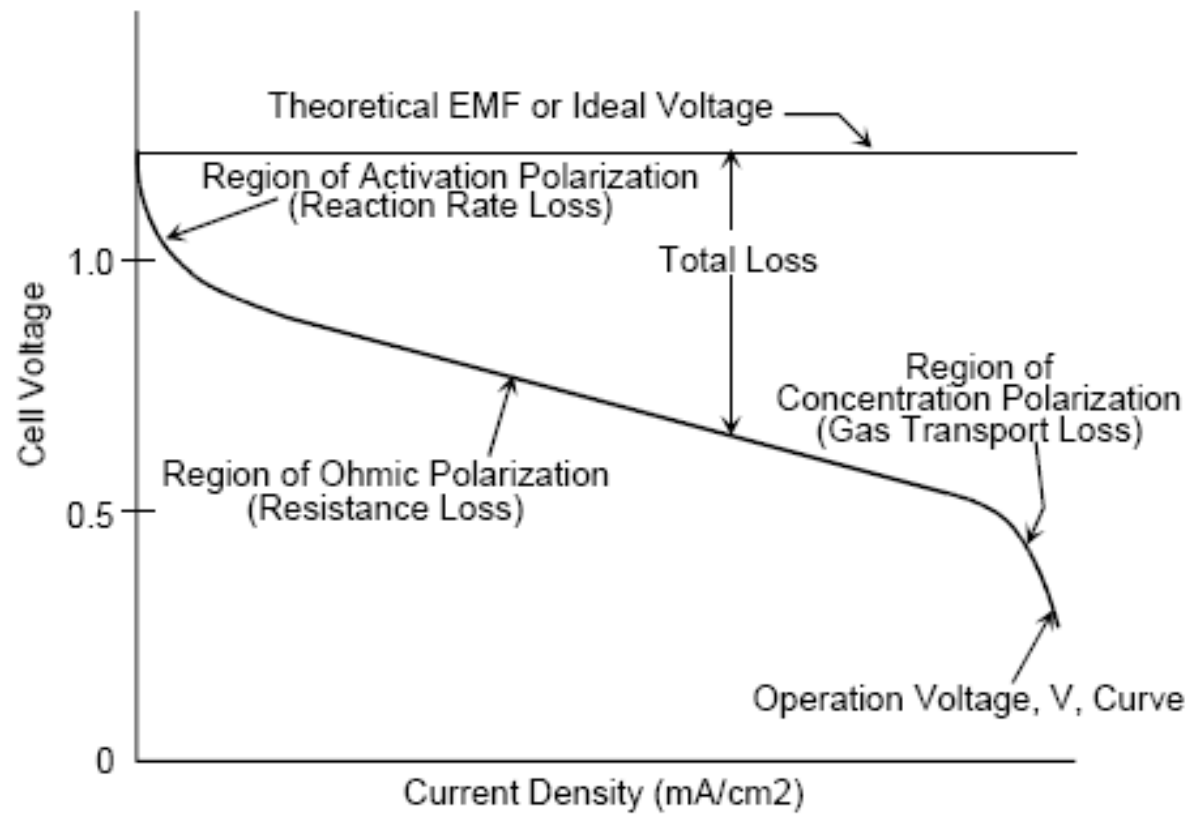

Figure 1.2 Typical performance curve for a fuel cell [Williams, 2000]

Improving PEM fuel cell stack performance requires the matching of many design and operating factors, e.g., stack manifold designs, flow channels on the bipolar plates and the stack operating conditions etc. Significant improvements of PEM fuel cell performance can be achieved by exploration innovative materials and component design and manufacturing [Haile, 2005; Mehta and Cooper, 2003]. In addition, the performance of a PEM fuel cell also depends on compression pressure resulting from stack assembly force based on experimental observations. Both the assembly force and component type are important factors influencing the performance of PEM fuel cells [Lee et al., 1999].

As fuel cell manufacturing scales up, the relationship between fuel cell performance and design, manufacturing, and assembly processes must be well understood. 
Assembly pressure plays a significant role in determining fuel cell performance. During the assembly of a PEM fuel cell stack, GDL, BPP, and membrane are clamped together using mechanical devices. A proper level of clamping pressure is needed to provide adequate gas sealing, as well as to reduce contact resistances at component interfaces. However, too high a pressure may over-compress the membrane and GDL, crushing their porous structures and cracking the BPP. In addition, the electrical contact resistance, which constitutes a significant part of the ohmic resistance in a cell, especially when stainless steel, titanium or molded graphite is chosen as the BPP material, can be significantly altered by clamping pressure and operating conditions.

Assembly pressure makes the part of GDL under the land area be compressed and the part under channel area be protruded into channel cavity (as shown in Fig. 1.3). This inhomogeneous compression causes unevenness of the material properties of GDL. Most of the fuel cell performance models do not account for the inhomogeneous compression of GDL and its effects since GDL thickness, porosity, and electrical conductivities are typically assumed constant over the cell area in these models. But in reality, the inhomogeneous deformation of GDL as well as significant change of material properties influences fuel cell performance and durability dramatically. Furthermore, when temperature and relative humidity increase during operation, the membrane absorbs water and swells. Since the relative position between the top and bottom end plates is fixed, the polymer membrane is spatially confined. Thus the GDL will be further compressed under the land and the intrusion into channel becomes more significant. Assembly pressure, contact resistance, membrane swelling and operating conditions, etc., combine to yield an optimum assembly pressure. 


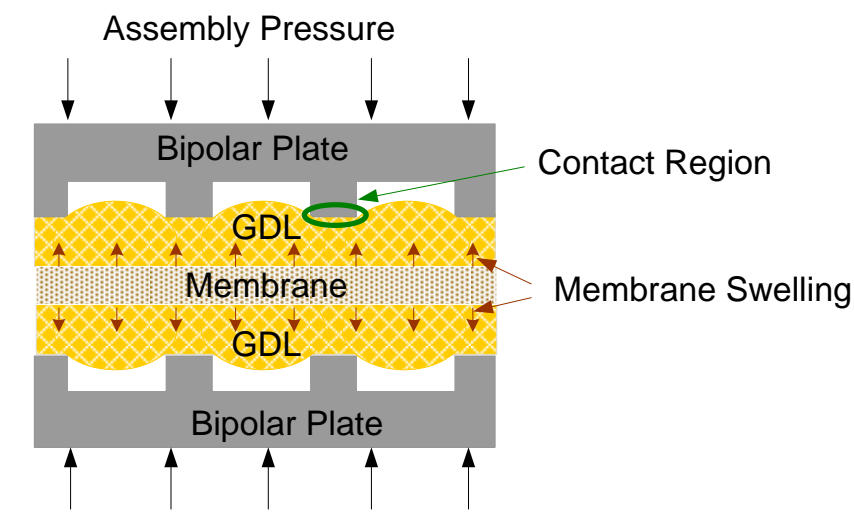

Figure 1.3 Schematic of stack assembly and membrane swelling

A flowchart summarizing the effects of increasing assembly pressure is presented in Fig. 1.4. Increasing assembly force will affect fuel cell performance from multiple mechanisms. The pore volume of GDL, membrane and catalyst layer will be reduced at higher assembly force, hence gas flow has more resistance and water removal path will be changed at the same time. However, stack components will be in better contact so the electrical and thermal contact resistances are decreased. Moreover, since GDL has a fiber-contact structure, when assembly pressure increases, the contact status between fibers will be enhanced, thus bulk conductivity of GDL is increased. Some of those effects have negative impacts on performance while some have positive ones. The total effects depend on the compromise of all those influencing factors.

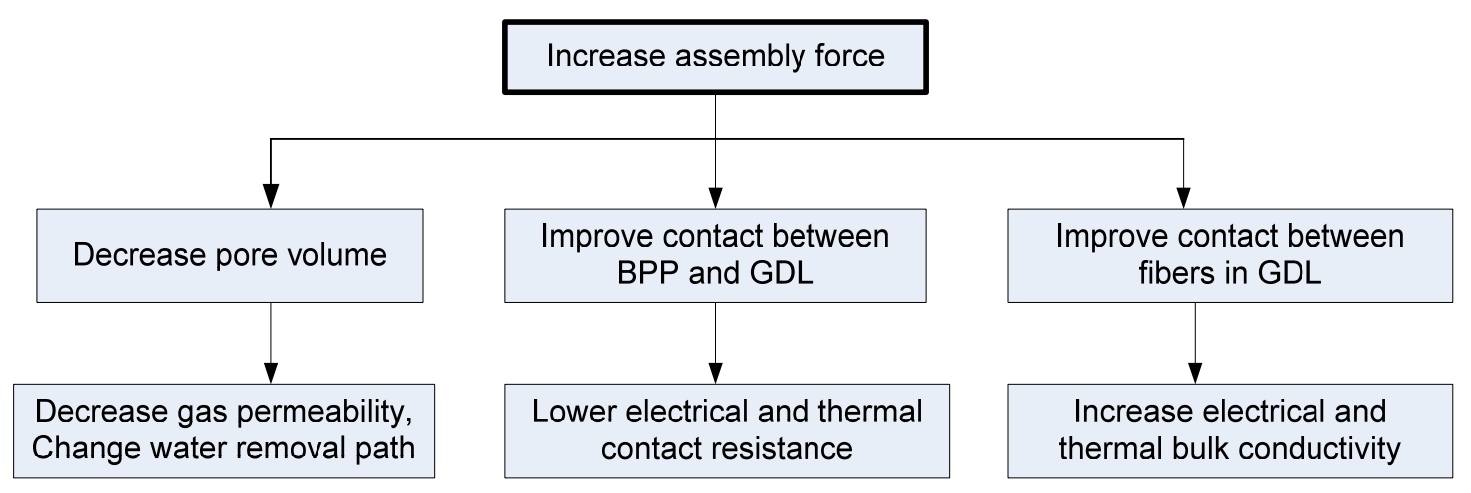

Figure 1.4 Effects of increasing assembly pressure 
A significant amount of research has been devoted to the study of PEM fuel cell stacks and several empirical and mathematical models have been developed for the purpose of understanding and predicting PEM fuel cell performance. Modeling studies of PEM fuel cell performance from 1960s to 2000 were reviewed by Costamagna and Srinivasan [2001], starting from membrane and electrode scale up to the system level analysis with particular emphasis on gas and water transport in the electrodes. A comprehensive review of fuel cell models can be found in Weber and Newman [2003].

Very few efforts have been made on the study of contact resistance and the impact of assembly pressure on performance. But in reality, fuel cell stacks are under significant compression after assembly and during operation. The wide range of compression is attributed to the swelling behavior of porous media, design of stack assembly and operating conditions. All these have an adverse impact on the performance and durability of fuel cells. Hence a comprehensive analysis of stack compression, contact resistance, operating conditions and performance is desired.

During the process of fuel cell stack assembly, the stack is vulnerable to misalignment due to its multi-layer structure. For example, the channel alignment of the bipolar plate on the anode side may not be in the perfect match of the channel on the cathode side. In this research, we focus on the fundamental phenomena induced by assembly force in a small scale. Therefore, it is assumed that the stack is in a perfect alignment. 


\subsection{Research objectives}

The objective of this research is to develop comprehensive multi-physics models to predict the performance of PEM fuel cells by incorporating assembly issues, contact resistance, component material properties, and operating conditions. Such a model will be utilized to improve fuel cell design and manufacturing to ensure robust performance. The specific tasks include:

(1) To develop a micro-scale model to predict the contact resistance between BPP and GDL, taking the material properties, surface profile and clamping pressure as inputs.

(2) To develop multi-physics models of fuel cell performance by incorporating the influence of assembly pressure, contact resistance, gas flow and diffusion, chemical reactions to predict fuel cell performance more accurately and optimize assembly pressure.

(3) To investigate assembly pressure and membrane swelling induced by elevated temperature and humidity during in PEM fuel cell operation; Contact resistance, stack inhomogeneous deformation, stack performance and current distribution will be studied at various assembly pressure, temperature and humidity.

Fulfillment of the objectives will provide a comprehensive understanding of the impact of assembly pressure on electrical contact resistance and performance in fuel cell stack assembly. Some manufacturing parameters and optimal assembly pressure will be established to optimize fuel cell performance, design and manufacturing. In summary, 
results from this dissertation will lead to improved manufacturing and assembly of PEM fuel cells as well as improved performance.

\subsection{Organization of the dissertation}

This dissertation is presented in a multiple manuscript format. Chapter 2, 3 and 4 are written as individual research papers, including the abstract, the main body and the references.

Chapter 2 develops a micro-scale numerical model to predict the contact resistance between BPP and GDL in PEM fuel cells taking the material properties, surface roughness and clamping pressure as inputs. Experimental measurements of contact resistance between BPP and GDL are also conducted to validate the model. The BPP surface roughness is simulated by adapting the classical statistical contact model to represent real BPP surface. The GDL is modeled as randomly distributed fibers with parameters obtained from experimental characterizations. The contact resistance thus can be predicted by locating each contact spot through the simulated surfaces [Zhou et al., 2007].

Chapter 3 establishes a finite-element-based structural and mass-transfer model by incorporating mechanical deformation, mass transfer resistance, and electrical contact resistance to study the fuel cell overall performance and the effects of assembly pressure. A finite element approach is implemented to model component deformation and the change of material properties induced by assembly pressure. A PEM fuel cell performance model is developed based on the deformed GDL geometry and modified 
GDL gas transport parameters obtained from stack structural model. Contact resistance is also included when evaluating performance. The comprehensive fuel cell performance predicted by the model is then compared with experimental measurements of PEM fuel cell voltage-current performance curves from existing literature. Local current density and oxygen mass fraction distribution are also discussed [Zhou et al., 2008].

Chapter 4 investigates fuel cell stack deformation, contact resistance and performance by taking into account the combined effects of assembly pressure and membrane swelling induced by elevated temperature and relative humidity during operation. A finite element model is first developed to model stack mechanical behavior under different assembly pressures, temperature and humidity. Component deformation, change of material properties and local contact pressure are obtained. Then gas flow and diffusion, ion transport and chemical reactions are modeled based the updated geometry and material properties. Contact resistance is also incorporated in the model. The impact of assembly pressure and operating conditions is evaluated by fuel cell performance and current density distribution [Zhou et al., 2008].

Chapter 5 draws the conclusions and summarizes the original contributions of the dissertation. Several topics are also proposed for future research. 


\section{References}

Costamagna, P., Srinivasan, S., (2001), "Quantum jumps in the PEMFC science and technology from the 1960s to the year 2000", Journal of Power Sources, Vol. 102, pp. 253-269.

Haile S., (2003), "Fuel cell materials and components," Acta Materialia, Vol. 51, pp. 5981-6000.

Lai, Y. H., Miler, D. P., Ji, C., Trahold, T. A., (2004), "Stack compression of PEM Fuel Cells", Proceedings of Second International Conference on Fuel Cell Science, Engineering and Technology.

Lee, W., Ho, C., Zee, J., Murthy, M., (1999), “The effects of compression and gas diffusion layers on the performance of a PEM fuel cell," Journal of Power Sources, Vol. 84, pp. 45-51.

Mehta V., Cooper J., (2003), "Review and analysis of PEM fuel cell design and manufacturing," Journal of Power Sources, Vol. 114, Issue 1, pp. 32-53.

Weber A., Newman J., (2003)," Modeling transport in polymer-electrolyte fuel cells," Chem. Rev. Vol. 104, pp. 4679-4726.

Williams, M. C., (2000), Fuel Cell Handbook (Fifth edition), U.S. Department of Energy Office of Fossil Energy National Energy Technology Laboratory.

Zhou, Y., Lin, G., Shih, A. J. and Hu, S. J. (2007), “A micro-scale model for predicting contact resistance between bipolar plate and gas diffusion layer in PEM fuel cells," Journal of Power Sources, Vol. 163, pp. 777-783.

Zhou, Y., Lin, G., Shih, A. J. and Hu, S. J. (2008), "Multi-Physics Modeling of Assembly Pressure Effects on PEM Fuel Cell Performance," ASME Journal of Fuel Cell Science and Technology, in press.

Zhou, Y., Lin, G., Shih, A. J. and Hu, S. J. (2008), “Assembly pressure and membrane swelling in PEM fuel cells," to be submitted to Journal of Power Sources. 


\title{
CHAPTER 2
}

\section{A MICRO-SCALE MODEL FOR PREDICTING CONTACT RESISTANCE BETWEEN BIPOLAR PLATE AND GAS DIFFUSION LAYER IN PEM FUEL CELLS}

\begin{abstract}
Contact resistance between BPP and GDL in a PEM fuel cell constitutes a significant portion of the overall fuel cell electrical resistance under normal operation conditions. Most current methods for contact resistance estimation are experimental and there is a lack of well developed theoretical methods. A micro-scale numerical model is developed to predict the electrical contact resistance between BPP and GDL by simulating the BPP surface topology and GDL structure and numerically determining the status for each contact spot. The total resistance and pressure are obtained by considering all contact spots as resistances in parallel and summing the results together. This model shows good agreements with experimental results. Influences of BPP surface roughness parameters on contact resistance are also studied. This model is beneficial in understanding the contact behavior between BPP and GDL and can be integrated with other fuel cell simulations to predict the overall performance of PEM fuel cells.
\end{abstract}

\footnotetext{
* Contents of this chapter have been published as Zhou, Y., Lin, G.., Shih, A. J. and Hu, S. J. (2007), "A micro-scale model for predicting contact resistance between bipolar plate and gas diffusion layer in PEM fuel cells," Journal of Power Sources, Vol. 163, pp. 777-783.
} 


\subsection{Introduction}

Fuel cells are a promising power technology with a wide variety of potential applications. Particularly, PEM fuel cells are one of the best candidates due to their low operation temperature, low emission and quick startup. One of the key technical barriers to the commercialization of PEM fuel cells is the cost effective manufacturing and precision assembly of fuel cell stacks to achieve the desired performance. One of such performance measures is the cell potential, which decreases from its equilibrium potential during operation because of irreversible losses caused by activation, concentration and ohmic resistances. Among all these resistances, ohmic resistance is dominant under the normal fuel cell operation conditions. Contact resistance constitutes a significant part of the ohmic resistance, especially when stainless steel, titanium or molded graphite is chosen as the BPP material [Makkus et al., 2002; Davies et al., 2000].

Contact resistance occurs at all interfaces inside the fuel cell, the most important one being at the interface between BPP and GDL, as shown in Fig. 2.1 and Fig. 2.2. BPP performs a number of functions within the PEM fuel cells which constitute more than $60 \%$ of the weight and $30 \%$ of the total cost in a fuel cell stack. Figure 2.3 shows an example of carbon bipolar plate provided by General Motors. BPPs have been used to

distribute the fuel and oxidant within the cell, to carry current away from the cell, and to facilitate water management within the cell. In the absence of dedicated cooling plates, the bipolar plates also facilitate heat management. Plate topologies and materials facilitate these functions. Groove topologies on the BPP can include straight, serpentine, or inter-digitated flow field. Besides materials and channel designs, flatness, parallelism of the faces, and uniformity of the flow fields are still important features for bipolar 
plates. Whether fabricated using molded graphite or formed stainless steels, the surfaces of a bipolar plate will contain components of various wavelengths, which are roughness and waviness. Performance, durability, and life of the fuel cell will all be impacted by these unintended features of BPP.

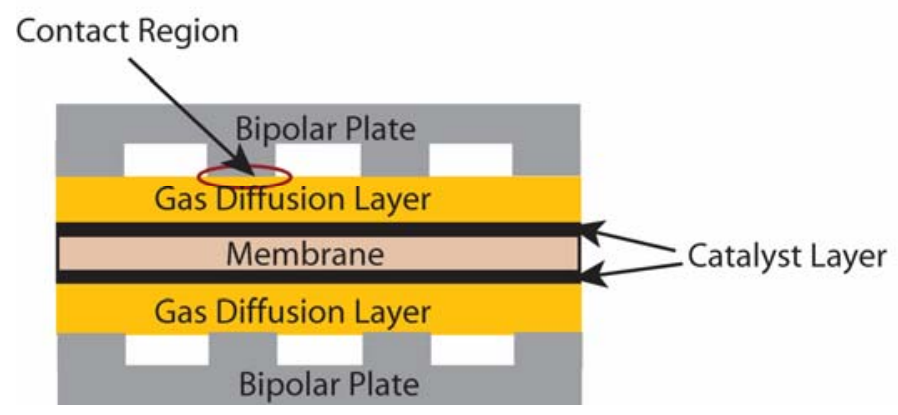

Figure 2.1 Schematic structure of a PEM fuel cell

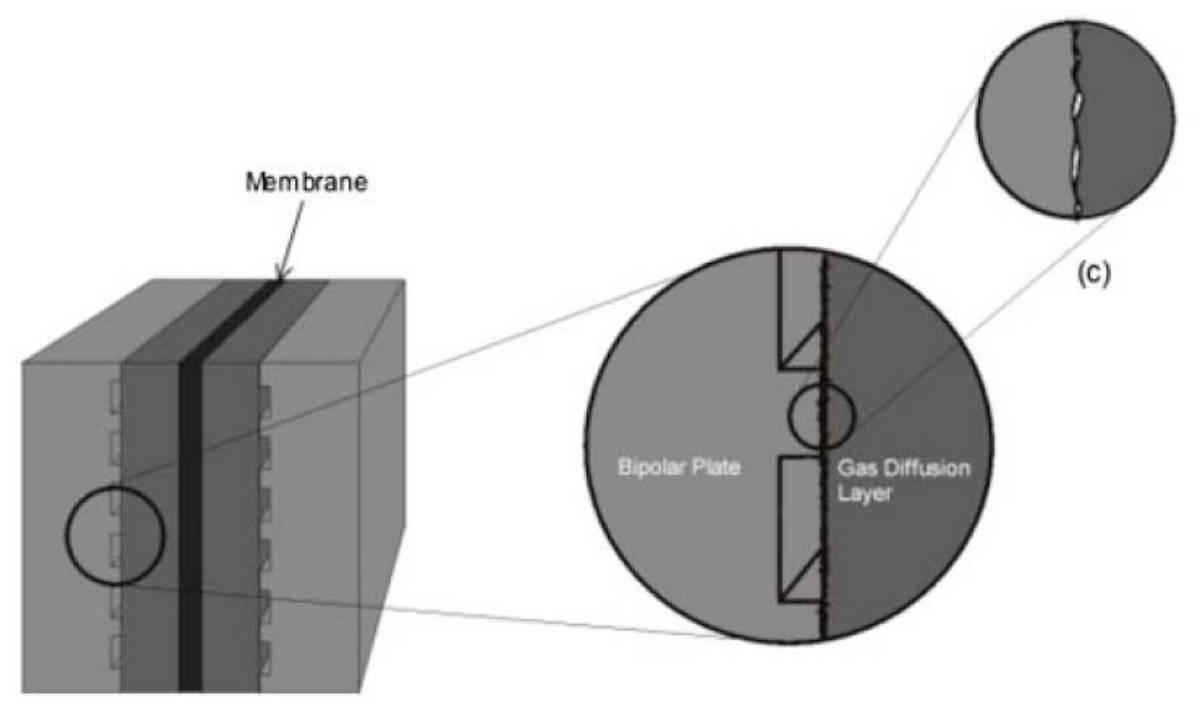

Figure 2.2 Schematic view of contact interface between BPP and GDL [Mishra et al., 2004]

The GDLs, one next to the anode and another next to the cathode, are usually carbon-fiber-based products, such as non-woven papers. Gas diffusion media has perhaps been the component most dependent on empiricism for its development. Despite its many functions, it has received very little development attention, as evidenced by the scarcity 
of publications on PEM fuel cell diffusion media in the literature. However, it is likely that issues in gas diffusion layers, such as, deformation when used in a real fuel cell assembly, contact status with bipolar plates, durability, flooding under steady-state and transient (e.g., start-up) conditions are not fully understood.

At this early stage in PEM fuel cell diffusion-media development, relatively little correlation has been achieved between ex-situ characterization results and in-situ performance. However, in fuel cell operation, the thickness, porosity and morphology of gas diffusion layer will be totally different due to temperature, humidity and clamping pressure. Moreover, carbon fibers in gas diffusion layer are usually in deformation and bending status. The development of diffusion media needs much more attention before the widespread commercialization of PEM fuel cells.

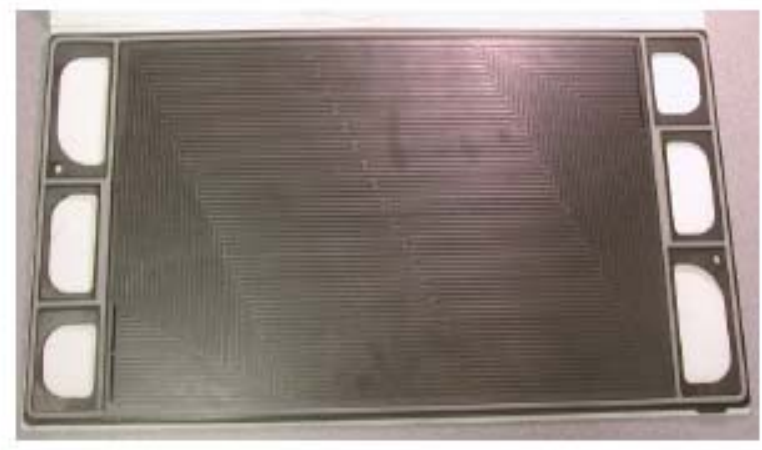

(a)

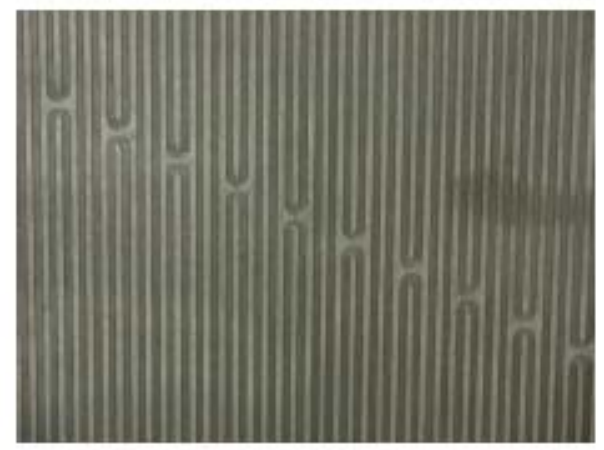

(b)

Figure 2.3 (a) Overview of a plate (b) cross view of channels

Some recent studies show that contact resistance between gas diffusion layers and bipolar plates is much greater than the bulk resistance of GDL and BPP [Mathias, 2003]. The extent of contact losses has been measured by Barbir et al. [1999], who found that for a normal fuel cell, the contact resistance can be as high as $150 \mathrm{~m} \Omega \mathrm{cm}$, i.e. the 
voltage loss due to contact resistance at a current density of $1.0 \mathrm{~A} / \mathrm{cm}^{2}$ would be as high as $0.15 \mathrm{~V}$.

Contact resistance is determined by material properties, surface topology, assembly pressure and operation conditions. During assembly, an optimal assembly pressure is needed to balance the contact resistance and flow resistance in GDL [Lee et al., 2005]. A high assembly pressure can reduce the contact resistance, but GDL will be over compressed with high stress which results in increased flow resistance. Thus, understanding the contact resistance mechanisms between BPP and GDL is important in optimizing clamping pressure as well as improving fuel cell performance.

Some experimental researches have been conducted on the contact resistance in PEM fuel cells. Mathias et al. [2003] showed that contact resistance between GDL and BPP is greater than the bulk resistance of GDL or BPP. Ihonen et al. [2001] developed a novel PEM fuel cell assembly to measure the clamping pressure and contact resistances simultaneously for laboratory investigations. Results showed that contact resistances depended on clamping pressure, gas pressure, current density and temperature. Also, the contact resistances of stainless steel could be drastically reduced by surface treatments. Lee et al. [1999] measured the PEM fuel cell performance with a variety of commercially available GDLs under various assembly pressures. Each GDL exhibited its own optimal assembly pressure due to the differences in mechanical properties and porous characteristics, resulting in different contact resistances in PEM fuel cells.

All of the above mentioned studies focused on obtaining the contact resistance experimentally. Only a few attempts were made on the development of theoretical models of the contact resistance in PEM fuel cells. Mishra et al. [2004] used a fractal 
based model to predict the contact resistance between GDL and BPP and measured the contact resistance experimentally. However, GDL surface roughness parameters, which are important inputs for the fractal model, change during compression and are difficult to characterize. In a recent work, Zhang et al. [2006] developed simple computational methods for estimating contact resistance between BBP and GDL based on experimentally obtained constitutive resistance-pressure relations.

Despite the lack of theoretical models of contact resistance in PEM fuel cells, a significant amount of literature exists in modeling of electrical contact resistance between contacting bodies. Most of these models incorporate the contact behavior of a single spherical asperity into a statistical model of multi-asperity contact [Greenwood and Williamson, 1966; Nayak, 1971; Bush et al., 1975; McCool, 1986]. The most recognized one is the Greenwood and Williamson (G\&W) statistical model [1966], which is based on the Hertz solution for individual elastic contacts and assumes that only asperities originally higher than the separation of the surfaces are in contact. This statistical method accounts for the stochastic nature of the interfacial phenomena and has been widely used to predict the contact of rough surfaces.

This paper develops a micro-scale numerical model to predict the contact resistance between BPP and GDL in PEM fuel cells taking the material properties, surface roughness and clamping pressure as inputs. The classical G\&W contact model of rough surfaces is adapted. Experimental measurements of contact resistance between BPP and GDL are also conducted to validate the model. The remainder of the paper is organized as follows: Section 2.2 introduces the micro-scale contact resistance model, 
Section 2.3 describes the numerical example and experiments, Section 2.4 presents the results and discussions and Section 2.5 draws the conclusions.

\subsection{Micro-scale contact resistance model}

In PEM fuel cells, BPP surface is rough in nature while GDL is a porous medium consisting of randomly distributed fibers. Real contact occurs microscopically between BPP asperities and GDL fibers. Therefore, the topologies of both BPP and GDL are important in understanding their interfacial contact behaviors. The micro-scale contact model is developed using the following procedures:

i. The BPP surface topology is simulated as randomly distributed asperities based on measured surface roughness using profilometrical measurements;

ii. The GDL is modeled as randomly distributed cylindrical fibers with its total fiber length estimated from the GDL porosity and measured fiber diameter;

iii. Given a nominal separation between the BPP and GDL, BPP asperities in contact with GDL are determined numerically;

iv. The contact area, force and contact resistance of every single contact spot between BPP and GDL are calculated using the Hertz theory;

v. The total contact resistance is calculated by considering all contact spots as resistances in parallel and the total clamping force is the summation of the forces on all contact spots;

vi. Experimental measurements of contact resistance were conducted to 
validate the modeling results.

\subsubsection{BPP surface topology simulation}

All surfaces are inherently rough. The surface of a BPP, whether molded using graphite or formed with stainless steel, contains surface roughness, which determines the contact behavior. Consistent with the classical statistical contact models of rough surfaces, the BPP surface is assumed to be covered with asperities whose summits are all spherical in shape with the same radius $R_{1}$. The summit height follows a normal distribution. The summits are also assumed to be uniformly distributed spatially with a known density $D_{\text {sum }}$, measured in "number of summits per unit area". Three parameters, summit radius $R_{1}$, standard deviation of summit height $\sigma_{s}$, and summit density $D_{\text {sum }}$ are needed to describe the surface roughness. According to McCool [1986], a non-dimensional parameter $\alpha$ is introduced,

$$
\alpha=\frac{\sigma^{2} \square \sigma_{x}^{\prime 2}}{\sigma_{x}^{\prime 4}}
$$

where $\sigma, \sigma_{x}^{\prime}$ and $\sigma_{x}^{\prime \prime}$ are the root mean square of surface height, slope and second derivative of a surface profile respectively.

The mean summit radius is expressed as

$$
R_{1}=\frac{3 \pi^{\frac{1}{2}}}{8 \sigma_{x}^{\prime \prime}}
$$

and the variance of the summit height distribution can be calculated from $\sigma$ [Bush et al., 1975],

$$
\sigma_{s}^{2}=\left(1-\frac{0.8968}{\alpha}\right) \sigma^{2}
$$


In a two-dimensional surface profile, the local highest point is a peak. The peak density is

$$
D_{\text {peak }}=\frac{1}{2 \pi} \frac{\sigma_{x}^{\prime \prime}}{\sigma_{x}^{\prime}}
$$

The surface profile was obtained using a profilometer with a lateral resolution of $0.5 \mu \mathrm{m}$, as shown in Fig 2.4. As can be seen in Fig 2.5, the surface height fits normal distribution well, which is consistent with our previous assumptions. Several scans in different parts of the BPP surface were conduced to obtain one set of roughness parameters for the entire surface. The surface roughness parameters obtained from the average values of several scans are

$$
\begin{gathered}
D_{\text {sum }}=1.16 \times 10^{4} \mathrm{\#} / \mathrm{mm}^{2} \\
D_{\text {peak }}=98 \# / \mathrm{mm} \\
R=3.67 \mu \mathrm{m} \\
\sigma_{s}=3.55 \mu \mathrm{m}
\end{gathered}
$$

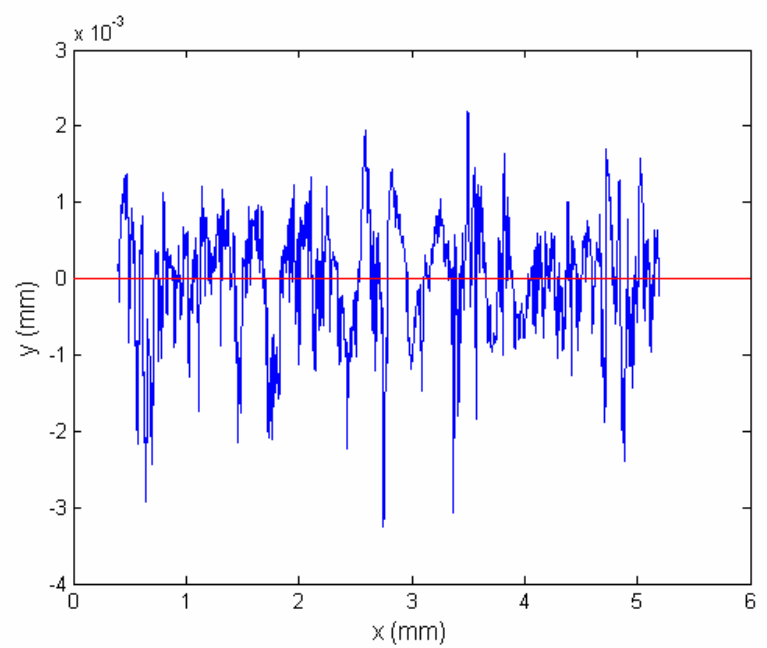

Figure 2.4 Two dimensional surface profile of bipolar plate from profilometer scans 


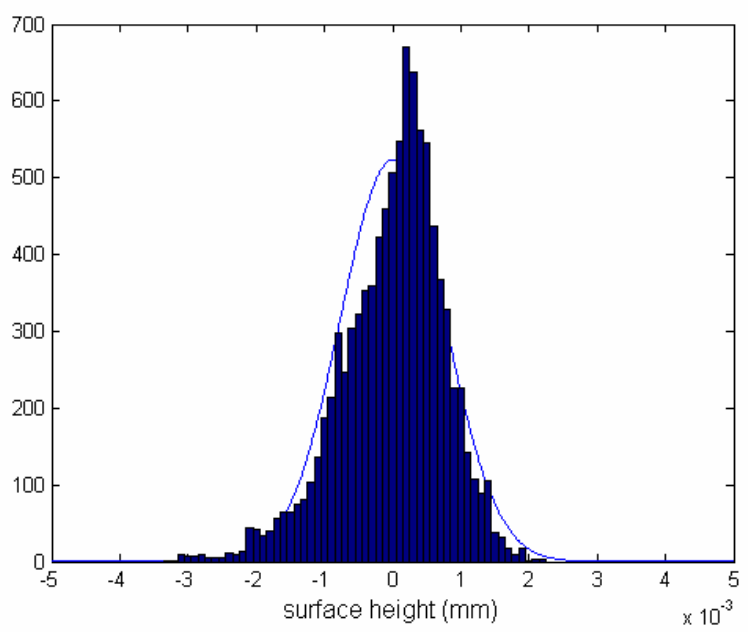

Figure 2.5 Histogram of surface height distribution

A three-dimensional surface profile has identical statistical characteristics in every two-dimensional direction. Therefore, the surface summit density is assumed to be $D_{\text {peak }}^{2}$, although it was shown to be slightly larger than $D_{\text {peak }}^{2}$ [McCool, 1986].

According to these surface roughness parameters, a surface profile is generated to simulate the BPP rough surface. A surface is generated with $98 \times 98 / \mathrm{mm}^{2}$ randomly distributed spherical summits with $3.67 \mu \mathrm{m}$ in radius. The summit height is normally distributed with a standard deviation of $3.55 \mu \mathrm{m}$. A sample area of the generated surface is illustrated in Fig. 2.6 which is obtained from one simulation. 


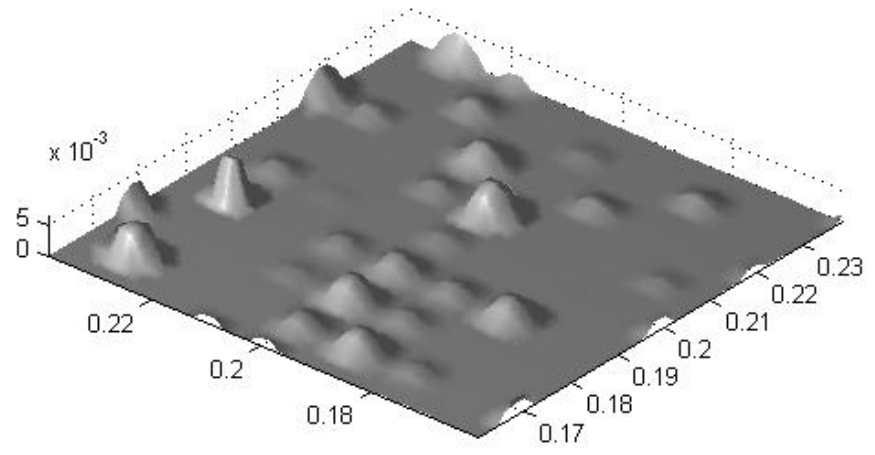

Figure 2.6 The generated BPP surface (unit: $\mathbf{m m}$ )

This generated surface provides the same surface roughness characteristics as the measured roughness of the real BPP. It also gives the position and height of each asperity summit, which are important inputs for the numerical contact resistance model.

\subsubsection{GDL structure simulation}

The GDL is made of carbon fiber paper or carbon fiber cloth. The carbon fiber paper is one of the primary materials due to its high porosity $(>70 \%)$ and good electrical conductivity. It is made from polyacrylonitrile-precursed-carbon fiber, the same material as used for reinforced composite. During the manufacturing process, the chopped carbon fibers are dispersed in water with binders and dried layer by layer to achieve the required thickness. Carbon fibers with a diameter of approximately $7 \mu \mathrm{m}$ and different lengths are randomly distributed to form the carbon fiber paper [Mathias et al., 2003]. 

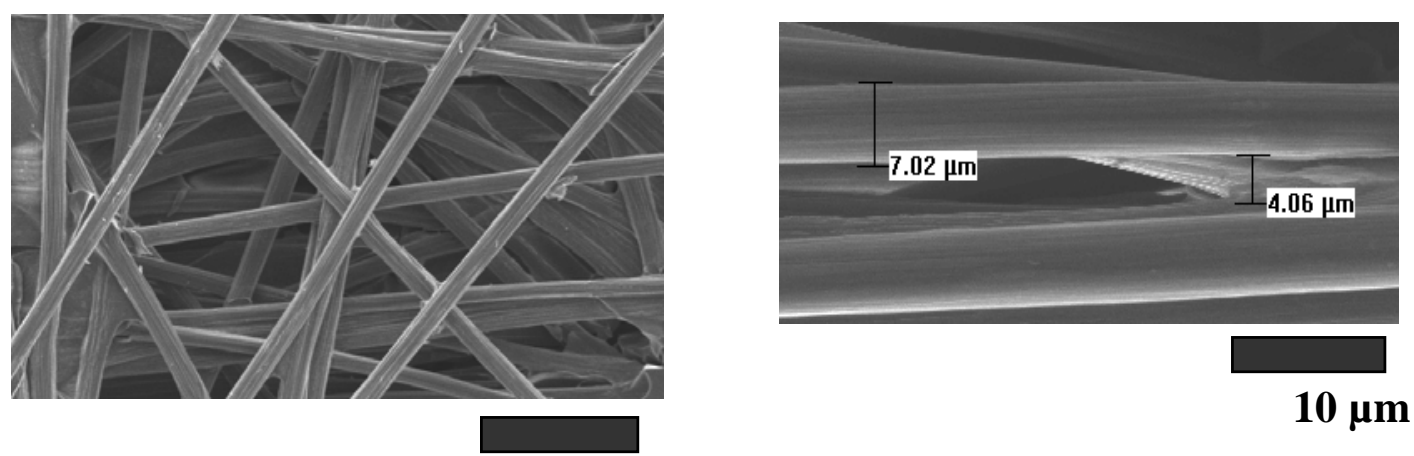

$50 \mu \mathrm{m}$

Figure 2.7 SEM micrographs of carbon fiber paper

As shown in the SEM micrographs, the GDL used in this study can be approximately treated as a layered structure with binders between fibers. The binder thickness between layers varies at different locations of GDL, from close zero to as much as $6 \mu \mathrm{m}$. The majority of the binder thickness is about $4 \mu \mathrm{m}$. According to the images and assumptions, the carbon fiber paper can be characterized as follows:

- $\quad$ The carbon paper is made of multi-layers of carbon fibers;

- $\quad$ The carbon fiber is cylindrical in shape with a diameter $d_{\text {fiber }}$ of $\sim 7 \mu \mathrm{m}$;

- The carbon fibers are randomly distributed in length and orientation at each layer; and

- The binder thickness $\delta_{\text {binder }}$ between two adjacent layers is $\sim 4 \mu \mathrm{m}$.

The total fiber length in a unit area of this sample can be obtained as

$$
L_{\text {fiber }}^{\text {tot }}=\frac{V_{G D L} \times(1-\varepsilon)}{\frac{1}{4} \pi d_{\text {fiber }}{ }^{2}}
$$


where $L_{f i b e r}^{\text {tot }}$ is the total fiber length in the unit area, $V_{G D L}$ is the volume of the GDL sample and $\varepsilon$ is the porosity. The fiber length in each layer is the total fiber length divided by the number of layers.

$$
l_{\text {fiber }}=\frac{L_{\text {fiber }}^{\text {tot }}}{\delta_{G D L} /\left(d_{\text {fiber }}+\delta_{\text {binder }}\right)}
$$

Based on these characteristics of the carbon fiber paper, one layer of GDL is simulated with randomly distributed carbon fibers, as shown in Fig. 2.8. The GDL structure is generated as follows: the location of center point and orientation of each fiber varies independently and uniformly in this area. The length of each fiber is assumed to be uniformly distributed from 0 to the diagonal length of this area. When a fiber intersects with existing fibers and boundaries, it is cut at the point of intersection, and the remainder of the fiber turns out to be the new fiber length. Hence, fibers which appear late have more chance to be cut and become shorter.

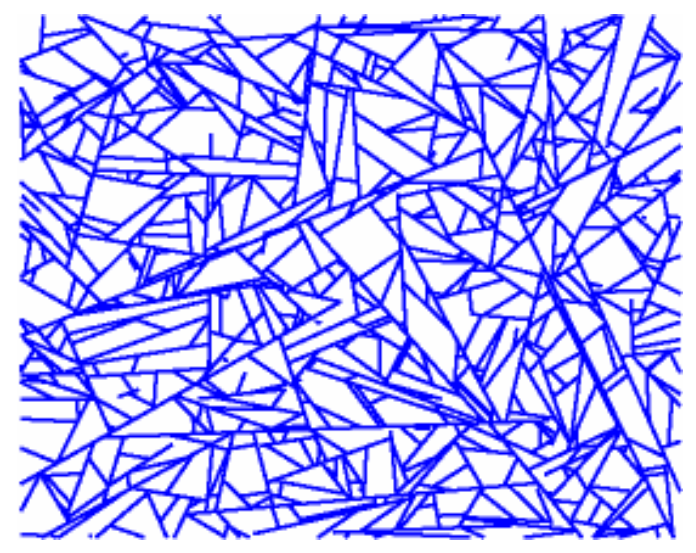

Figure 2.8 Simulation of one layer of carbon fiber in a GDL 
The fiber locations and lengths are deterministic for each simulation. Every individual contact spot can be located based on the information of the relative positions between fibers and BPP asperities.

\subsubsection{Contact resistance numerical model}

The contact resistance between BPP and GDL is governed by the surface topography and material properties of the contacting pairs. The BPP surface is a rough surface with spherical asperities which are in the same order of magnitude as the carbon fiber diameter $(\sim 7 \mu \mathrm{m})$. For asperities with heights between 0 and $2 \sigma_{s}$, the contact with GDL is in the first carbon fiber layer. The contact problem is then simplified as asperities contacting with one layer of carbon fibers while neglecting carbon fiber surface roughness.

The behavior of an individual point of contact is known from Hertzian equations [Johnson, 1985]. When a cylinder contacts a sphere with nearly the same radius, as in this study, the contact spot is close to a circle and the relation between contact area $a$ and the load $F$ can be expressed approximately in terms of deformation $\delta$ as,

$$
\begin{aligned}
a & \approx \pi R_{e} \delta \\
F & \approx \frac{4}{3} E^{*} R_{e}^{\frac{1}{2}} \delta^{\frac{3}{2}}
\end{aligned}
$$

and

$$
E^{*}=\left(\frac{1-v_{1}^{2}}{E_{1}}+\frac{1-v_{2}^{2}}{E_{2}}\right)^{-1}
$$


where $E_{1}, E_{2}, v_{1}, v_{2}$ are Young's moduli and Possion's ratios of the two contacting bodies, respectively. $R_{e}$ is the equivalent radius of the principal radii of curvature of the surfaces at the contact origin.

$$
R_{e}=R_{1} \sqrt{\frac{R_{2}}{R_{1}+R_{2}}}
$$

where $R_{2}$ denotes the carbon fiber radius.

According to Holm [1967], the electrical constriction resistance of this single contact was:

$$
R=\frac{\rho_{1}+\rho_{2}}{4 r}
$$

where $r$ is the radius of the contact area. $\rho_{1}$ and $\rho_{2}$ are the resistivities of the two contacting bodies respectively.

Three basic assumptions for the contact model are made: 1) asperities are far apart and there is no interaction among these asperities; 2) there is no bulk deformation in the bipolar plate; 3) contact is entirely elastic.

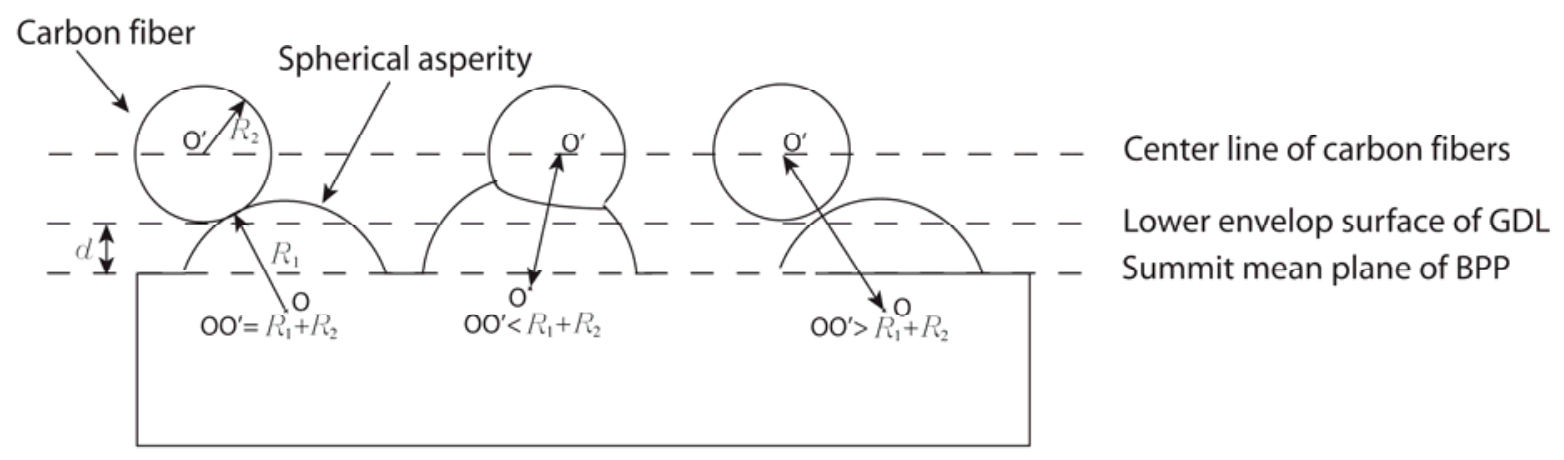

Figure 2.9 Two-dimensional illustration of the relative position between BPP asperities and carbon fibers 
Figure 2.9 shows a two-dimensional illustration of the relative distance between asperities and fibers. In reality, the fibers are not necessarily parallel and can be located in any direction. $\mathrm{O}$ and $\mathrm{O}^{\prime}$ denote the center of spherical asperity and carbon fiber. If the distance OO' is less than the summation of two radii $R_{1}+R_{2}$, the cylinder and the asperity are in contact. Otherwise, there is no contact between them. For a given separation $d$, the deformation between the asperities and fibers is easy to calculate, so the contact area, force and resistance for each contact spot can be determined. The total contact area is the summation of all contact spots and the total contact resistance is calculated by considering the resistance of all contact spots in parallel. The total force is the summation of all contact forces.

\subsection{Numerical example and experiments}

\subsubsection{Numerical example}

The above procedure is implemented numerically. A rough BPP surface of $4 \mathrm{~mm}$ $\times 4 \mathrm{~mm}$ is simulated at an initial separation of $7.5 \mu \mathrm{m}$ from a GDL layer with the same area. In this study, the BPP is a grade FU 4369 graphite plate from PEM Technology Inc and the GDL is Toray TGP-H-030 from Toray Industries, Inc. All of the relevant material properties are listed in Table 2.1. Table 2.2 lists the inputs parameters for the numerical models. Parameters for BPP are obtained based on the profilometerical scans. Parameters for GDL are estimated from the GDL porosity and SEM micrographs. Other inputs to the numerical model include carbon fiber material properties. The carbon fiber has more favorable mechanical and electrical properties in the longitudinal direction than in the transverse direction [Mathias et al., 2003]. However, the transverse material properties 
have a more significant influence on the contact resistance in PEM fuel cells. Hence such material properties are used in the numerical model. The transverse compressive modulus of Toray carbon fiber is $3.2 \mathrm{GPa}$ [Donnet et al., 1998]. The transverse electrical resistivity is $70 \mu \Omega \mathrm{m}$, which is estimated using the Bruggman correlation [Bear et al., 1991],

$$
\rho_{1}=\rho_{G D L}(1-\varepsilon)^{1.5}
$$

where $\rho_{G D L}$ is the through plane resistivity of the GDL.

Table 2.1 Properties for the BPP and the GDL

\begin{tabular}{ccc}
\hline \hline Properties & BPP & GDL \\
\hline Thickness $(\mathrm{mm})$ & 5 & 0.11 \\
Area $\left(\mathrm{mm}^{2}\right)$ & $101.6 \times 101.6$ & $100 \times 100$ \\
Porosity & & $80 \%$ \\
Young's modulus $(\mathrm{GPa})$ & 10 & \\
$\begin{array}{c}\text { Electrical resistivity-Through } \\
\text { plane }(\mu \Omega \mathrm{m})\end{array}$ & 190 & 800 \\
\hline \hline
\end{tabular}

Table 2.2 Inputs parameters for the numerical contact model

\begin{tabular}{ccc}
\hline \hline & Parameters & Value \\
\hline \multirow{4}{*}{ BPP } & Asperity Peak density $D_{\text {peak }}(\# / \mathrm{mm})$ & 98 \\
& Summit radius $R(\mu \mathrm{m})$ & 3.67 \\
& Summit Standard deviation $\sigma_{s}(\mu \mathrm{m})$ & 3.55 \\
\multirow{4}{*}{ GDL } & Fiber diameter $d_{\text {fiber }}(\mu \mathrm{m})$ & 7 \\
& Total fiber length $L_{\text {fiber }}$ tot $\left(\mathrm{mm} / \mathrm{mm}^{2}\right)$ & 572 \\
& Fiber length in one layer $l_{\text {fiber }}\left(\mathrm{mm} / \mathrm{mm}^{2}\right)$ & 57 \\
\hline \hline
\end{tabular}


Based on the simulated BPP surface and GDL structure, the relation between clamping pressure and contact resistances can be obtained by changing the separation.

\subsubsection{Experimental validation}

Experimental investigations were conducted to validate the numerical model results. Two experimental setups were built to measure the contact resistance [Mathias et al., 2003; Mishra et al., 2004; Zhang et al., 2006]. Setup 1 as shown in Fig. 2.10 was built using a stack of a GDL and two graphite BPPs. This stack was inserted between two copper plate current collectors. Plexiglas plates were used for insulation. The measured resistance from Setup 1 includes the bulk resistances of two BPPs, the bulk resistance of GDL, contact resistances between cooper plates and BPPs, BPPs and GDL. Setup 2 uses a similar stack but with only one BPP between two copper plates in order to extract the contact resistance between BPP and GDL. An MTS machine was used to provide the clamping load and a DC milli-ohmmeter (GW-Instek GOM-802) was used to measure the resistance with a resolution of $0.1 \mu \Omega$.

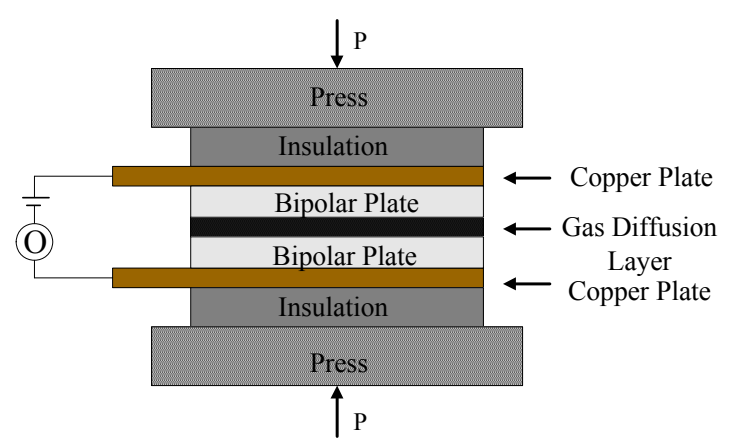

Setup 1

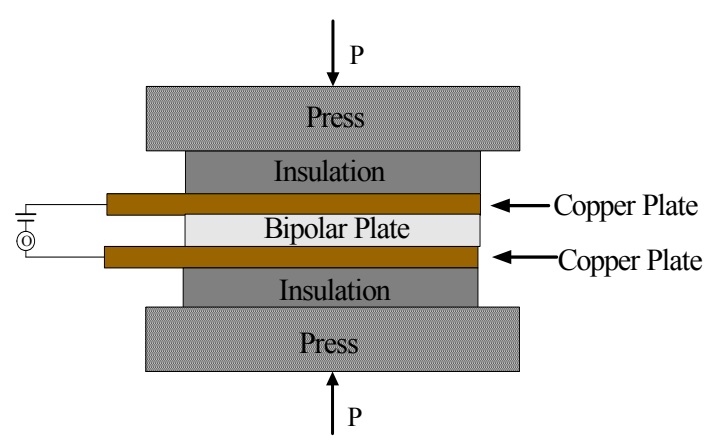

Setup 2

Figure 2.10 Schematic of two experimental setups

Insulation

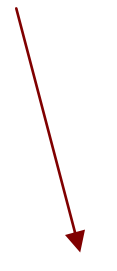

Bipolar plate 


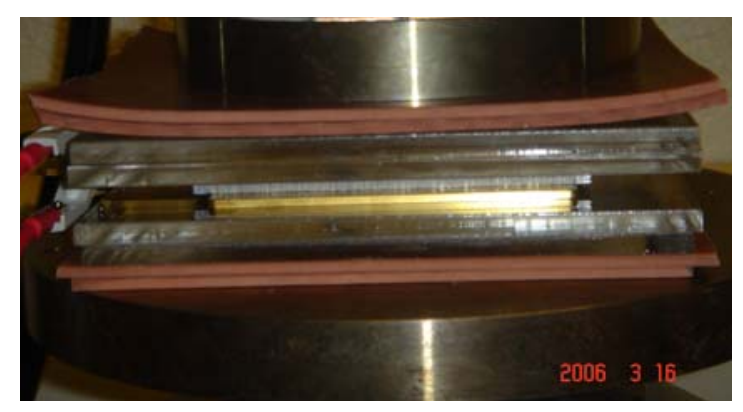

Figure 2.11 Experimental setup for contact resistance measurement

The contact resistance between BPP and GDL can be deduced as [Mishra et al., 2004]

$$
R_{\text {contact }}=\frac{\operatorname{Res}_{1}-\operatorname{Res}_{2}-R_{B P P}-R_{G D L}}{2}
$$

where $\operatorname{Res}_{1}$ and $\operatorname{Res}_{2}$ are measured resistances from Setup 1 and Setup 2, respectively. $R_{B P P}$ is the bulk resistance of graphite BPP and $R_{G D L}$ is the bulk resistance of GDL. $R_{B P P}$ and $R_{G D L}$ are calculated according to their bulk resistivity. The change of the bulk resistance of BPP and GDL during compression is neglected. A series of compression pressures from 0.5 to $3 \mathrm{MPa}$ were applied and the corresponding contact resistances were measured. Under each clamping pressure, the contact resistance measurements were repeated four times to obtain the average values. Two GDL samples are used and results are identified as Experiments 1 and 2. 


\subsection{Results and Discussions}

Results from the numerical model and experiments are presented in Fig. 2.12. Results from Experiments 1 and 2 are very comparable. The discrepancy between two experiments is less than 5\%, which illustrates that the contact resistance measurement is repeatable. For every clamping pressure, the simulation was repeated five times. Results from repeated simulations show a small range of variability, in particular, when the clamping pressure becomes large. This is because, at high clamping pressure, the number of contact spots increases and the calculation is more accurate. The maximum relative error among different simulation runs is less than 3.5\%. Furthermore, the numerical prediction shows the same trend as the experimental results and the difference is less than $20 \%$. This consistency indicates that the numerical model captures reasonably well the contact phenomena between BPP and GDL in PEM fuel cells.

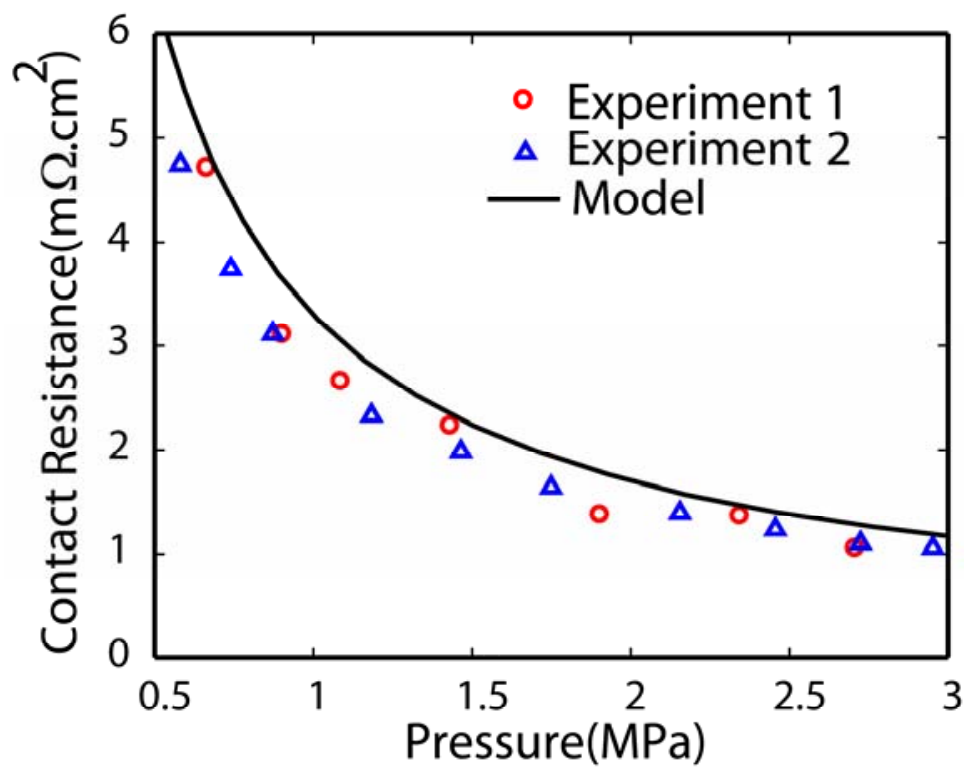

Figure 2.12 Comparison of experimental data with numerical prediction 
The number of contact spots increases rapidly when two contacting parts start to come into contact. The real contact area increases fast at this early stage because many asperities are coming into contact with the fibers. Thus, the contact resistance changes greatly during the initial clamping pressure increase as shown in Fig. 2.12. As the distance between two surfaces decreases further, only a few new asperities are becoming involved in the contact. Contact resistance decreases mainly due to the area increase of the existing contact spots. This slight increase of the contact area results in only small changes in the contact resistance. Although greater clamping pressure can reduce the contact resistance, high pressure may damage BPP, GDL and obstruct gas flow. From fuel cell performance prospective, electrical resistance and flow resistance need to be optimized simultaneously to obtain a proper clamping pressure.

In the numerical model, several assumptions were made to model BPP surface and GDL structure. In modeling the BPP surface roughness, the assumption of spherical asperities with identical radius is consistent with the G\&W model. Some researchers have developed contact models with different asperity shapes and radii, but only shown that the G\&W model is nevertheless quite accurate [Nayak, 1971; Bush et al., 1975; McCool, 1986 \& 2000].

Although the length of each fiber is initially assumed to follow a uniform distribution, the final distribution will change after cutting. However, the different fiber length distributions after cutting will not change the total contact resistance. This is because BPP surface is a random surface, and every location of the GDL surface is statistically equivalent. To verify this numerically, a simplified GDL structure with the same total fiber length is modeled, in which all the fibers are in the horizontal direction. 
The difference between these two results is within $3 \%$, therefore this assumption is reasonable.

The influences of BPP surface roughness parameters are also investigated. As shown in Fig. 2.13, when the peak density increases from 50/mm to $150 / \mathrm{mm}$, contact resistance decreases because more asperities are in contact. However, the contact resistance decreases about $14 \%$, not as much as the change of peak density. For a given distance between two contacting surfaces, the larger summit density will result in an increased contact area and a smaller contact resistance, but larger clamping pressure is needed accordingly. In order to compare the resistances at different peak densities with a given pressure, the distance between the contact surfaces will be different. That is, smaller distance for low density and bigger distance for high density are required respectively. The combined effect of the distance and the peak density makes the contact resistance not sensitive to the summit density changes. The contact resistance is also insensitive to summit radius change, as illustrated in Fig. 2.14.

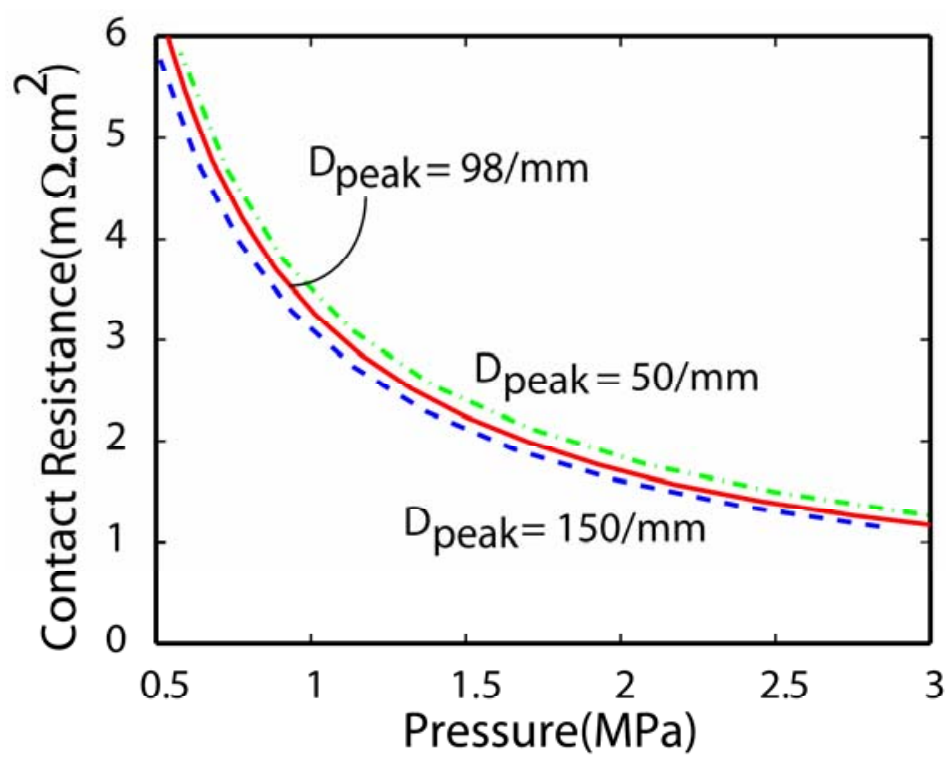

Figure 2.13 Influence of BPP summit density 


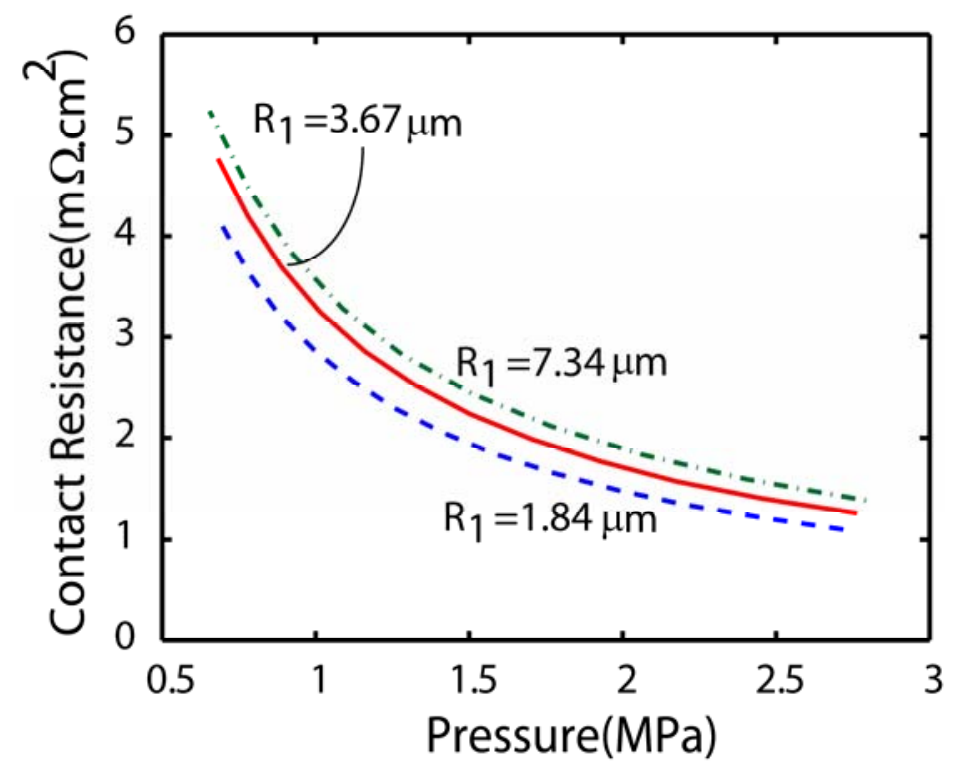

Figure 2.14 Influence of BPP summit radius

The summit standard deviation of a BPP surface is another important surface roughness parameter. As shown in Fig. 2.15, when $\sigma_{s}$ changes from $3.55 \mu \mathrm{m}$ to $7 \mu \mathrm{m}$, the contact resistance increases by about $20 \%$. For the surface with $\sigma_{s}=7 \mu \mathrm{m}$, the likelihood to have high asperities is higher than that of smaller standard deviation. This results in the fact that the contact spot concentrates in a few asperities at the same clamping pressure. Thus, the contact area is smaller and the contact resistance turns out to be larger. 


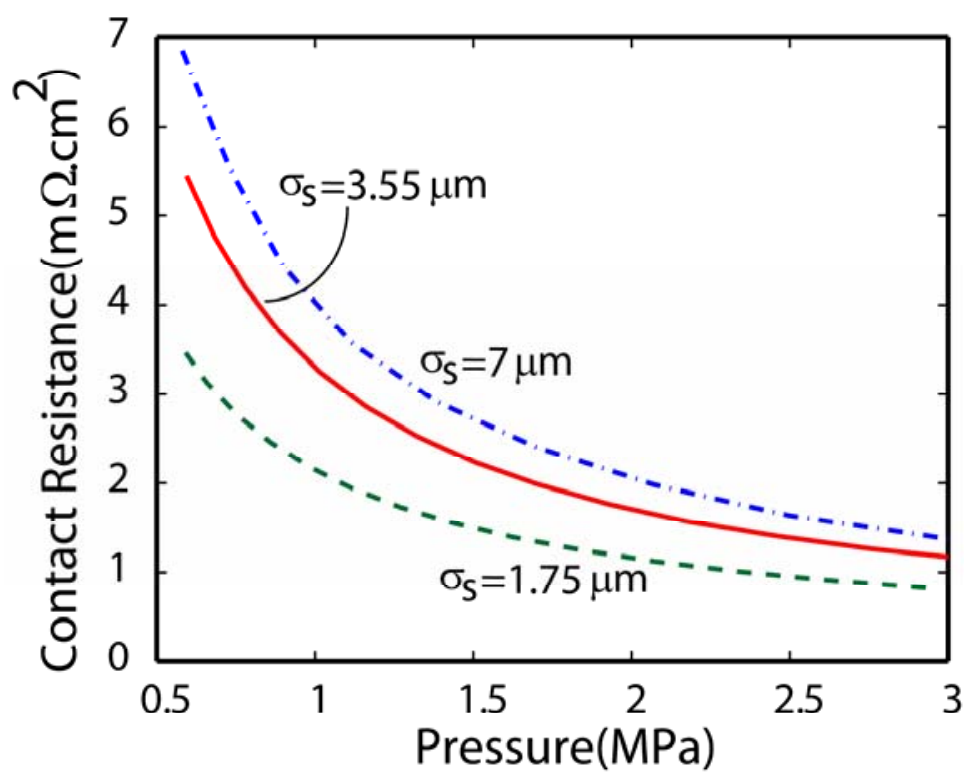

Figure 2.15 Influence of BPP summit height standard deviation

The contact resistance is more sensitive to summit standard deviation than summit density and summit radius. Hence, BPP surface should be fabricated with small standard deviation to ensure the consistency of contact resistance and the performance of PEM fuel cells.

Furthermore, BPP summit height standard deviation has significant practical importance in BPP manufacturing. As shown in Fig. 2.16, when assembly pressure increases, the reciprocal of contact resistance almost falls into a straight line starting from the origin, which denotes the status of zero assembly pressure and an infinitly large contact resistance. That means the product of assembly pressure and contact resistance can be approximately treated as a constant. And at various BPP summit height standard deviations, this constant varies. 


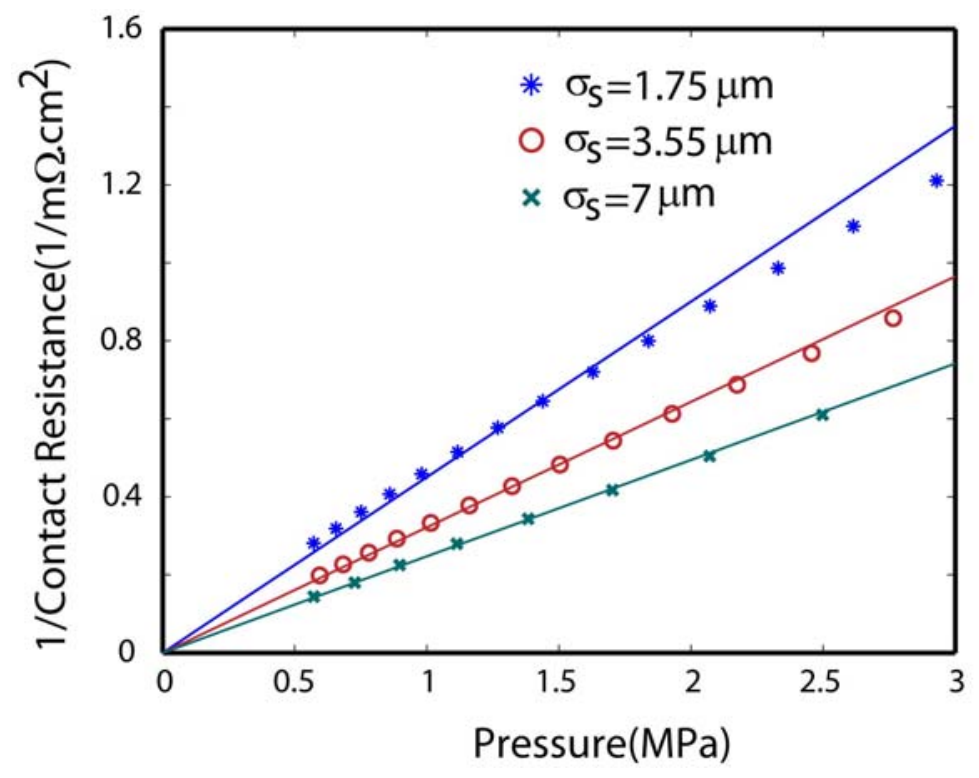

Figure 2.16 The relationship between assembly pressure and the reciprocal of contact resistance at various BPP summit height standard deviations

The product of pressure and contact resistance changes with summit height standard deviation, which is shown in Fig. 2.17. And this product almost has a linear relationship with BPP summit height standard deviation. The intersection point of $Y$-axis means the BPP summit height standard deviation is zero. This corresponds to the case where a perfectly flat plane contacts with a fiber material. Thus the contact resistance at this value is attributed to the surface profile of GDL only. This can be used to further investigate the impact of GDL structure on contact resistance in PEM fuel cells. 


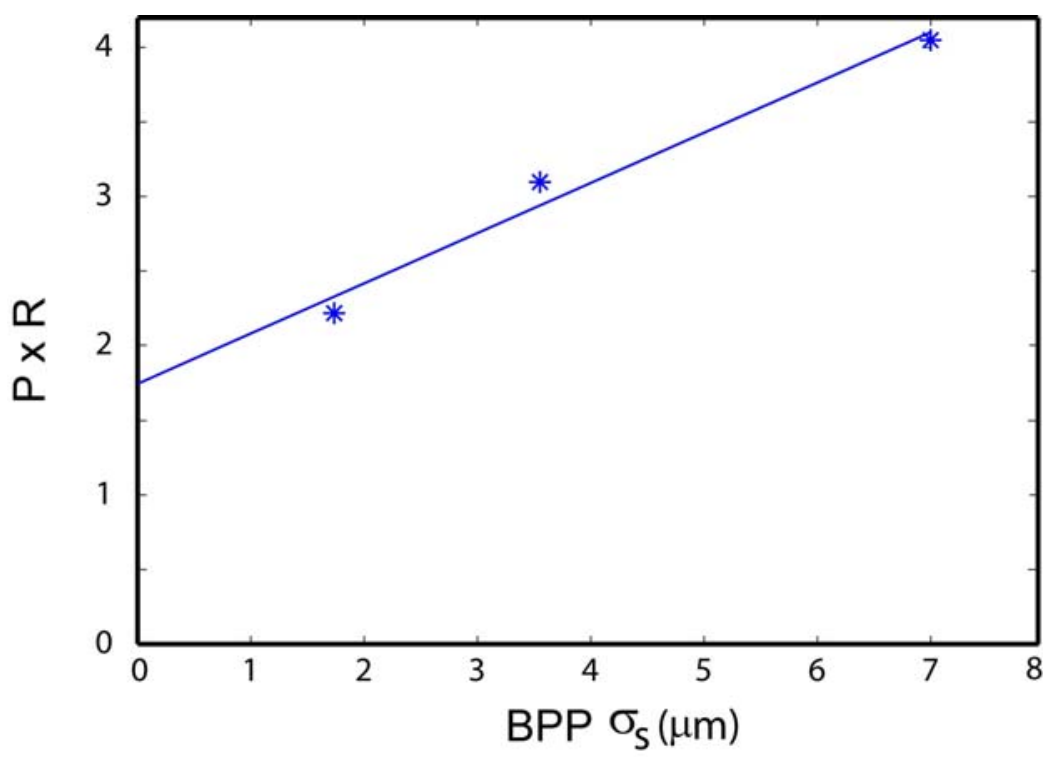

Figure 2.17 The relationship between $P * R$ and BPP summit height standard deviation

\subsection{Conclusions}

A micro-scale contact model was developed to predict the contact resistance between BPP and GDL in PEM fuel cells. BPP surface roughness was simulated by adopting the classical statistical contact model and the GDL was modeled as randomly distributed fibers with estimated total fiber length. According to these two simulated contacting surfaces, contact spots between BPP and GDL can be determined numerically given a separation of these two surfaces. The contact status for every single contact spot was calculated using the Hertz theory. The total resistance and pressure were obtained by summarizing the results from each contact spot. Compared with experimental results, the modeling results showed good agreements with less than $20 \%$ discrepancy. Influences of BPP surface roughness parameters on contact resistance were also studied. It was found that the summit standard deviation has greater impact than other surface roughness 
parameters. The model developed in this study may be applied to predict the contact resistance of GDL in contact with other BPP materials, only if the GDL characteristics and BPP surface topology are determined. This micro-scale contact model is beneficial to understand the basic mechanisms of contact behavior between the rough surface and a fibrous medium and can be integrated with other fuel cell simulations to predict the overall fuel cell performance. 


\section{References}

Barbir, F., Braun, J., Neutzler, J., (1999), "Properties of molded graphite bi-polar plates for PEM fuel cell stacks," Journal of New Materials for Electrochemical Systems, Vol. 2, pp. 197-200.

Bear, J., Buchlin, J. M., (1991), Modeling and Application of Transport Phenomena in Porous Media, Kluwer Academic Publishers, Boston, MA.

Bush, A. W., Gibson, R. D., Thomas, T. R., (1975), “The elastic contact of a rough surface," Wear, Vol. 35, pp. 87-111.

Davies, D. P., Adcock, P. L., Turpin, M. , Rowen, S. J., (2000), “Bipolar plate materials for solid polymer fuel cells," Journal of Applied Electrochemistry, Vol. 30, pp. 101-105.

Donnet, J. B., Wang, T. K., Rebouillat, S., Peng, J., (1998), Carbon Fibers, New York: Marcel Dekker, pp. 319.

Greenwood, J. A., Williamson, J. B. P., (1966), “The contact of nominally flat surfaces," Proceedings of the Royal Society of London, Vol. A295, pp. 300-319.

Holm, R., (1967), Electric Contacts Theory and Application, New York: Springer-Verlag, pp. 9-16.

Ihonen, J., Lindbergh, G., Sundholm, G., (2001), “A novel polymer electrolyte fuel cell for laboratory investigations and in-situ contact resistance measurements," Electrochimica Acta, Vol. 46, pp. 2899-2911.

Johnson, K. L., (1985), Contact Mechanics, Cambridge University Press, pp. 84-106.

Lee, S. J., Hsu, C. D., Huang, C. H., (2005), “Analyses of the fuel cell stack assembly pressure," Journal of Power Sources, Vol. 145, pp. 353-361.

Lee, W., Ho, C., Zee, J., Murthy, M., (1999), “The Effects of compression and gas diffusion layers on the performance of a PEM fuel cell," Journal of Power Sources, Vol. 84, pp. 45-51.

Makkus, R. C, Janssen, A. H. H., Bruijn, F. A., Mallant R., (2000), "Use of stainless steel for cost competitive bipolar plates in the SPFC," Journal of Power Sources, Vol. 86, pp 274-282. 
Mathias, M., Roth. J., Fleming, J., Lehnert, W., (2003), in: W. Vielstich, A. Lamm, H.A. Gasteiger (Eds), Handbook of Fuel Cells - Fundamentals, Technology and Applications, V3: Fuel Cell Technology and Application, Wiley, pp. 517-538.

McCool, J. I., (1986), “Comparison of models for the contact of rough surfaces," Wear Vol. 107, pp. 37-60.

McCool, J. I., (2000), "Extending the capability of the Greenwood Williamson microcontact model," Journal of Tribology, Vol. 122, pp. 96-502.

Mishra V., Yang F., Pitchumani R., (2004), "Measurement and prediction of electrical contact resistance between gas diffusion layers and bipolar plate for applications to PEM fuel cells," ASME Journal of Fuel Cell Science and Technology, Vol.1, pp. 2-9.

Nayak, P. R., (1971), "Random process model of rough surfaces," Journal of Lubricant Technology, Vol. 93, pp. 398-407.

Zhang, L., Liu,Y., Song, H., Wang, S., Zhou, Y. and Hu, S. J. (2006) "Estimation of contact resistance in proton exchange membrane fuel cells based on experimental constitutive relation,” Journal of Power Sources, Vol. 162, No. 2, pp.1165-1171. 


\title{
CHAPTER 3
}

\section{MULTI-PHYSICS MODELING OF ASSEMBLY PRESSURE EFFECTS ON PEM FUEL CELL PERFORMANCE*}

\begin{abstract}
The clamping pressure used in assembling a PEM fuel cell stack can have significant influences on the overall cell performance. The pressure causes stack deformation, particularly in the GDL, and impacts gas mass transfer and electrical contact resistance. Existing research for analyzing the assembly pressure effects is mostly experimental. This paper develops a sequential approach to model the combined mechanical and electrochemical phenomena in fuel cells. The model integrates gas mass transfer analysis based on the deformed GDL geometry and modified parameters with micro-scale electrical contact resistance analysis. The modeling results reveal that higher assembly pressure increases cell resistance to gas mass transfer, causes an uneven current density distribution and reduces electrical contact resistance. With the combination of these effects, as assembly pressure increases the PEM fuel cell power output first increases to a maximum and then decreases over a wide range of pressures. An optimum assembly pressure is observed. The model is validated against published experimental data with good agreements. This study provides a basis for determining the assembly pressure required to optimize PEM fuel cell performance.
\end{abstract}

\footnotetext{
* Contents of this chapter have been published as Zhou, Y., Lin, G., Shih, A. J. and Hu, S. J. (2008), "Multi-physics modeling of assembly pressure effects on PEM fuel cell performance," ASME Journal of Fuel Cell Science and Technology, in press.
} 


\subsection{Introduction}

PEM fuel cells are recognized as a promising device for a wide variety of power applications. Among the technological challenges associated with PEM fuel cells, design and assembly are considered the most critical to further reducing cost and ensuring high performance. As fuel cell manufacturing scales up, the relationships between fuel cell performance and the assembly process must be well understood. A proper level of clamping pressure is needed to provide adequate gas sealing, as well as to reduce contact resistances at the component interfaces. However, high pressure may over-compress membrane and GDL, crushing their porous structures and cracking BPP. These effects may combine to yield an optimum assembly pressure.

Several models have been developed to account for the multi-physics processes in PEM fuel cells including the gas and water mass transfer, electrochemical reactions, etc. [Springer et al., 1991; Bernardi and Verbrugge, 1991; Fuller and Newman, 1993; Nguyen and White, 1993; Chi et al., 2006; Berning et al., 2002; Berning and Djilali, 2003]. Assembly pressure effects, however, were not incorporated into these models. Assembly pressure causes stack compression. Most of the compression is attributed to GDL deformation, which is critical to the performance and durability of PEM fuel cells. Lai et al. [2004] investigated the compression of the Membrane Electrode Assembly (MEA, an assembly of GDL and catalyst layers) and GDL over the channel area, where thermal expansion and swelling of the membrane can lead to buckling and separation of the membrane from the GDL. It was suggested that a higher transverse shear modulus is favored in the GDL. Lee et al. [1999] studied the relationship between bolting torques used in assembling PEM fuel cell stacks and the performance. An optimum bolt torque 
was observed in experiments. Lee et al. [2005] analyzed PEM fuel cell stack assembly pressure distribution and the compliance of a single cell using finite element analysis. The pressures are higher near the bolts, but lower at the center of the assembled PEM fuel cell stack. It was also found that assembly pressure could significantly change the porosity of GDL. Chu et al. [2003] investigated the porosity change and the results showed that a PEM fuel cell with an embedded GDL with a larger porosity consumes a greater amount of oxygen and a better fuel cell performance especially at high current density region. Most recently, Ge et al. [2006] designed a single PEM cell to measure GDL compression and cell performance without disassembling the cell. Experimental results showed that the fuel cell performance generally decreases with increased compression, and one should expect an optimal compression ratio, especially in the low pressure region.

Most previous research attempted to obtain the assembly pressure effects via experiments, and few efforts have been made to model the effects of assembly induced GDL deformation on gas mass transfer and contact resistance, including a number of papers which are published very recently. Most of them are purely experimental [Ge $e t$ al., 2006; Bazylak et al., 2007; Chang et al., 2007] or partly experimental studies [Nitta et al., 2007; Zhou and $\mathrm{Wu}, 2007]$.

In this paper, a comprehensive finite-element-based numerical model to simulate the entire process including GDL deformation, GDL property change, mass transfer process and electrical contact resistance. GDL deformation is first modeled under different assembly pressures. Then, a PEM fuel cell mass transfer model is developed based on the deformed GDL shape and modified GDL gas transport parameters. Effects 
on mass transfer resistance and contact resistance are analyzed in detail. The comprehensive fuel cell performance predicted by the model is then compared with experimental measurements of PEM fuel cell voltage-current performance curves of [Ge et al., 2006]. Local current density and oxygen mass fraction distribution are also discussed.

\subsection{Model description}

\subsubsection{GDL deformation model}

A representative 2D, single-channel, half-cell model for the cathode side of a PEM fuel cell is developed to study the effects of assembly pressure on the deformation of the PEM fuel cell components. Figure 3.1(a) is the cross-section of a PEM fuel cell, including BPP, GDL, and membrane. The size of the computational domain is reduced by taking advantage of the geometrical periodicity of the cell. As shown in Fig. 3.1(b), only one channel and half of the land areas on each side need to be incorporated in the domain. Here, the $X$ axis denotes the cell width direction, the $Y$ axis is in the cell thickness direction, and the $Z$ axis represents the cell length direction. In addition, because the length of gas channels is typically much larger (by $\sim 2$ orders of magnitude) than their cross-section dimensions, which justifies the assumption of plane-strain, only a 2D model is built to reduce computational time.

The model is built using commercial finite element software ABAQUS. Fournode quadrilateral plane-strain elements (CPE4) are used to mesh the components with typical element sizes being $0.04 \mathrm{~mm} \times 0.04 \mathrm{~mm}$. The bottom membrane surface is fixed 
vertically (in $Y$-direction), and $X$-symmetry conditions are applied to the side vertical boundaries of all components. The component interfaces are bonded, with no slip allowed. In the stack assembly, it is desirable to have a uniform assembly pressure in the BPP, even though the clamping load may be localized. As such, a uniform assembly pressure is assumed for the BPP.

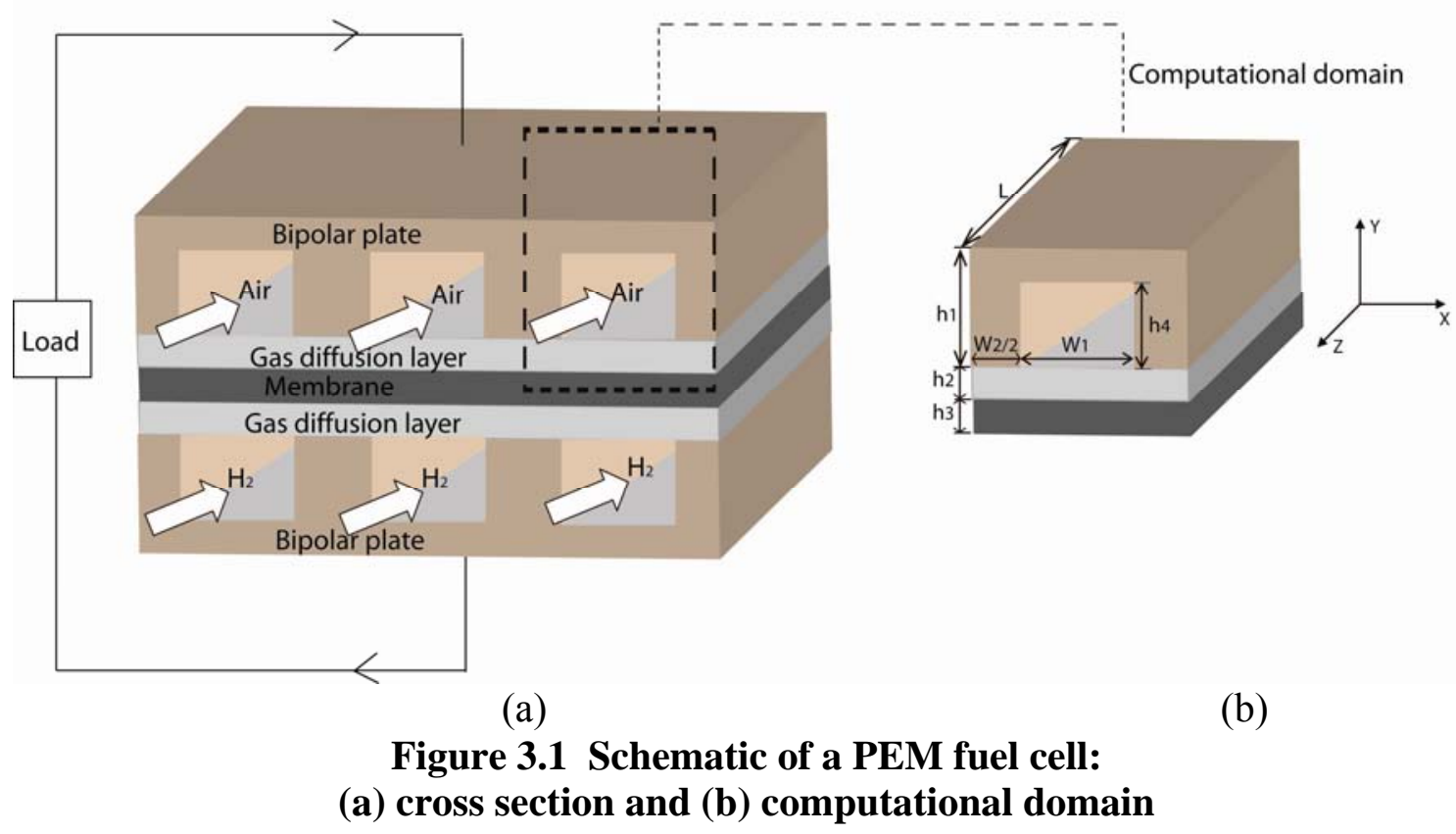

The geometric and physical properties of the components are listed in Table 3.1. It is assumed the effective porosity as 0.3 before compression according to Springer et al. [1993] and Inoue et al. [2006]. The effective porosity of GDL in the operating cell may be significantly smaller because of possible "flooding" by liquid water and compression by assembly. A series of assembly pressures from 0.04 to $15 \mathrm{MPa}$ are applied to the BPP top surface under which the GDL deformation is calculated. Meanwhile, the volumetric strain of every element in the GDL can be used to estimate its modified porosity. Based 
on the deformed configuration and the modified GDL porosity, mass transfer analysis is conducted.

\section{Table 3.1 Geometric and physical parameters for the multi-physics performance model}

\begin{tabular}{cc}
\hline \hline Parameter & Value \\
\hline Channel length $(L)$ & $20 \mathrm{~mm}$ \\
BPP thickness $\left(h_{1}\right)$ & $2 \mathrm{~mm}$ \\
GDL thickness $\left(h_{2}\right)$ & $200 \mu \mathrm{m}$ \\
Membrane thickness $\left(h_{3}\right)$ & $50 \mu \mathrm{m}$ \\
Channel height $\left(h_{4}\right)$ & $0.8 \mathrm{~mm}$ \\
Channel width $\left(w_{1}\right)$ & $1 \mathrm{~mm}$ \\
Land width $\left(w_{2}\right)$ & $1 \mathrm{~mm}$ \\
GDL initial porosity & 0.3 \\
Compressive modulus of BPP & $10 \mathrm{GPa}$ \\
compressive modulus of membrane & $200 \mathrm{MPa}$ \\
GDL compressive modulus & Nonlinear elastic \\
GDL permeability & $1.76 \times 10^{-11} \mathrm{~m}^{2}$ \\
Transfer coefficient for oxygen & 0.5 \\
\hline \hline
\end{tabular}

\subsubsection{Mass transfer analysis}

The same half cell analysis domain as shown in Fig. 3.1(b) is also used in the gas mass transfer analysis. Only the overpotential on the cathode side is modeled based on the assumption that the hydrogen oxidation reaction rate is so fast that the anodic overpotential is negligible. It is assumed that the cathode is fed with humidified air: a mixture of oxygen, nitrogen and water vapor. Steady state operation under fullyhumidified conditions is assumed. The model is limited to single-phase water transport. Other assumptions used in developing the half-cell model of the gas mass transfer analysis are as follows: 
(1) Steady state conditions,

(2) Constant cell temperature,

(3) Laminar flow in the fuel cell,

(4) Isotropic and homogenous GDL and catalyst layer,

(5) Ideal gas mixtures,

(6) Catalyst layer modeled as reactive boundaries, and

(7) Product water in the liquid phase.

Under these assumptions, a 3D model is developed to study the multi-component flow, diffusion of reactants through the porous GDL, and electrochemical reactions. In the BPP channel, fluid flow is modeled in combination with diffusion and convective transport. The gas flow field is obtained by solving the steady-state Navier-Stroke equations, and the pressure difference drives the flow in the channel in the following way:

$$
\begin{gathered}
\rho \frac{\partial u}{\partial t}-\nabla \llbracket \mu\left(\nabla u+(\nabla u)^{T}\right)+\rho(u \square \nabla) u+\nabla p=0 \\
\nabla \llbracket u=0
\end{gathered}
$$

where $\rho$ denotes the density of the gas mixture, $\mu$ is the dynamic viscosity, $p$ is the pressure, and $u$ is the velocity vector.

The mass flux in the gas phase is computed based on the Maxwell-Stephan diffusion and convection equation and for gas component $i$,

$$
\nabla\left[-\rho \omega_{i} \sum_{j=1}^{N} D_{i j} \frac{M}{M_{j}}\left(\nabla \omega_{j}+\omega_{j} \frac{\nabla M}{M}\right)+\rho \omega_{i} u\right]=0
$$


where $M$ is the total molar mass of the mixture, $M_{j}$ and $\omega_{j}$ are the molar mass and mass fraction of gas $j$, respectively. $D_{i j}$ (with units of $\mathrm{m}^{2} / \mathrm{s}$ ) is the Maxwell-Stephan diffusivity.

The binary diffusivities $D_{i j}$, which experimentally obtained values at atmospheric pressure (listed in Table 3.2), are scaled with the temperature and pressure according to [Cussler, 1984].

$$
D_{i j}=D_{i j}\left(T_{0}, p_{0}\right) \frac{p}{p_{0}}\left(\frac{T}{T_{0}}\right)^{1.5}
$$

Table 3.2 Binary diffusivities at reference temperatures and $1 \mathrm{~atm}$ [Inoue et al., 2006]

\begin{tabular}{ccc}
\hline \hline Gas pair & $\begin{array}{c}\text { Reference } \\
\text { temperature }\end{array}$ & $\begin{array}{c}\text { Binary diffusivities } D_{i j} \\
\left(\mathrm{~m}^{2} / \mathrm{s}\right)\end{array}$ \\
\hline$D_{\mathrm{O}_{2}-\mathrm{H}_{2} \mathrm{O}}$ & 308.1 & $2.82 \times 10^{-5}$ \\
$D_{\mathrm{O}_{2}-\mathrm{N}_{2}}$ & 293.2 & $2.2 \times 10^{-5}$ \\
$D_{\mathrm{H}_{2} \mathrm{O}-\mathrm{N}_{2}}$ & 307.5 & $2.56 \times 10^{-5}$ \\
\hline \hline
\end{tabular}

In the GDL region, Darcy's law is used to model the flow through the porous media, with the pressure gradient as the driving force,

$$
u=-\frac{k_{p}}{\mu} \nabla p
$$

where $k_{p}$ is the permeability of the GDL.

For multi-component diffusion in the GDL, the Maxwell-Stephan equations remain the same. However, due to the porous structure of the GDL, the binary diffusivity terms, $D_{i j}$, need to be corrected for the porosity $\varepsilon$, according to the Bruggenman correlation 


$$
D_{i j}^{e f f}=D_{i j} \varepsilon^{1.5}
$$

Because the catalyst layer is very thin compared to other elements within a fuel cell, it is treated as a reactive boundary. The current density distribution at the surface of the catalyst layer can be expressed as [Newman, 1991]

$$
i_{c}=i_{0} \frac{\omega_{O_{2}}}{\omega_{O_{2,0}}} \exp \left(-\alpha \frac{F \eta}{R T}\right)
$$

where $i_{\mathrm{c}}$ is the current density, $i_{0}$ represents the exchange current density of the cathode, $\eta$ is the cathode activation overpotential, $\alpha$ is the transfer coefficient, and $T$ is the cell operating temperature. This kinetic expression is derived from the general Butler-Volmer equation, based on the fact that the cathode has relatively slow kinetics. Because the anode exhibits fast electrokinetics, the anodic overpotential is neglected in this study. In most cases, overpotential in fuel cells refers to cathode overpotential. Hence, if only incorporating mass transfer resistance, the cell voltage is calculated as

$$
E=E^{0}-\eta
$$

where the open circuit potential $E^{0}$ for the overall reaction is calculated as [Parthasarathy et al., 1992]

$$
E^{0}=0.2329+0.0025 T
$$

The electrochemical reaction at the catalyst layer determines the flux at the reactive boundary. The mass flux for consumed oxygen is 


$$
N_{O_{2}}=-M_{O_{2}} \frac{i_{c}}{4 F}
$$

where $N_{\mathrm{j}}$ represents the mass flux of gas $j$, and $F$ denotes Faraday's constant.

It is assumed that the gas mixture enters at the gas flow field channel normal to the inlet cross section. All walls in the channel have no-slip boundary conditions. The mass and momentum transport boundary conditions between the BPP shoulders and the GDL are all insulated. The gas mixture enters and leaves the GDL through the boundary between the channels and the GDL. The inlet gas flow rate is calculated based on the same stoichiometric ratio as in [Ge et al., 2006]. All operating parameters are listed in Table 3.3.

Table 3.3 Operating parameters for the multi-physics performance model

\begin{tabular}{cc}
\hline \hline Parameters & Value \\
\hline Cathode outlet pressure & $1 \mathrm{~atm}$ \\
Cathode temperature & $65^{\circ} \mathrm{C}$ \\
Relative humidity of inlet fuel & $100 \%$ \\
Inlet nitrogen/water mole faction ratio & $0.79 / 0.21$ \\
Cathodic transfer coefficient & 0.5 \\
Dynamic viscosity $\mu$ & $2 \times 10^{-5} \mathrm{~m}^{2} / \mathrm{s}$ \\
Faraday's constant & 96487 \\
Air flow rate & $2.9 \times 10^{-4} \mathrm{~L} / \mathrm{s}$ \\
\hline \hline
\end{tabular}

A finite-element computational fluid dynamics package, the COMSOL Multiphysics ${ }^{\circledR}$ Chemical Engineering Module, is used to solve the fluid flow/chemical reaction equations. Using deformed geometry and parameters for each assembly pressure, the relationship between activation overpotential and current density can be obtained. Kinetic parameters for electrochemical reactions used in the simulation are adjusted in a reasonable range to fit experimental results. 


\subsubsection{Electrical contact resistance}

Electrical contact resistance constitutes a significant part of the ohmic resistance in a fuel cell and needs to be considered when evaluating fuel cell performance.

Assembly pressure affects electrical contact resistance in PEM fuel cells, with the most significant one being at the interface between the BPP and GDL. Electrical contact resistance can be estimated based on the surface roughness parameter and features of the GDL structure. A detailed description of a recently developed contact resistance model has been published [Zhou et al., 2007].

BPP surface topology is simulated as randomly distributed asperities and is based on measured surface roughness. The GDL is modeled as randomly distributed cylindrical fibers. Upon obtaining these two simulated surfaces, each contact spot is located according to their relative positions. The total resistance and pressure are obtained by considering all contact spots as resistances in parallel and summing the results together.

Based on the analysis in Sec. 3.2.2, higher assembly pressure increases the gas phase mass transfer resistance, so less assembly pressure is favored. On the other hand, the electrical contact resistance decreases with the increase of assembly pressure, meaning the ohmic overpotential can be significantly reduced. The contributions of these two effects are different in different pressure regions and can combine to yield an

optimum assembly pressure. Consequently, to evaluate the overall performance of a PEM fuel cell, both effects need to be considered. By neglecting other bulk resistances, the cell voltage is expressed as

$$
E=E^{0}-\eta-\eta_{\text {contact }}
$$


where $\eta_{\text {contact }}=2 I R_{\text {contact }}$ because of the two contacting surfaces between the BPP and GDL in a PEM fuel cell.

\subsection{Results and discussions}

\subsubsection{GDL deformation}

The predicted deformation of PEM fuel cell components under a pressure of 15 MPa using the above model is shown in Fig. 3.2. The GDL is deformed severely, with the true strain in the $Y$-direction being up to $43.6 \%$, while the BPP and membrane are nearly un-deformed. Fig. 3.3(a) shows the cell geometry before deformation, where $Y \in[0-0.05$ $\mathrm{mm}]$ is the membrane, and $\mathrm{Y} \in[0.05-0.25 \mathrm{~mm}] \mathrm{mm}$ is the GDL region $(0.2 \mathrm{~mm}$ thick). The deformed GDL shape under three different assembly pressures $(0.1,1$ and $15 \mathrm{MPa})$ is illustrated in Fig. 3.3(b).

Under compression, the GDL will be compressed and deformed into the BPP channels, which affects a number of process parameters critical to the performance of PEM fuel cells. The primary effects are: the reduction of gas flow channel area, the decrease of diffusion path under the land area and the change of porosity. 

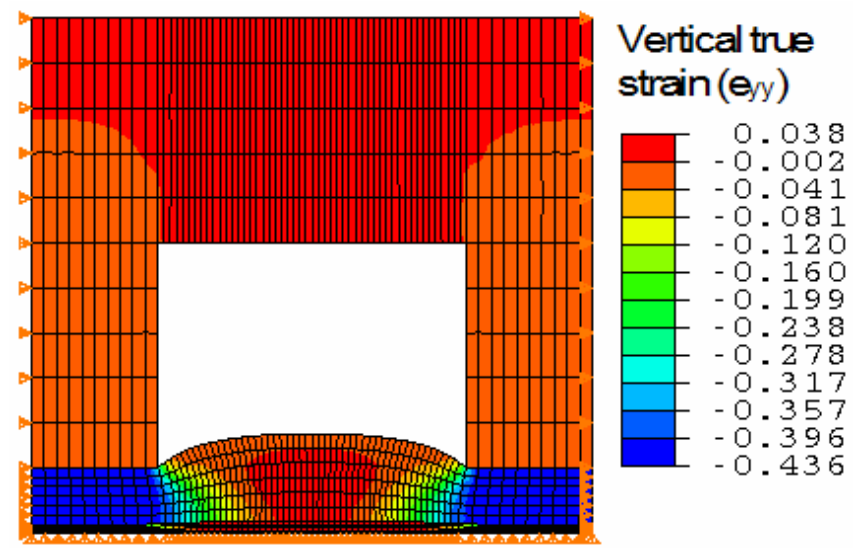

Figure 3.2 Predicted contour of effective strain at $15 \mathrm{MPa}$ pressure

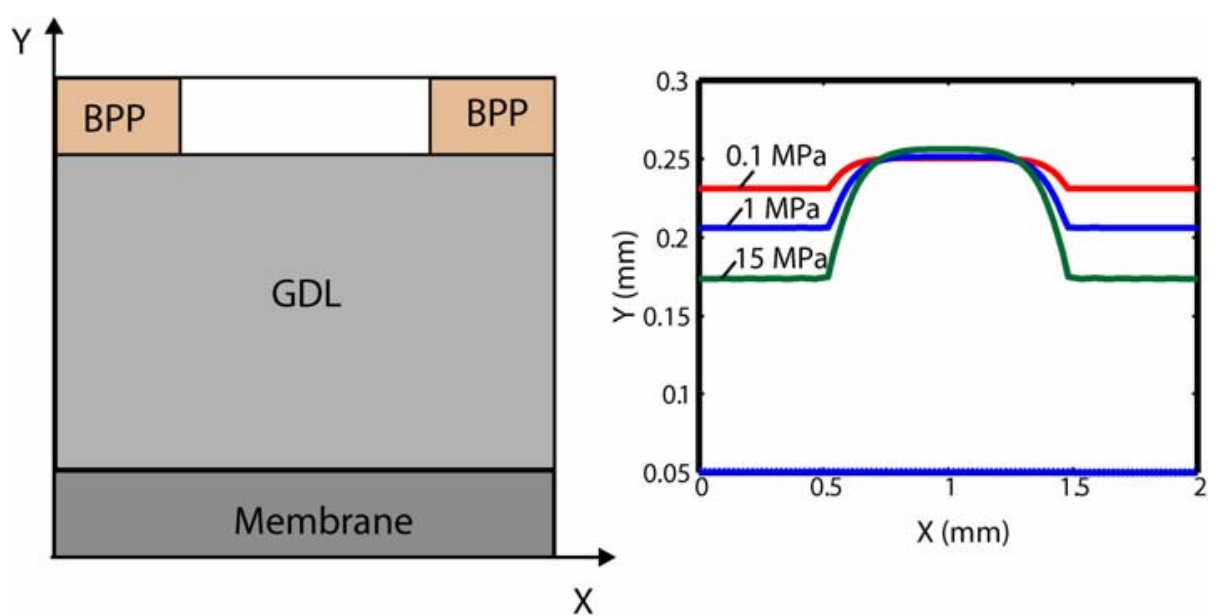

(a)

(b)

Figure 3.3 (a) Cell geometry before deformation and (b) deformed shapes of GDL under assembly pressures $0.1,1$ and $15 \mathrm{MPa}$ respectively

In addition to the change of GDL geometry, the porosity which is assumed to be uniform over the whole GDL also changed under compression. The GDL compression ratio, which is defined as the ratio of compressed thickness (under land area) to original thickness, and the porosity under the land area are shown in Fig. 3.4. 


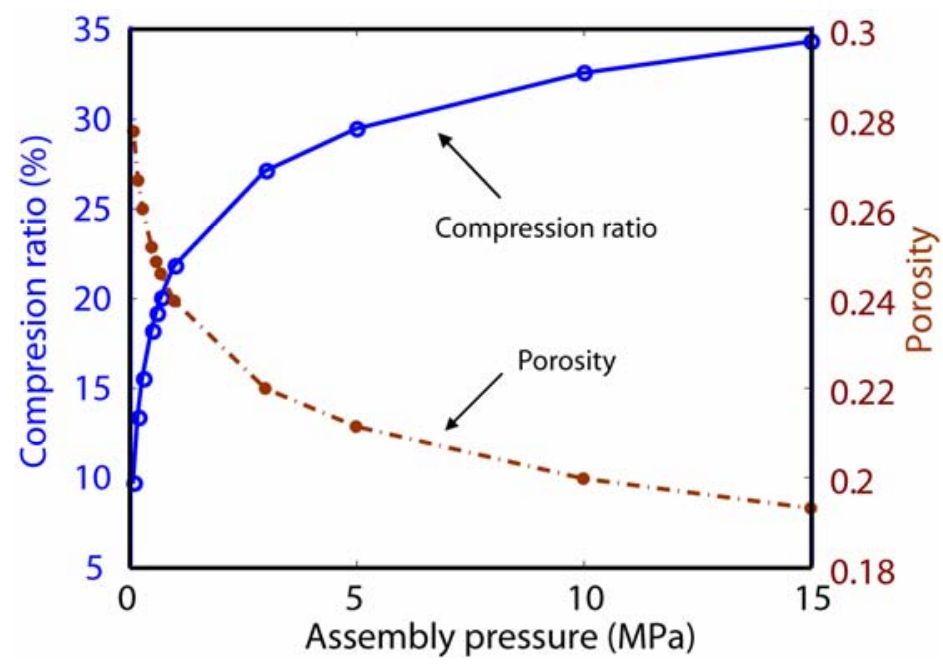

Figure 3.4 Compression ratio and porosity vs. assembly pressure

\subsubsection{Assembly pressure effects on mass transfer}

After assembly, the GDL is compressed and deformed into the flow channels of the BPP. As shown in Fig. 3.5, at the same voltage, current density is reduced at higher assembly pressure. This reflects the fact that mass transfer resistance is increased with the increase of assembly pressure. Specifically, the current density decreases by $27 \%$ when assembly pressure increases from 0.1 to $15 \mathrm{MPa}$. When assembly pressure is less than 0.1 $\mathrm{MPa}$, the current-voltage curve changes very slightly and stays almost the same.

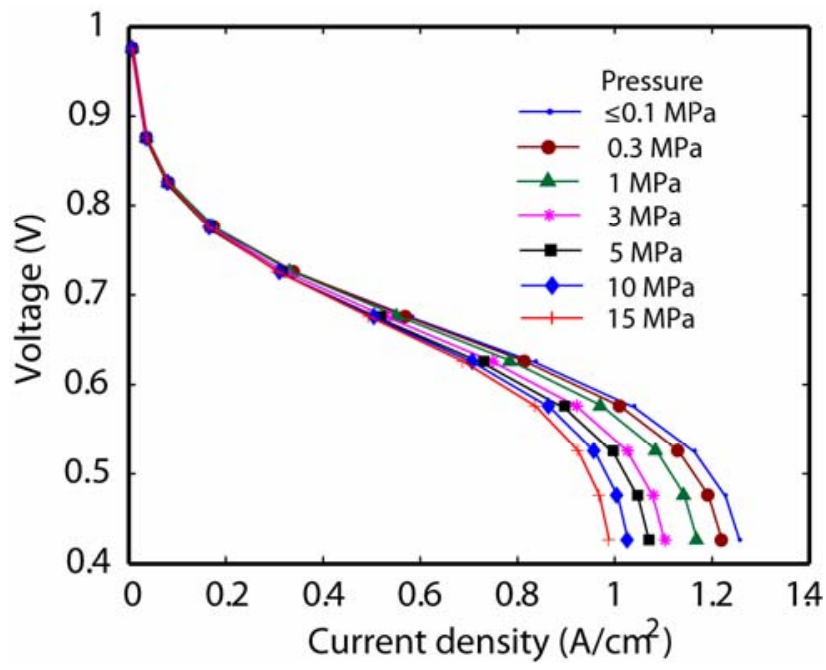

Figure 3.5 Assembly pressure effect on PEM fuel cell performance with only mass transfer resistance being considered 
This phenomenon is caused by the combined effects of flow area reduction in the channels in the BPP and a decrease in GDL thickness and porosity. The thickness and porosity of the GDL change depending on the assembly pressure. The thickness of the GDL under the land area is reduced significantly (around 36\%) when the assembly pressure reaches $15 \mathrm{MPa}$. A thinner GDL indicates a shorter path for gas transportation, which could facilitate the gas transfer. At the same time, the channel flow area is reduced, and the gas velocity in the channel is increased. Both benefit gas transfer. In contrast, under compression, the porosity of the GDL decreases. It is expected that a lower porosity would impede gas transfer in the region under the land. Therefore, one effect is countered by others. To analyze these effects in detail, they are considered separately under $15 \mathrm{MPa}$ assembly pressure and $0.6 \mathrm{~V}$ overpotential. The modeling results show the reduction in flow area and GDL thickness could increase the generated current density by about $5 \%$, while the decrease of GDL porosity has more prominent effect and decreases the current density by as much as $26 \%$. Total current density, therefore, decreases around $21 \%$ compared to non-deformed case.

Lower porosity obstructs gas transfer in the GDL, which is the dominant reason for the assembly pressure effects on mass transfer resistance. For the same surface overpotential $\eta$, the current density increases with porosity. Again, this is obviously due to the fact that a larger porosity in the GDL leads to a larger consumption of oxygen in the catalyst layer, from which a larger current density is generated. Moreover, a change in the porosity of the GDL has virtually less influence on the voltage level when the current density is at a medium or low value. It has a significant effect, however, on the 
polarization curve when the current density is close to the limiting value. This result is consistent with the fact that the voltage curve in the regime close to the limiting current density is governed by the mass transfer resistance, as stated in previous studies [Hoogers, 2003].

In this model, the reduction of channel flow area and GDL thickness has little impact on overall performance. However, if the initial thickness of the GDL is larger, or the channel depth is smaller, this effect could be more prominent.

\subsubsection{Assembly pressure effects on electrical contact resistance}

The surface roughness parameters of the same type of BPP (POCO AXF-5QCF) used in single cell tests [Ge et al., 2006] are measured to estimate the electrical contact resistance in the cell, which is then integrated into the performance model results. The surface roughness parameters obtained from the average values of several scans are: peak density $D_{\text {peak }}=150 / \mathrm{mm}$, mean asperity summit radius $R_{1}=3.26 \mu \mathrm{m}$, and variance of the summit height distribution $\sigma_{s}=0.728 \mu \mathrm{m}$. The GDL material properties and structure used in the simulation is based on the characteristics of Toray carbon fiber paper. The contact resistance change with assembly pressure, which is applied at the top of BPP, is shown in Fig. 3.6. 


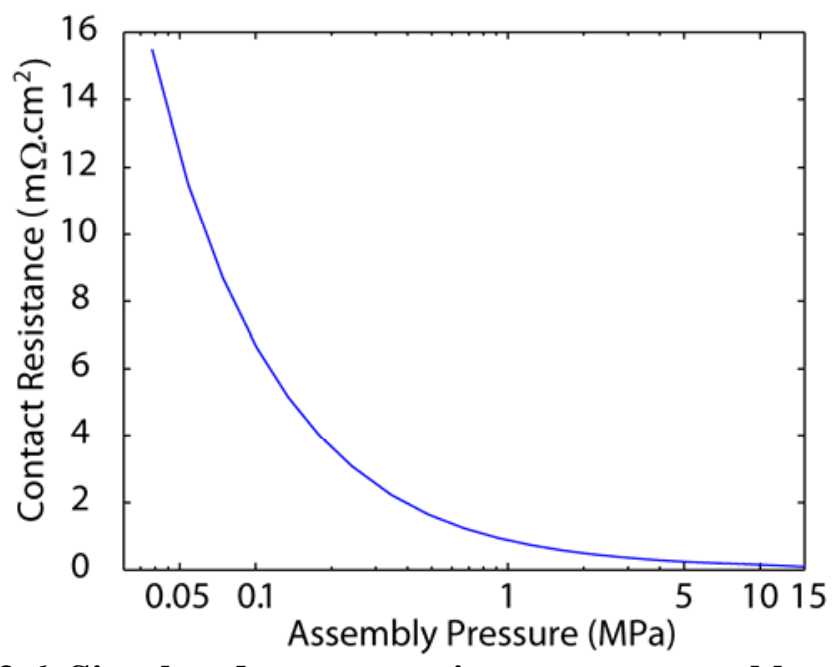

Figure 3.6 Simulated contact resistance vs. assembly pressure

\subsection{Model validation and discussions}

\subsubsection{Validation}

To validate the numerical model presented in Section 3.3, the comprehensive model results are compared to the experimental data from Ge et al. [2006] for a cell with a single serpentine channel and the same geometry and operation parameters.

Figure 3.7 compares the simulated voltage curves with the measured ones at $0.6,5$ and $15 \mathrm{MPa}$ assembly pressures. The simulated curves are generally in good agreements with the experimental data. However, the simulated cell current densities in the high current density region are slightly higher than the experimental values. This discrepancy is a common feature of single phase models where the effect of water flooding in the cathode at high current density is not accounted for. More current is produced under the channel area than under the land area because of the reduced oxygen diffusion in the compressed region. Thus, water flooding under the channel area is more severe than under the land. This makes the GDL porosity uneven, sometimes considerably. In this 
model, the porosity only depends on assembly pressure. Ideally, if the porosity is allowed to decrease in the model in proportion to cell current, to account for enhanced generation of water in the GDL, as well as change with cell dimensions due to compression, the model could predict the performance more accurately.

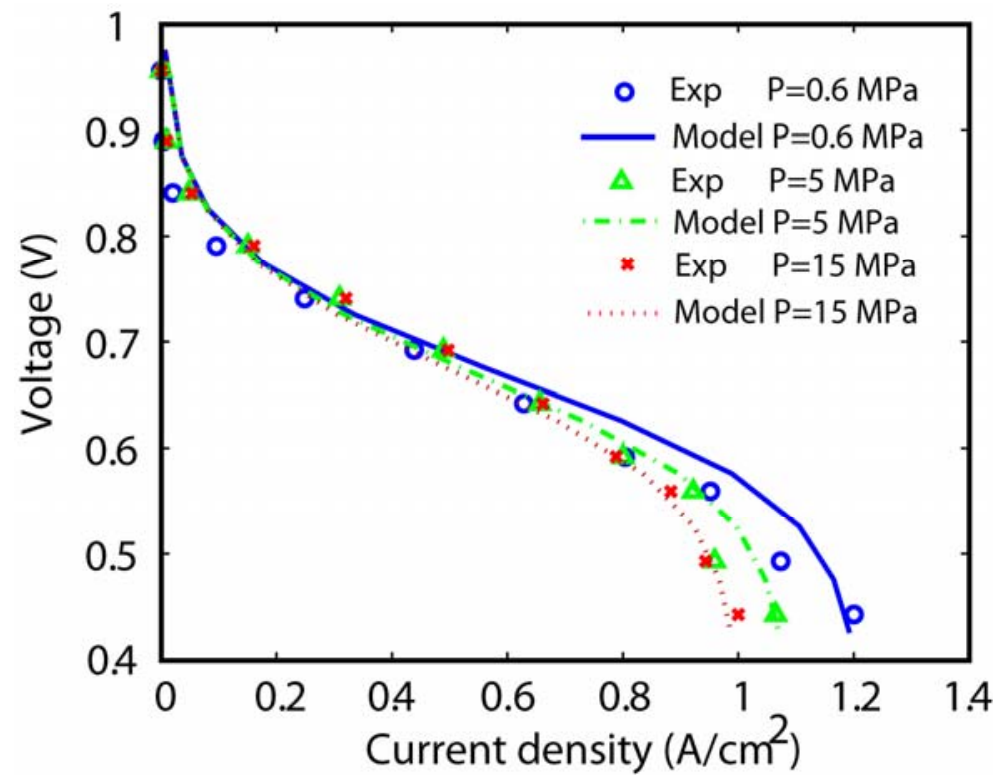

Figure 3.7 Polarization curves comparison between the modeling results with the experimental data under different assembly pressures.

\subsubsection{Assembly pressure effects on the overall PEM fuel cell performance}

Upon obtaining assembly pressure effects on mass transfer resistance and contact resistance above, the overall PEM fuel cell performance can be evaluated, as shown in Fig. 3.8. 


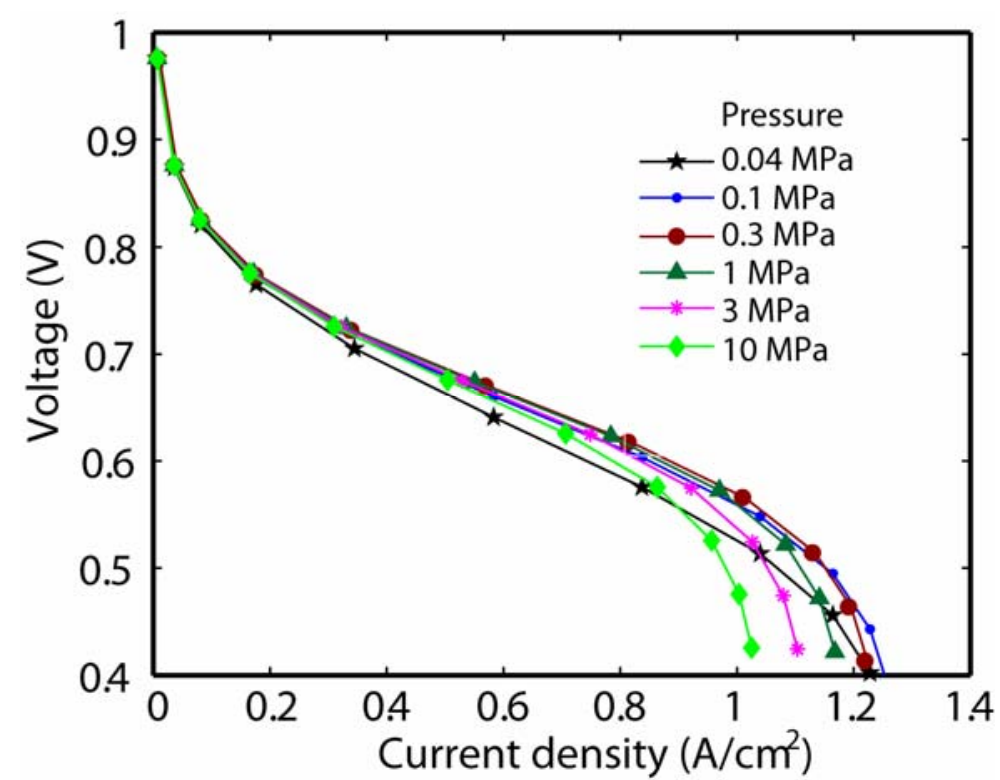

(a)

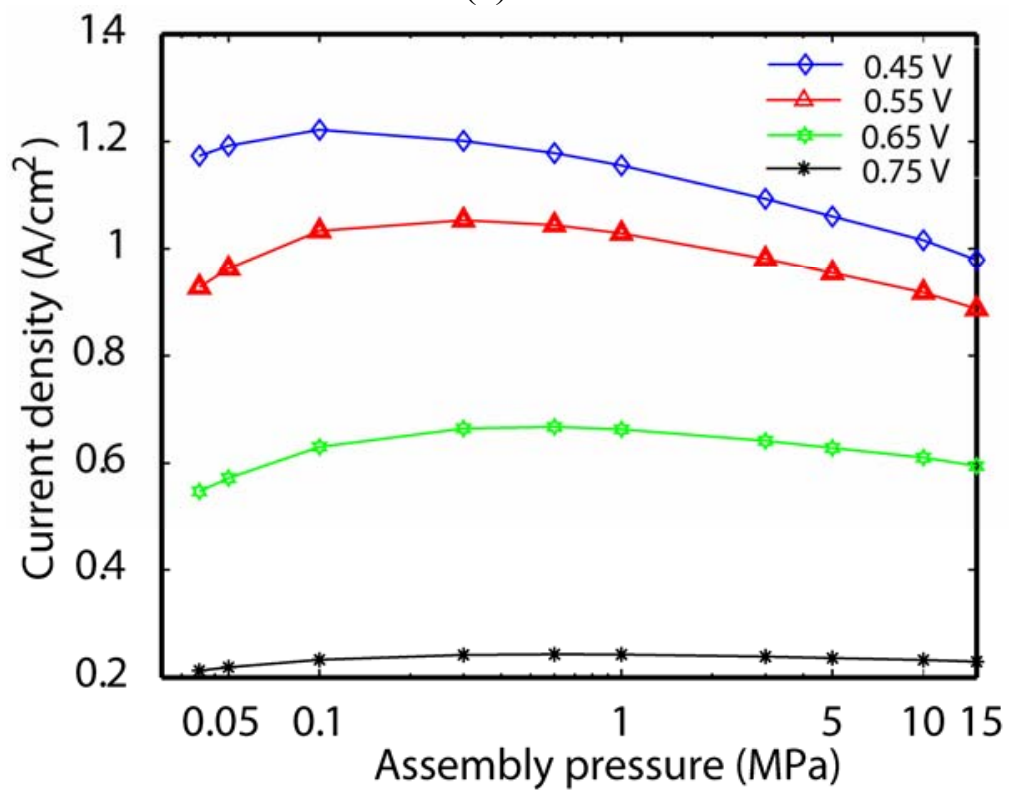

(b)

Figure 3.8 Effect of assembly pressure on overall fuel cell performance: (a) polarization curves at different assembly pressures and (b) current density vs. assembly pressure at different cell voltages

From Fig. 3.8, the fuel cell performance decreases with increasing compression in most of the assembly pressure region. However, an optimum assembly pressure exists within the lower pressure region. This optimal value is the result of the competing effects of contact resistance and mass transfer resistance. When the assembly pressure is very 
low, contact resistance could be high and reverse the effect of low mass transfer resistance. Obviously, an assembly pressure near this optimum value is preferred. Furthermore, if surface parameters of the BPP change, especially when the surface standard deviation becomes larger, the contact resistance tends to be higher. The optimum assembly pressure could then shift to a higher level, which can be achieved in practical assembly processes.

In addition to the overall polarization curve changes with assembly pressure, local current density distribution at the catalyst layer surface also differs, as presented in Fig. 3.9. For a lower value of assembly pressure ( $0.6 \mathrm{MPa})$, a much higher current density is generated under the channel area. This is because a compressed GDL increases the resistance of oxygen diffusion into the region under the land, resulting in a lower local oxygen concentration. Moreover, the current density distribution becomes slightly more non-uniform as the assembly pressure increases because of the reduced oxygen diffusion in compressed region. Higher assembly pressure (15 MPa) leads to smaller porosity, which imposes more impedance to gas transfer. Thus the current density generated under the land area is less and has more variation in its distribution. 

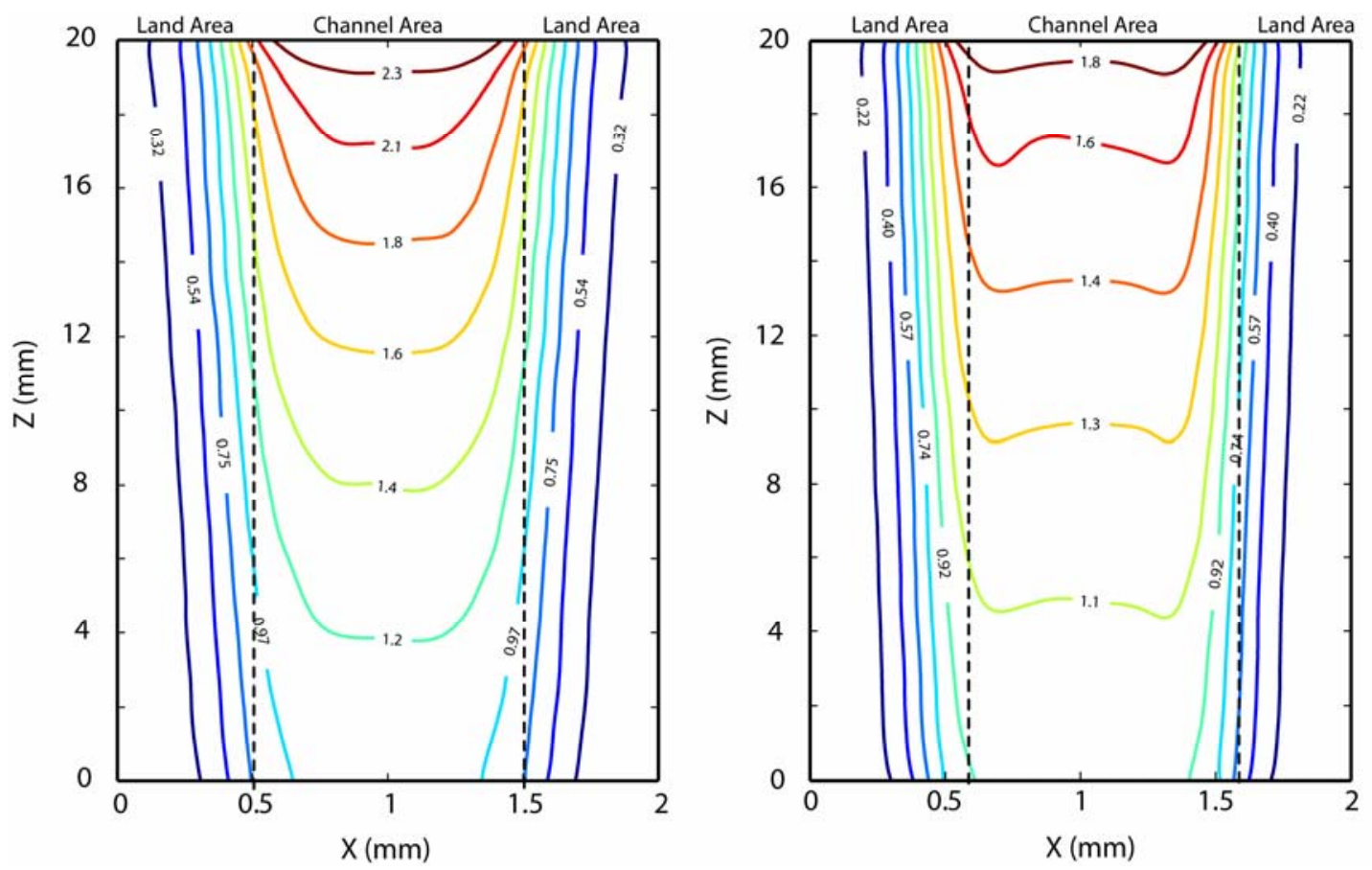

(a)

(b)

Figure 3.9 Contours of current density at $0.58 \mathrm{~V}$ cell voltage and assembly pressure of: (a) 0.6 MPa and (b) $15 \mathrm{MPa}$

Figure 3.10 shows the $\mathrm{O}_{2}$ mass distribution of the cross section of the GDL at the channel outlet for the same overpotential under 0.6 and $15 \mathrm{MPa}$ assembly pressure. The $\mathrm{O}_{2}$ mass fraction decreases noticeably inside the GDL, particularly under the land area. This effect is more pronounced for high assembly pressure conditions, where $\mathrm{O}_{2}$ mass fraction still remains very low regardless of the high $\mathrm{O}_{2}$ mass fraction gradient. 


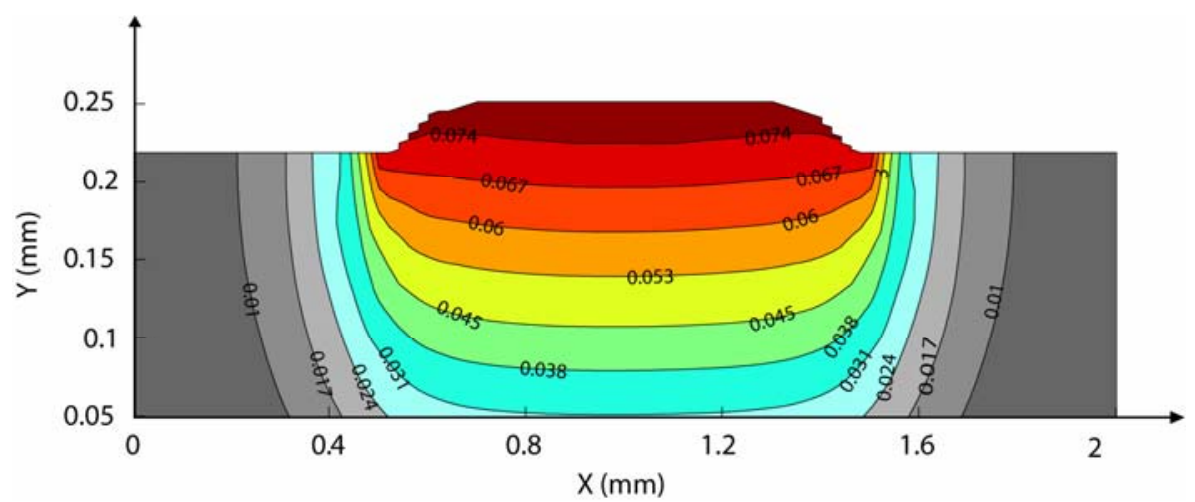

(a)

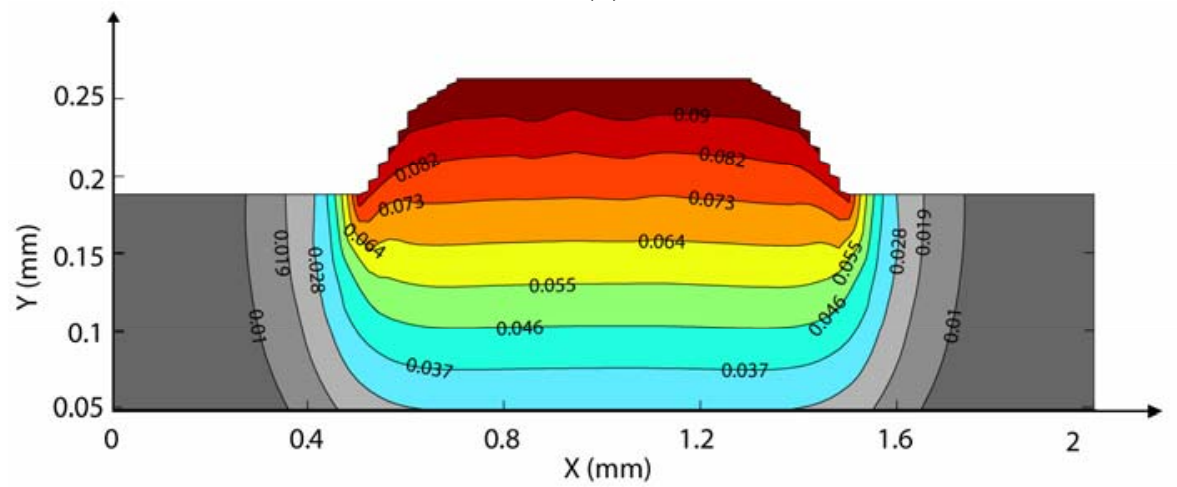

(b)

Figure $3.10 \mathrm{O}_{2}$ mass faction in GDL at channel outlet at assembly pressure: (a) 0.6 MPa and (b) $15 \mathrm{MPa}$

\subsection{Conclusions}

In order to study the effects of assembly pressure on the performance of PEM fuel cells mathematically, a multi-physics model was developed to simulate the entire process including the effects of mechanical deformation, mass transfer resistance and electrical contact resistance. After obtaining GDL deformation numerically, a 3D model was built to predict the mass transfer of gas based on the deformed geometry and associated parameters. Next, an overall PEM fuel cell performance model was proposed by integrating a mass transfer resistance model and a micro-scale electrical contact 
resistance model previously developed by the authors. Model results were in good agreements with available experimental data from literature.

It has been observed that assembly pressure has significant effects on PEM fuel cell performance. Generally, high assembly pressure increases mass transfer resistance. Current density decreases dramatically with an increase of assembly pressure. However, by incorporating the competing effects of electrical contact resistance, the overall performance first increases and then decreases with the increase of assembly pressure. There exists an optimum assembly pressure, in the lower-pressure region, at which fuel cell performance is maximized. Finally, current density distribution and $\mathrm{O}_{2}$ mass fraction distribution are also discussed. This study could provide guidance for potential improvements in PEM fuel cell design and assembly.

\section{Acknowledgements}

The authors would like to thank Prof. Hongtan Liu and Jiabin Ge from the University of Miami for providing the experimental data for model validation. 


\section{References}

Bazylak, A., Sinton, D., Liu, Z. S., Djilali, N., (2007), "Effect of compression on liquid water transport and microstructure of PEMFC gas diffusion layers," Journal of Power Sources, Vol. 163, pp. 784-792.

Bernardi, D. M. and Verbrugge M. W., (1991), "Mathematical Model of a Gas Diffusion Electrode Bonded to a Polymer Electrolyte," AIChE Journal, Vol. 37, pp. 11511162.

Berning, T., Lu, D. M., and Djilali, N., (2002), "Three-dimensional Computational Analysis of Transport Phenomena in a PEM Fuel Cell," Journal of Power Sources, Vol. 106, pp. 284-294.

Berning, T., and Djilali, N., (2003), "Three-dimensional Computational Analysis of Transport Phenomena in a PEM Fuel Cell-a Parametric Study," Journal of Power Sources, Vol. 124, pp. 440-452.

Chang, W.R., Hwang, J.J., Weng, F.B., Chan, S.H., (2007), "Effect of clamping pressure on the performance of a PEM fuel cell," Journal of Power Sources, Vol. 166, pp.149-154.

Chu, H. S., Yeh, C. and Chen, F., (2003), "Effects of Porosity Change of Gas Diffuser on Performance of Proton Exchange Membrane Fuel Cell," Journal of Power Sources, Vol. 123, pp. 1-9.

Chi, P. H., Weng, F. B., Su, A., and Chan, S. H., (2006), "Numerical Modeling of Proton Exchange Membrane Fuel Cell With Considering Thermal and Relative Humidity Effects on the Cell Performance," ASME Journal of Fuel Cell Science and Technology, Vol. 3, pp. 292-302.

Cussler, E.L., (1984), Diffusion-Mass Transfer in Fluid Systems, Cambridge University Pressure, Cambridge, UK.

Fuller, T. F. and Newman J., (1993), "Water and Thermal Management in Solid Polymer Electrolyte Fuel Cells," Journal of the Electrochemical Society, Vol. 140, pp. 1218-1225.

Ge, J., Higier, A. and Liu, H., (2006), "Effect of Gas Diffusion Layer Compression on PEM Fuel Cell Performance," Journal of Power Sources, Vol. 159, pp. 922-927.

Hoogers, G., (2003), Fuel Cell Technology Handbook, Boca Raton, FL.: CRC Press, 
Chap. 4.

Inoue, G., Matsukuma, Y., Minemoto, M., (2006), "Effect of gas channel depth on current density distribution of polymer electrolyte fuel cell by numerical analysis including gas flow through gas diffusion layer," Journal of Power Sources, Vol. 157, pp. 136-152.

Lai, Y. H., Miler, D. P., Ji, C. and Trabold, T. A., (2004), "Stack Compression of PEM Fuel Cells," Proceedings of Fuel Cell 2004: The 2nd International Conference on Fuel Cell Science, Engineering and Technology, 14-16 June 2004, Rochester, NY.

Lee, W. K., Ho, C. H., Van Zee, J.W. and Murthy, M., (1999), "The Effects of Compression and Gas Diffusion Layers on the Performance of a PEM Fuel Cell," Journal of Power Sources, Vol. 84, pp. 45-51.

Lee, S. J., Hsu, C. D. and Huang, C. H., (2005), "Analyses of the Fuel Cell Stack Assembly Pressure," Journal of Power Sources, Vol. 145, pp. 353-361.

Mathias, M., Roth, J., Fleming, J. and Lehnert W., in: W. Vielstich, A. Lamm, H.A. Gasteiger (Eds), 2003, Handbook of Fuel Cells - Fundamentals, Technology and Applications, Wiley, Vol. 3, pp. 13.

Newman, J. S., (1991), Electrochemical Systems, Peentice Hall, New Jersey, Chap. 1.

Nitta, I., Hottinen, T., Himanen, O., Mikkola, M., (2007), "Inhomogeneous compression of PEMFC gas diffusion layer," Journal of Power Sources, Vol. 171, pp. 26-36.

Nguyen, T. V. and White R. E., (1993), "A Water and Heat Management Model for Proton Exchange Membrane Fuel Cells," Journal of the Electrochemical Society, Vol. 140, pp. 2178-2186.

Parthasarathy, A., Srinivasan, S., and Appleby, A. J., (1992), “Temperature Dependence of the Electrode Linetics of Oxygen Reduction at the Platinum/Nafion Interfacea Microelectrode Investigation," Journal of the Electrochemical Society, Vol. 139, pp. 2530-2537.

Springer, T. E., Wilson, M. S., and Gottesfeld, S., (1993), "Modeling and Experimental Diagnostics in Polymer Electrolyte Fuel Cells," Journal of the Electrochemical Society, Vol. 140, pp 3513-3526.

Springer, T. E., Zawodzinski, T. A. and Gottesfeld S., (1991), "Polymer Electrolyte Fuel Cell Model," Journal of the Electrochemical Society, Vol. 138, pp. 2334-2342. 
Zhou, P., Wu, C. W., (2007), "Numerical study on the compression effect of gas diffusion layer on PEMFC performance," Journal of Power Sources, Vol. 170, pp 93-100.

Zhou, Y., Lin, G., Shih, A. J. and Hu, S. J., (2007), “A Micro-scale Model for Predicting Contact Resistance between Bipolar Plate and Gas Diffusion Layer in PEM Fuel Cells," Journal of Power Sources, Vol. 163, pp. 777-783. 


\title{
CHAPTER 4
}

\section{ASSEMBLY PRESSURE AND MEMBRANE SWELLING IN PEM FUEL CELLS}

\begin{abstract}
Assembly pressure along with membrane swelling induced by elevated temperature and humidity causes inhomogeneous compression and performance variation in PEM fuel cell stacks. This research conducts a comprehensive analysis on the effects of assembly pressure and operating temperature and humidity on PEM fuel cell stack deformation, contact resistance, overall performance and current distribution by advancing the model previously developed by the authors [Zhou et al., 2008, Chapter 3]. A finite element model is first developed to simulate the stack deformation when temperature and humidity fields are applied. Then a multi-physics simulation, including gas flow and diffusion, proton transport, and electron transport in a three-dimensional cell geometry, is conduced. The modeling results reveal that elevated temperature and humidity enlarge GDL and membrane inhomogeneous deformation, increase contact pressure and reduce contact resistance due to the swelling and change of material property of GDL and membrane. When assembly pressure is applied, the fuel cell overall performance is improved by increasing temperature and humidity. However, significant spatial variation of current distribution is observed at elevated temperature and humidity, which may cause performance degradation and affect fuel cell durability.
\end{abstract}

\footnotetext{
* Contents of this chapter are ready to be submitted to Journal of Power Sources.
} 


\subsection{Introduction}

A PEM fuel cell stack consists of several single cells connected in series by bipolar plates which provide reactants to the MEAs. Assembly pressure can increase the overall electrical conductivity of GDL, improve contact resistance, and hence, reduce the electrical resistance losses inside the cell. Assembly pressure determines the contact status and stack deformation especially that of the GDL, which is the most deformable component in a PEM fuel cell stack. Under the land of a bipolar plate, the GDL is compressed by the assembly force. Under the channel area, the GDL protrudes into the channel cavities. The thickness and porosity of the GDL are affected under compression; consequently, the mass, heat, and charge transfer properties are changed. It is well recognized that GDL can influence PEM fuel cell performance significantly [Ge et al., 2006]. However, most of PEM fuel cell performance models do not consider this GDL inhomogeneous compression and its effects. Limited research has been conducted to address this issue. Zhou et al. [2008] developed a multi-physics model to investigate assembly pressure effects on PEM fuel cell performance by considering contact resistance and flow resistance. Sun et al. [2005] assumed a GDL compression ratio and analyzed the influence of performance and current density distribution. Hottinen et al. [2007] conducted a study on the effect of inhomogeneous compression of GDL on the mass and charge transfer in PEM fuel cells using experimentally obtained GDL parameters as a function of compression thickness. However, the room temperature and dry conditions, which do not reflect the real PEM fuel cell operating conditions, were assumed in both modeling and experimental investigation on GDL deformation. 
In practice, most fuel cells operate at elevated temperature and 100\% relative humidity (RH). Elevated temperature and high RH influence PEM fuel cell polarization losses in many ways including catalyst activity [Neyerlin et al., 2005], membrane mechanical and electrical properties [Tang et al., 2006], gas transport [Coppo et al., 2006] etc. In addition, GDL and MEA deformation are also affected. Since the relative position between the top and bottom end plate of PEM fuel cell stack is fixed after assembly, the polymer membrane is spatially confined under the BPP (with the gas flow channels) and the porous carbon electrodes, as shown in Fig. 4.1. As the relative humidity increases, membrane absorbs water, swells and pushes the electrodes. As a consequence, GDL will be further compressed under the land and the protrusion into channel increases due to the tendency of membrane swelling. This membrane swelling also changes the local contact forces due to the redistribution of stress field in fuel cell stacks.

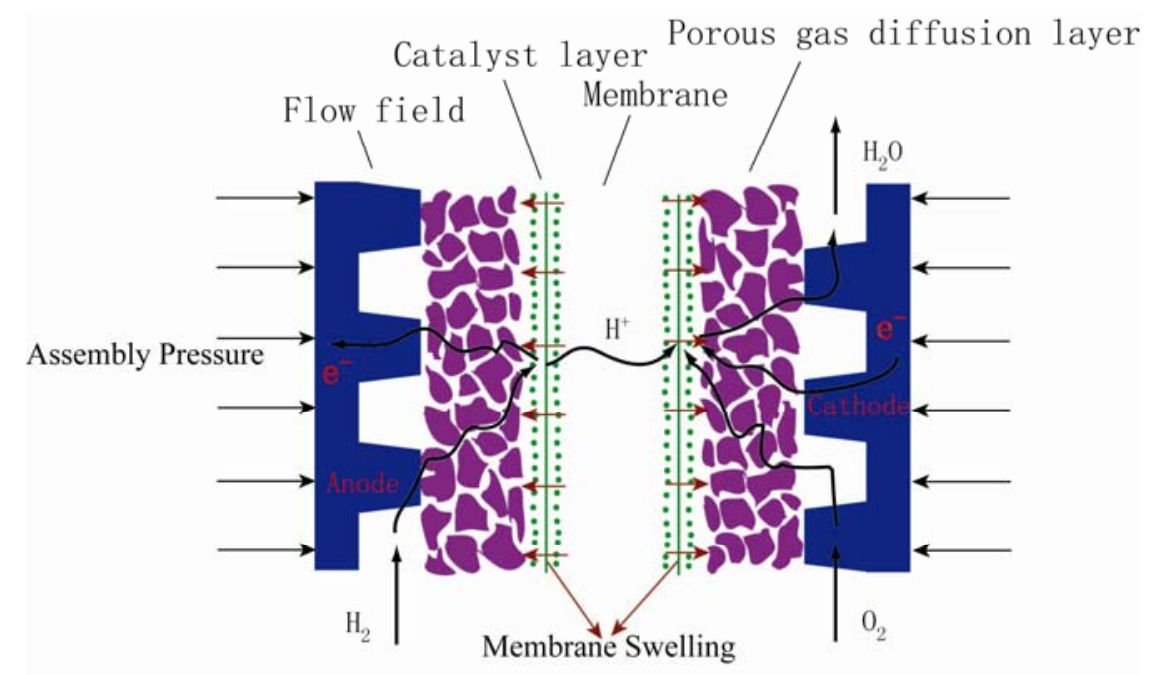

Figure 4.1 Schematic of assembly and swelling a PEM fuel cell

Few efforts have been made to study the influence of operating conditions (temperature and $\mathrm{RH}$ ) on stack deformation and contact resistance. The aim of this study is to improve the model previously developed by the authors [Zhou et al., 2008] with 
respect to the assembly pressure effects on performance by incorporating temperature and RH effects with GDL deformation and contact resistance.

Furthermore, this paper also investigates the current density distribution. During the operation of a PEM fuel cell, significant variation of the local current density exists across the plane of the cell. This causes sharp local temperature and stress gradient as well as degrading the efficiency of water management [Zhang et al., 2006; Um et al., 2000; Gurau et al., 1998]. Current density distribution is also a significant signature to evaluate fuel cell performance and durability. Current density distributions under various assembly pressure and operating conditions are investigated.

In this study, temperature and $\mathrm{RH}$ effects are incorporated into our previous model [Zhou et al., 2008]. A sequential approach is implemented. A finite element model is first developed to model the stack deformation under different levels of assembly pressure, and temperature and RH. Component deformation, the change of material properties and local contact pressure are obtained. Then gas flow and diffusion, chemical reactions, ion and electron transport are modeled based the updated geometry and material properties. Contact resistance is also analyzed in the model. The impact of assembly pressure and operating conditions is evaluated by fuel cell performance and current density distributions.

\subsection{Model description}

A finite-element-based structural model is developed to simulate stack deformation under various assembly pressures, temperatures and RHs. Upon obtaining 
the deformed geometry and material properties of GDL and membrane, a computational fluid dynamic (CFD) based fuel cell performance model is developed to analyze the multi-component gas transport, chemical reactions, charge transfer and contact resistance based on the deformed GDL shape and modified GDL gas transport parameters.

Specifically, the local contact force between BPP and GDL can be obtained. The contact resistance is then simulated based on Zhou et al. [2007] and included in the multi-physics performance model to predict fuel cell performance.

Four different cases are modeled: 1) a base model with homogeneous properties of GDL (no compression and $25^{\circ} \mathrm{C}$ and $40 \% \mathrm{RH}$ ) which represents the most common case without considering compression in previous fuel cell modeling work and operating conditions at start-up; 2) under assembly pressure of $3 \mathrm{MPa}$ and $25^{\circ} \mathrm{C}$ temperature and $40 \% \mathrm{RH}$, which represents the fuel cell stack under assembly pressure at the start of operation; 3) $3 \mathrm{MPa}$ assembly pressure, $85^{\circ} \mathrm{C}$ and $40 \% \mathrm{RH}$; and 4) $3 \mathrm{MPa}$ assembly pressure, $85^{\circ} \mathrm{C}$ and $90 \% \mathrm{RH}$, which are reasonable values for the PEM fuel cell stack in operation.

\subsubsection{Stack deformation model under elevated temperature and humidity}

The model used in the current investigation is an extension of a model developed by Zhou et al. [2008]. In the current work, we incorporate temperature- and humiditydependent properties of the membrane in investigating stack deformation under various assembly pressures and operating conditions. The geometric parameters and physical properties of the components are listed in Tables 4.1 to 4.3, where the elastic constants, coefficients of swelling and thermal expansion of the component materials, are collected from various references [Mathias et al., 2003; Kusoglu et al., 2006; Tang et al., 2006]. 
Table 4.1 Geometric and physical parameters for the structural deformation and mass transfer analysis

\begin{tabular}{|c|c|}
\hline Parameter & Value \\
\hline BPP thickness $\left(h_{I}\right)$ & $2 \mathrm{~mm}$ \\
\hline GDL thickness $\left(h_{2}\right)$ & $100 \mu \mathrm{m}$ \\
\hline Catalyst layer thickness $\left(h_{3}\right)$ & $20 \mu \mathrm{m}$ \\
\hline Membrane thickness $\left(h_{4}\right)$ & $50 \mu \mathrm{m}$ \\
\hline Channel height $\left(h_{5}\right)$ & $0.5 \mathrm{~mm}$ \\
\hline Channel width $\left(w_{l}\right)$ & $1 \mathrm{~mm}$ \\
\hline Land width $\left(w_{2}\right)$ & $1 \mathrm{~mm}$ \\
\hline Channel length & $5 \mathrm{~mm}$ \\
\hline GDL initial porosity & 0.6 [Lin et al., 2006] \\
\hline Catalyst layer porosity & 0.06 [Lin et al., 2006] \\
\hline GDL electric conductivity & uncompressed \\
\hline In-plane & $3.4 \times 10^{4} \mathrm{~S} / \mathrm{m}$ [Mathias et al., 2003] \\
\hline Through-plane & $1.4 \times 10^{2} \mathrm{~S} / \mathrm{m}$ [Mathias et al., 2003] \\
\hline GDL permeability & $1.76 \times 10^{-11} \mathrm{~m}^{2}$ \\
\hline Catalyst layer electronic conductivity & $100 \mathrm{~S} / \mathrm{m}$ [Fischer et al., 1998] \\
\hline Catalyst layer ionic conductivity & $1.7 \mathrm{~S} / \mathrm{m}$ [Bevers et al., 1997] \\
\hline
\end{tabular}

The material properties for the graphite plates are set to those of commercial graphite material and material properties for the carbon paper are from TORAY ${ }^{\circledR}$ TGP$\mathrm{H}-030$. It is assumed that these materials have linear elastic behavior and do not swell in response to moisture. 
Table 4.2 Component material mechanical properties [Mathias et al., 2003; Kusoglu et al., 2006; Tang et al., 2006]

\begin{tabular}{|c|c|c|c|c|}
\hline Component (Material) & $\begin{array}{l}\text { Elastic modulus } \\
\quad(\mathrm{MPa})\end{array}$ & $\begin{array}{l}\text { Poisson's } \\
\text { ratio }\end{array}$ & $\begin{array}{l}\text { Coefficient } \\
\text { of thermal } \\
\text { expansion } \\
(\mathrm{CTE})(\alpha) \\
\left(10^{-6} /{ }^{\circ} \mathrm{C}\right)\end{array}$ & $\begin{array}{c}\text { Swelling } \\
\text { coefficient }(\beta) \\
\quad(1 / \mathrm{RH})\end{array}$ \\
\hline BPP (graphite) & 10000 & 0.25 & 5 & Neglected \\
\hline GDL (Carbon paper) & Nonlinear elastic & 0.25 & -0.8 & Neglected \\
\hline $\begin{array}{c}\text { Membrane }\left(\text { Nafion }^{\circledR}\right. \\
112)\end{array}$ & Table 4.3 & 0.253 & 123 & From Fig. 4.2 \\
\hline
\end{tabular}

Linear-elastic, perfectly plastic constitutive behavior with temperature- and humidity- dependent material properties is assumed for the membrane. Young's modulus and yield strength of the membrane are defined at four temperature and $\mathrm{RH}$ levels based on experimental data for Nafion ${ }^{\circledR} 112$ from literature. Even though a slight anisotropy in the material properties was observed experimentally [Tang et al., 2006], for simplicity, we assume for simplicity that the material properties are isotropic in this study.

Table 4.3 Young's modulus (MPa) at various temperature and humidity for Nafion ${ }^{\circledR} 112$ [Tang et al., 2006]

\begin{tabular}{ccccc}
\hline \hline & $H=30 \%$ & $H=50 \%$ & $H=70 \%$ & $H=90 \%$ \\
\hline$T=25 \circ \mathrm{C}$ & 197 & 192 & 132 & 121 \\
$T=45 \circ \mathrm{C}$ & 161 & 137 & 103 & 70 \\
$T=65{ }^{\circ} \mathrm{C}$ & 148 & 117 & 92 & 63 \\
$T=85{ }^{\circ} \mathrm{C}$ & 121 & 89 & 59 & 46 \\
\hline \hline
\end{tabular}




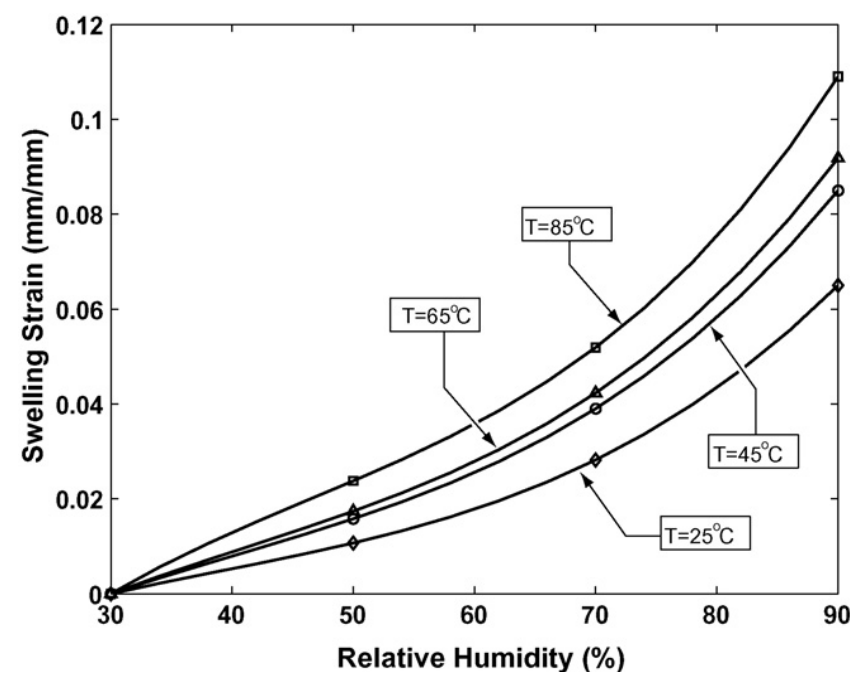

Figure 4.2 Swelling expansion as a function of humidity and temperature for Nafion ${ }^{\circledR} 112$ [Tang et al., 2006]

The model is built using the commercial finite element software ABAQUS. Fournode quadrilateral plane-strain elements (CPE4) are used to mesh the components, as shown in Fig. 4.3. The bottom membrane surface is fixed vertically (in $Y$-direction), and $X$-symmetry conditions are applied to the side vertical boundaries of all components. The component interfaces are bonded, with no slip allowed. The analysis consists of two sequential steps, as described in the following.

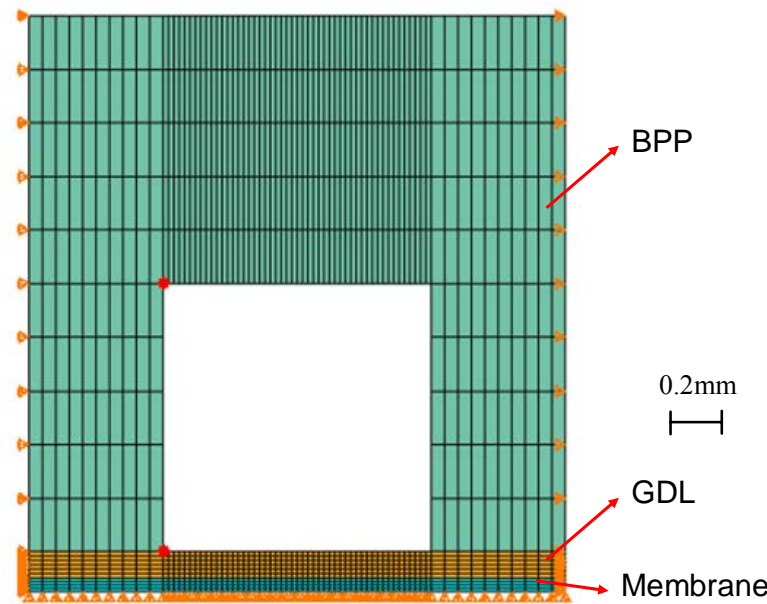

Figure 4.3 Finite element model for stack deformation analysis 
Simulation of assembly-induced stack deformation: In the stack assembly, it is desirable to have a uniform assembly pressure in the BPP, even though the clamping load may be localized. As such, a uniform assembly pressure is assumed for the BPP. Under ambient conditions, i.e., temperature at $25^{\circ} \mathrm{C}$ and relative humidity at $40 \%$, a series of assembly pressures of $0.3,0.5,0.7,1.0,2.0,3.0$, and $6.0 \mathrm{MPa}$ are applied to the BPP top surface. The stack deformation is calculated under these assembly pressures.

\section{Simulation of stack deformation due to swelling and thermal expansion:}

After the equilibrium state of the components is achieved under the applied pressure, the top surface of the BPP is fixed in the vertical direction at the deformed position.

Temperature and $\mathrm{RH}$ of the whole stack are then raised to the desired levels, i.e., $85^{\circ} \mathrm{C}$ and $40 \% \mathrm{RH}$, and $90 \% \mathrm{RH}$, under which the components expand and swell. Meanwhile, the increase of temperature and RH also changes the material properties, and leads to the redistribution of deformations in the whole stack under the constraint of end plates, or the constraint of BPP for the single-cell.

The total strain in the membrane due to moisture and temperature change is calculated based on the coefficients of swelling and thermal expansion. The swelling behavior is temperature-dependent, which makes the total strain calculation difficult to implement in finite element modeling since ABAQUS, which is similar to most of the commercial software packages, can only simulate the expansion caused by the temperature field change. Thus, a new parameter, denoted as equivalent coefficient of expansion, $\bar{\alpha}$, is defined to overcome this challenge by combining the effects of swelling and thermal expansion. As the temperature and humidity are increased to $T$ and $R H$, respectively, $\bar{\alpha}$ can be expressed as, 


$$
\bar{\alpha}(T, R H)=\frac{[1+\alpha(T) \Delta T][1+\beta(R H, T) \Delta R H(T)]-1}{\Delta T}
$$

where $\alpha$ is the coefficient of thermal expansion (CTE), $\beta$ is the coefficient of swelling expansion and calculated by data obtained from Fig. 4.2. $\Delta R H$ and $\Delta T$ are the changes of relative humidity and temperature, respectively, from one state to another state. When the humidity effect is neglected, i.e., $\beta(R H, T)=0, \bar{\alpha}(T, R H)=\alpha(T)$ and when the thermal expansion effect is neglected, i.e., $\alpha(T, R H)=0, \bar{\alpha}(T, R H)=\beta(R H, T)$.

The elevated temperature and humidity cases simulated are $85^{\circ} \mathrm{C}$ and $40 \% \mathrm{RH}$, and $85^{\circ} \mathrm{C}, 90 \% \mathrm{RH}$, which will be compared with the base case at $25^{\circ} \mathrm{C}$ and $40 \% \mathrm{RH}$. Then the change of $\mathrm{RH}$ is converted to the equivalent of temperature change using Eqn.(1). This way, the swelling and thermal expansion can be both considered in ABAQUS simulation.

Under the applied assembly pressure and the given temperature and $\mathrm{RH}$, the volumetric strain of every element or the thickness of the GDL can be used to estimate its modified porosity. Based on the deformed configuration and the modified GDL porosity, mass transfer analysis is conducted.

It is assumed that the change in thickness under compression is due to change in volume of void space, not in volume of solid material. Thus, the porosity of the GDL can be calculated

$$
\varepsilon^{\prime}=\varepsilon_{0} \frac{v^{\prime}-v_{\text {solid }}}{v_{0}-v_{\text {solid }}}
$$


where $\varepsilon_{0}$ is the initial porosity of GDL, $V_{0}$ is the uncompressed volume and $V^{\prime}$ is the volume after compression. From the structure model above, the individual element volume can be exported so that local porosity is calculated accordingly.

\subsubsection{Contact resistance}

Contact resistance constitutes a significant part of ohmic resistance in the fuel cell, and needs to be considered when evaluating fuel cell performance. A high contact resistance exists between the GDL and BPP due to the fact that the GDL is porous $(60 \%$ $80 \%$ porosity) and the surface of BPP engaging GDL is rough. Hence, current flow between BPP and GDL occurs only at sites where the BPP contacts GDL.

Assembly pressure affects contact resistance in PEM fuel cells. Contact resistance can be estimated based on surface roughness parameters of BPP and features of GDL structure. A detailed description of the model is presented in Zhou et al. [2007].

BPP surface topology is simulated as randomly distributed asperities, and is based on measured surface roughness. The GDL is modeled as randomly distributed cylindrical fibers. Upon obtaining these two simulated surfaces, each contact spot is located according to relative positions. The total resistance and pressure are obtained by considering all contact spots as resistances in parallel and summing the results together.

In this study, the contact resistance between graphite BPP and carbon fiber paper GDL, the most common materials used in PEM fuel cells, is applied in the model. The surface roughness parameters obtained from the average values of several scans are: peak density $D_{\text {peak }}=150 / \mathrm{mm}$, mean asperity summit radius $R_{1}=3.26 \mu \mathrm{m}$, and variance of the 
summit height distribution $\sigma_{s}=0.728 \mu \mathrm{m}$. The model predicted results of contact resistance change with assembly pressure is shown in Fig. 4.4.

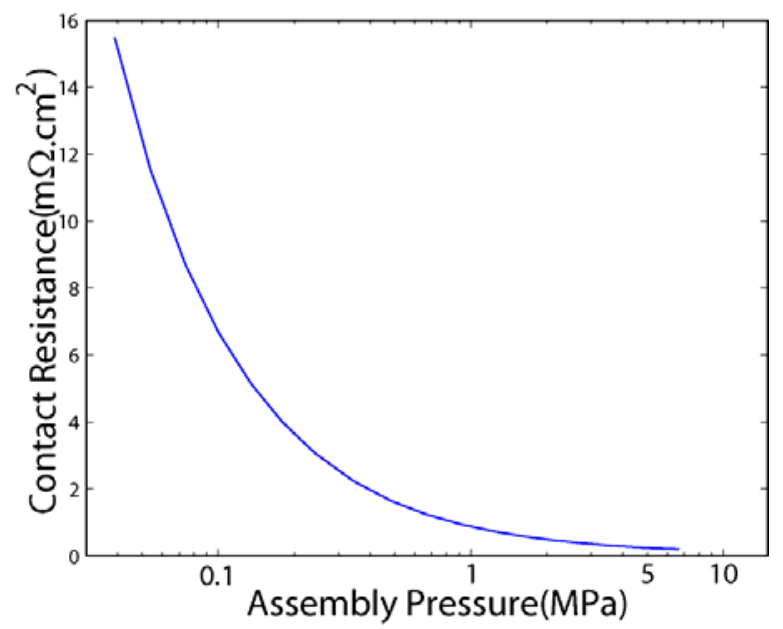

Figure 4.4 Contact resistance vs. assembly pressure

Since the operating conditions will influence local contact force and GDL porosity, two crucial factors for determining contact resistance, the changes of contact resistance should be considered. The contact force and GDL porosity will be obtained from the structural model in Section 4.2.1.

\subsubsection{PEM fuel cell performance analysis}

A finite-element computational fluid dynamics package, the COMSOL Multiphysics ${ }^{\circledR}$, is applied to solve the coupled nonlinear equations representing the physical phenomena of gas and charge transfer. Fig. 4.5 shows the model domain for the base case with no assembly pressure, $25^{\circ} \mathrm{C}$ temperature and $40 \% \mathrm{RH}$. The $3 \mathrm{D}$ model domain consists of a conventional gas channel, cathode GDL, catalyst layer (CL), membrane, and anode electrode interface. Because of the symmetrical characteristic of the structure, only half the width of the shoulder and channel is analyzed to reduce computational time. 


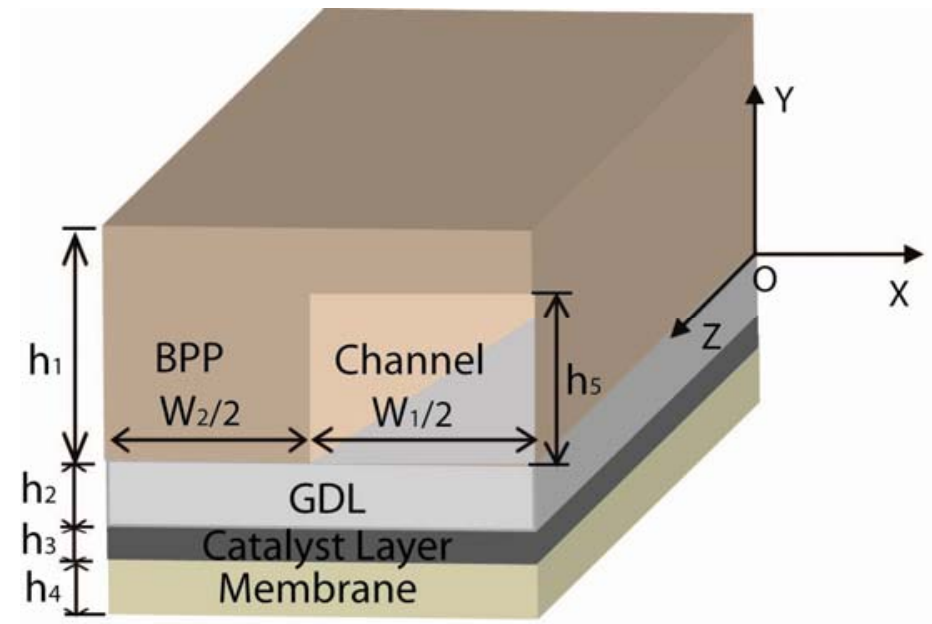

Figure 4.5 Computational domain for the base case

There exist coupled gas mass transfer and charge transfer in PEM fuel cell stacks. In the BPP channel, multi-component gases consist of $\mathrm{N}_{2}, \mathrm{O}_{2}$ and $\mathrm{H}_{2} \mathrm{O}$. The gas flow is modeled in combination with diffusion and convective transport. In the GDL and CL, $\mathrm{N}_{2}$, $\mathrm{O}_{2}$ and $\mathrm{H}_{2} \mathrm{O}$ transport is driven by diffusion mechanism. Three sets of Navier-Stroke equations are used to model the incompressible gas flow of $\mathrm{N}_{2}, \mathrm{O}_{2}$ and $\mathrm{H}_{2} \mathrm{O}$ in channels and another three sets of Maxwell-Stefan equations are used to simulated multicomponent diffusion and convection in channels and gas distribution layers. Darcy's law is utilized for the flow of species in porous electrodes. The rate of $\mathrm{O}_{2}$ consumption and $\mathrm{H}_{2} \mathrm{O}$ production are determined by coupled effects of gas transfer rate and charge transfer processes.

Charge balance in the solid phase (GDL, membrane and CL) is taken into account in this model, including the ion transport in CL and membrane and electron transport in GDL and CL. In GDL, due to no chemical reactions, the electronic charge is conserved. Within the CL, electrons are consumed by the $\mathrm{O}_{2}$ reduction reaction and the $\mathrm{O}_{2}$ consumption rate varies across the CL. The gradient of the electronic current is 
proportional to the oxygen consumption rate. The contact resistance between GDL and the land of BPP is taken into account by modeling the boundary as a thin layer. The electric conductivity and thickness of the boundary layer are calculated so that its total resistance corresponded to the contact resistance values obtained from the mechanical deformation model and contact resistance simulation in Sec 4.2.2. Ion transfer only takes place in CL and membrane. Ions are consumed at the CL due to chemical reactions. The ion transfer is conserved in the membrane domain.

For boundary conditions, gas mixture is assumed to enter the channel normal to the inlet cross section. All walls in the channel have no-slip boundary conditions. The mass and momentum transport boundary conditions between the BPP shoulders and the GDL are all insulated. At the interface between GDL and CL, it is assumed that no contact resistance exists. The electronic current and the fluxes of $\mathrm{N}_{2}, \mathrm{O}_{2}$ and $\mathrm{H}_{2} \mathrm{O}$ in the $Y$-direction are continuous. The flux of protons is set to zero because there is no ionic phase in the GDL. At the boundary between the CL and the membrane, the fluxes of $\mathrm{N}_{2}$, $\mathrm{O}_{2}$ and $\mathrm{H}_{2} \mathrm{O}$, and electronic current in the $Y$-direction are set to zero while the ionic current are continuous. The anode is assumed to be an interface, and the ionic potential is approximately zero at the interface between the anode CL and the membrane based on the assumption that the hydrogen oxidation reaction rate is so fast that the anodic overpotential is negligible [Lin and Nguyen, 2006]. All other boundaries are assumed to be insulated due to symmetry.

Consistent with traditional fuel cell models [Berning et al., 2002; Bernardi and Verbrugge, 1991], the model is assumed to be steady-state, isothermal and isobaric. Another assumption is that single-phase water transport. Water exists only in the gas 
phase. The existence of liquid water is taken into account by using effective porosity as the initial porosity for GDL, which may be significantly smaller than the raw material because of possible flooding by liquid water.

The geometric and physical properties of the components are listed in Table 4.1. The electrical conductivity in the CL is assumed to be $100 \mathrm{~S} / \mathrm{m}$ for all the cases. For the GDL, the electrical conductivity is anisotropic. The relationship between in-plane $\sigma_{x z}$ vs. the through-plane conductivity $\sigma_{y}$ follows the relationship related to channel geometry and thickness of GDL [Mathias et al., 2003]:

$$
\frac{\sigma_{x z}}{\sigma_{y}}=\frac{\left(w_{1}+w_{2}\right) w_{1}}{8 h_{2}^{2}}
$$

A wide range of GDL conductivity values have been employed in various PEM fuel cell models. In this study, based on the experimental data from Mathias et al. [2003], through-plane conductivity for Toray carbon fiber paper is $1369 \mathrm{~S} / \mathrm{m}$ in the base case (no compression). The in-plane conductivity of carbon fiber paper is over an order of magnitude larger than the through-plane value. And the channel/land geometry imposes stricter requirements on the through-plane conductivity.

Both in-plane and through-plane conductivities monotonically increase when assembly pressure is applied, especially significant change of through-plane conductivity. The change of GDL conductivities follows the relationship experimental obtained by [Hottinen et al., 2007], as shown in Table 4.4. 
Table 4.4 GDL electrical conductivities

\begin{tabular}{ccc}
\hline \hline GDL Electrical conductivity & Base case (uncompressed) & $3 \mathrm{MPa}$ \\
\hline In-plane & $3.4 \times 10^{4} \mathrm{~S} / \mathrm{m}$ [Mathias et al., 2003] & $3.43 \times 10^{4} \mathrm{~S} / \mathrm{m}$ \\
Through-plane & $1.4 \times 10^{2} \mathrm{~S} / \mathrm{m}$ [Mathias et al., 2003] & $1.65 \times 10^{2} \mathrm{~S} / \mathrm{m}$ \\
\hline \hline
\end{tabular}

Some parameters change with temperature and humidity. The open circuit potenti al $E^{0}$ for the overall reaction is calculated as [Parthasarathy et al., 1992]:

$$
E^{0}=0.2329+0.0025 T
$$

The binary diffusivities $D_{i j}$, obtained experimentally at atmospheric pressure, are scaled with the temperature and pressure according to Cussler [1984].

$$
D_{i j}=D_{i j}\left(T_{0}, p_{0}\right) \frac{p}{p_{0}}\left(\frac{T}{T_{0}}\right)^{1.5}
$$

The membrane conductivity depends on RH. The following relationship between ionic conductivity $\sigma$ (in the unit of $\mathrm{S} / \mathrm{cm}$ ) and $\mathrm{RH}$ obtained from curve fitting the experimental data is employed [Yang et al., 2004].

$$
\sigma=1.3 \times 10^{-7} \exp \left(14 R H^{0.2}\right)
$$

Using deformed geometry and parameters for each case, the relationship between cell voltage and current density can be obtained by setting the potential of cathode current collector to cell voltage. COMSOL Multiphysics ${ }^{\circledR}$ is used to solve the coupled nonlinear equations for gas and charge transfer. Details of the model, geometry meshing and solver settings were consistent with previous model [Zhou et al., 2008]. 


\subsection{Results and discussions}

\subsubsection{GDL and membrane deformation}

The membrane and GDL is pre-stressed due to the applied clamping as explained previously, the displacement under $3 \mathrm{MPa}$ assembly pressure $\left(25^{\circ} \mathrm{C}\right.$ temperature and $40 \%$ $\mathrm{RH})$ is calculated and shown in Fig. 4.6. Compared to GDL and membrane, BPP is a very stiff material and has very small deformation. Fig. 4.6 only shows the bottom parts of Fig. 4.3, including GDL and membrane. The GDL is deformed severely under the land, but it is almost unchanged under the channel. Membrane has very little deformation because it has larger Young's modulus compared to that of GDL.

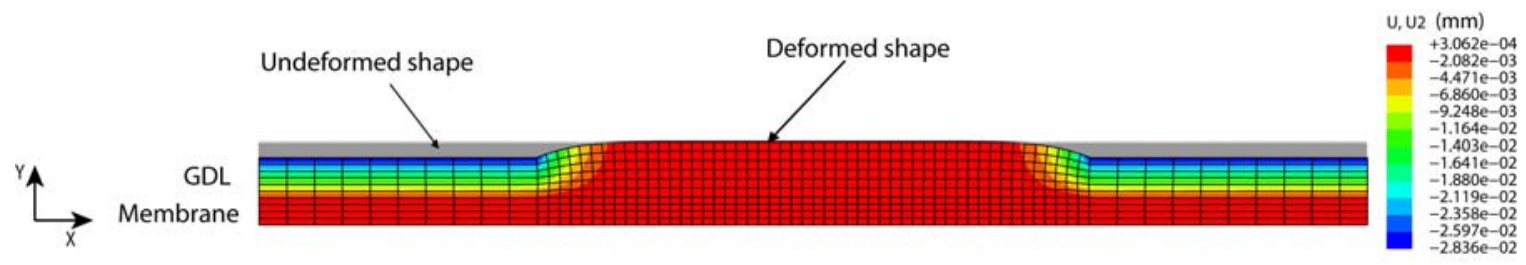

Figure 4.6 Predicted displacement contour at $\boldsymbol{Y}$-direction under $3 \mathrm{MPa}$ assembly pressure

Figure 4.7 shows the deformation of GDL and membrane when temperature and RH change under the same (3 MPa) assembly pressure. When temperature and RH increase, swelling of membrane pushes GDL more into channel cavity and the contact surface between GDL and membrane becomes curved. But the thickness of GDL under the channel almost remains the same, and that the total change from the original uncompressed volume remains small. 


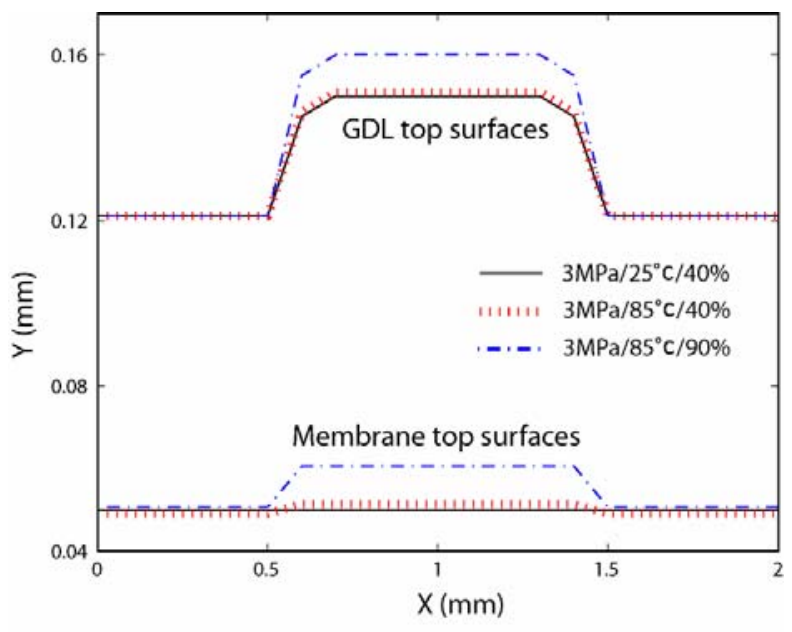

Figure 4.7 Deformed shape of GDL and membrane at various conditions

BPP, GDL and membrane all have thermal expansion to some extent, although the thermal expansion coefficients for GDL and BPP are very small. For membrane, the special characteristic is that it also expands with respect to humidity. Therefore, the total strain in the membrane due to change in the moisture and temperature is calculated from the coefficients of swelling and thermal expansion. When temperature increases to $85^{\circ} \mathrm{C}$, there is a slight variation of the GDL and membrane deformation. It is mainly due to the temperature induced strain for both GDL and membrane is very small even though the Young's modulus of membrane drops by about $40 \%$. Swelling expansion coefficient due to moisture absorption is defined as the relative change in length per $1 \% \mathrm{RH}$ change. When RH increases to $90 \%$, membrane becomes softer since its Young's modulus drops from $197 \mathrm{MPa}$ to $46 \mathrm{MPa}$. Whereas, swelling induced strain for membrane is significant.

Fig. 4.8 shows the change of contact pressure and contact resistance. The contact pressure at $3 \mathrm{MPa} / 25^{\circ} \mathrm{C} / 40 \% \mathrm{RH}$ condition is $5.78 \mathrm{MPa}$ and contact resistance is 0.22 $\mathrm{m} \Omega \mathrm{cm}^{2}$. When temperature increases to $85^{\circ} \mathrm{C}$, the contact pressure goes up to $7.2 \mathrm{MPa}$ and contact resistance decreases to $0.198 \mathrm{~m} \Omega \mathrm{cm}^{2}$. When RH further increases from $40 \%$ to $90 \%$ at $85^{\circ} \mathrm{C}$, the contact pressure increases to $9.3 \mathrm{MPa}$ and contact resistance is 0.12 
$\mathrm{m} \Omega \mathrm{cm}^{2}$. That is due to the re-distribution of stress field in the stack. Since the relative location between upper surface of BPP and lower surface of membrane is fixed after assembly, the resulting displacement at the upper boundary from the previous step is fixed throughout the analysis. The internal forces have to be redistributed to accommodate additional loading. Hence the contact force is changed when fuel cell operating conditions change. When membrane swells, the contact force becomes larger. The contact force between BPP shoulder and GDL determines the contact resistance in between. The change of contact resistance should be considered when evaluating fuel cell overall performance.

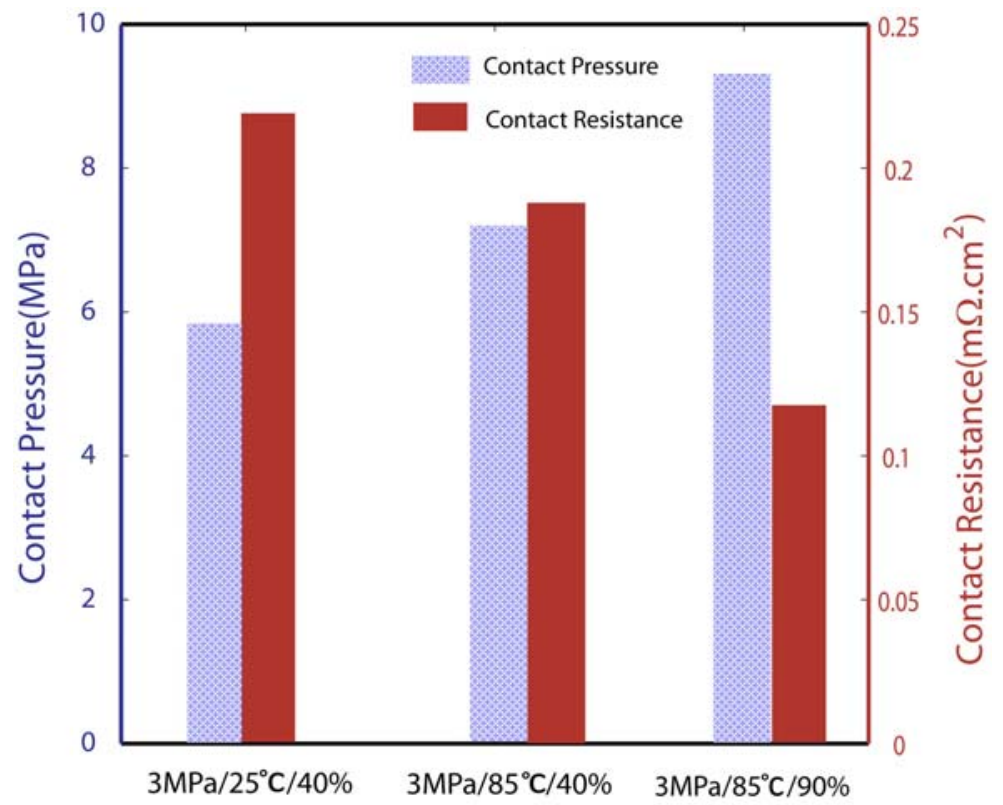

Figure 4.8 Contact pressure and contact resistance at various operating conditions

When the stack is not well assembled, the contact resistance could be very high, ranging up to a few hundreds $\mathrm{m} \Omega \mathrm{cm}^{2}$ in a fuel cell stack [Ihonen et al., 2001]. A reasonable value of $20 \mathrm{~m} \Omega \mathrm{cm}^{2}$ is assumed in the base case model [Escribanoa et al., 2006]. The contact resistance under $3 \mathrm{MPa}$ assembly pressure and various operating 
conditions are significantly smaller due to higher electrical conductivity and smoother contacting surfaces used in the simulation.

\subsubsection{PEM fuel cell performance}

\section{Polarization Curves}

The polarization curves are achieved by solving the average current density for different values of cell voltage. Fig. 4.9 shows the polarization curves for the four cases. In brief, assembly pressure causes performance decrease but higher temperature and $\mathrm{RH}$ increase the polarization curves over the entire operating range of the cell.

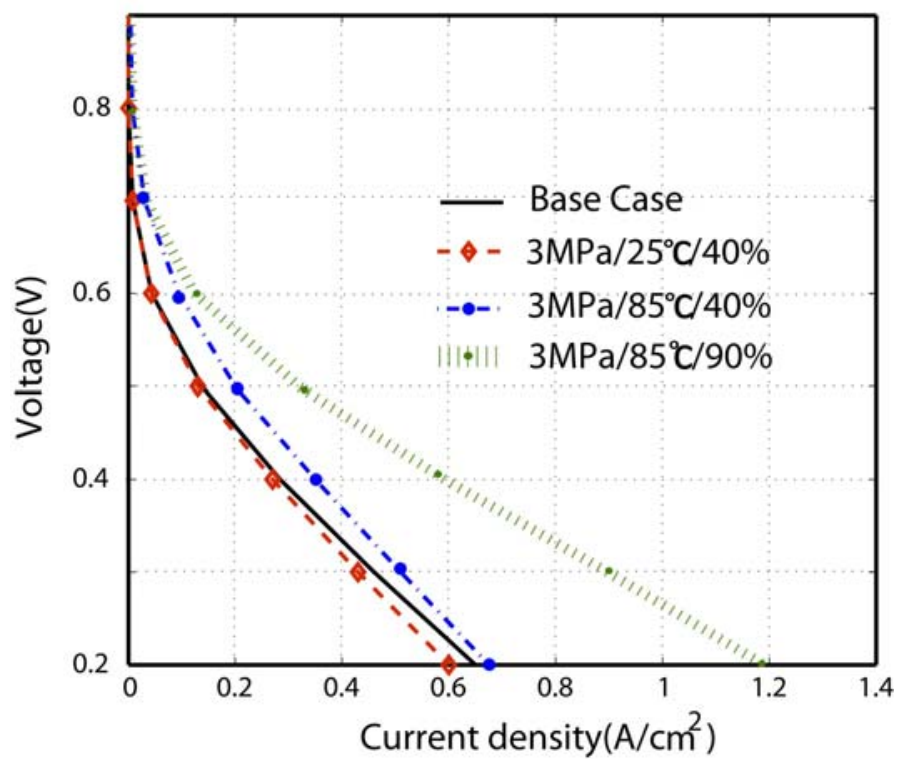

Figure 4.9 Polarization curves for various cases

It is observed that under the assembly pressure of $3 \mathrm{MPa}$, the performance decreases as consistent with previous findings [Zhou et al., 2008]. It is mainly due to the fact that compression causes the decrease of GDL porosity so that imposes more resistance to gas flow, even though compression reduces contact resistance on the other hand. There are no significant differences between the compression case $\left(3 \mathrm{MPa} / 25^{\circ} \mathrm{C} / 40 \% \mathrm{RH}\right)$ and the base case at the cell voltage level, indicating that the 
overall cell performance is not significantly affected by the assembly pressure at $3 \mathrm{MPa}$ for this set of component geometry and material properties.

When temperature increases from $25^{\circ} \mathrm{C}$ to $85^{\circ} \mathrm{C}$, the performance curve has a moderate increase. This is due to the total effects of contact resistance reduction, GDL protrusion and the change of some kinetic parameters. Contact resistance reduction leads to the decrease of ohmic voltage loss. GDL protrusion reduces gas flow area, which can facilitate the gas flow therefore reduce flow resistance. Also, the diffusion characteristics of gas mixture and kinetic parameters increase with temperature, which benefit for gas diffusion, and result in the decrease of the cathode activation overpotential with temperature.

When RH goes to $90 \%$, the performance curve has a more significant increase. When RH increases, the ionic conductivity the membrane increases, so that the overpotential is decreased. In terms of cell performance, this is desirable because lower ovepotentials result in higher cell voltage. Also the change of RH has more impacts on contact pressure and contact resistance between BPP and GDL, as shown in Fig. 4.8. When $\mathrm{RH}$ increases from $40 \%$ to $90 \%$, the contact resistance drops more. This is one of the contributing factors for the performance increase. In addition, GDL is more protruded into BPP channel due to swelling and the change of material properties, and the change of porosity and flow channel area reduction are beneficial to gas flow and diffusion, which will in turn improve performance. All those effects integrate together to yield the performance better with higher temperature and humidity. 


\section{Current Production Rate in CL along the channel length direction}

Figures 4.10 (a) and (b) present the current production rate and variation at the interface between GDL and catalyst layer along the channel direction for three cases when the cell voltage is $0.5 \mathrm{~V}$. When the assembly pressure effects and elevated temperature and $\mathrm{RH}$ are taken into account, there is a significant change of the current production rate at this interface.

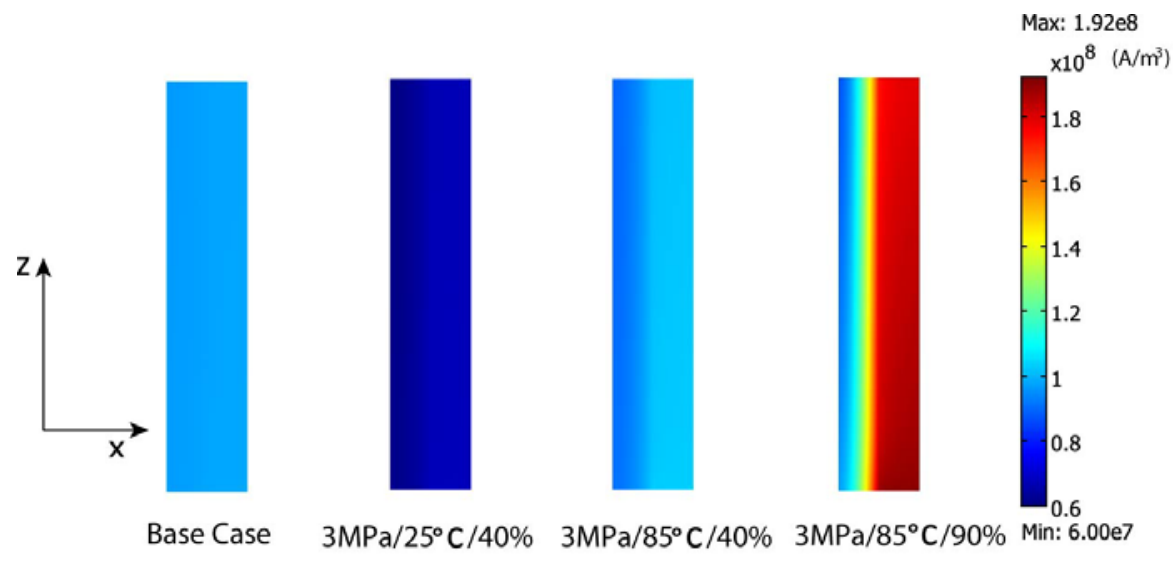

(a)

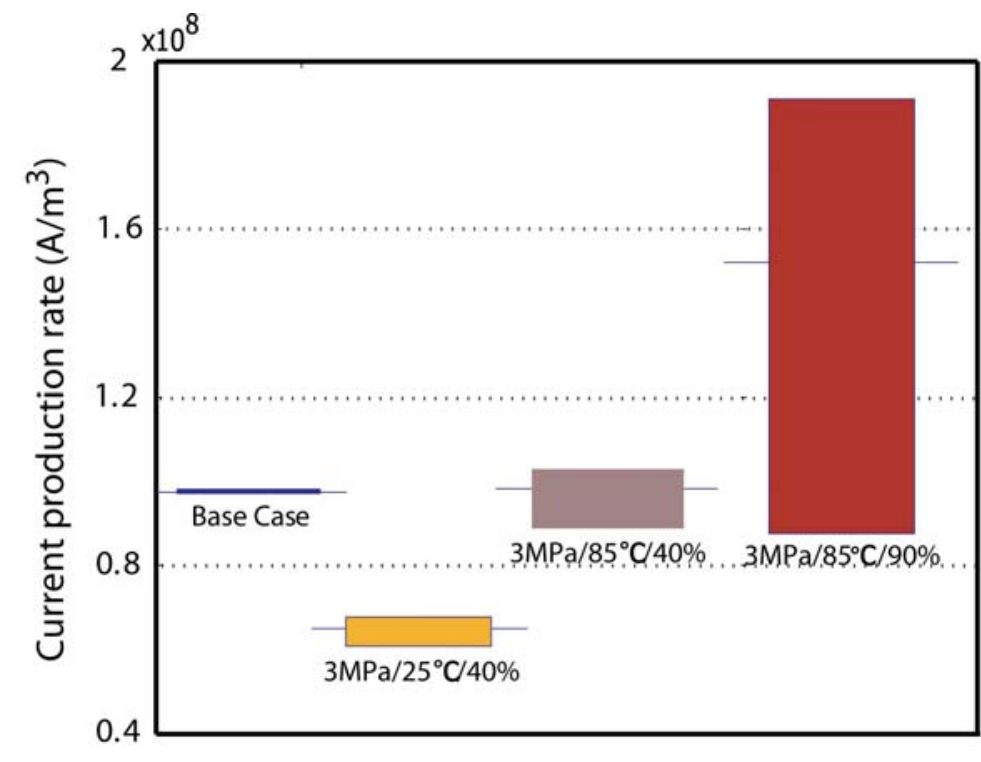

(b)

Figure 4.10 Current production rate profiles at the interface between CL and GDL for different cases at $0.5 \mathrm{~V}$ 
When an assembly pressure of $3 \mathrm{MPa}$ is applied, the average current density of the case at $3 \mathrm{MPa} / 25^{\circ} \mathrm{C} / 40 \%$ is lower than the base case $\left(0 \mathrm{MPa} / 25^{\circ} \mathrm{C} / 40 \%\right)$ since assembly pressure causes performance decrease. The current production rate starts to have some variations along the channel length direction at this interface. At the base case, the current production rate only has $1.7 \%$ variation compared with the average value over the whole surface. At the compression case $\left(3 \mathrm{MPa} / 25^{\circ} \mathrm{C} / 40 \%\right)$, the current production rate variation is increased to $10 \%$. This is due to the fact that assembly pressure induces large unevenness of GDL porosity. GDL porosity is approximately 0.3 under the BPP land while 0.6 under the BPP channel for the compression case. This variation in GDL porosity causes the variation in current production rate.

When temperature rises to $85^{\circ} \mathrm{C}$, the average current production rate is higher since the voltage output increases with temperature, while the variation of current production rate increases to $15 \%$. Temperature increase causes more inhomogeneous compression, which in turn causes more current generation under the channel and less current generation under the land.

When $\mathrm{RH}$ increases to $90 \%$, the average current production rate is substantially increased since the voltage output increases greatly at higher RH because of higher membrane conductivity and smaller contact resistance. Meanwhile, the current production rate variation is also increased to $68 \%$. A notable portion of current is generated mostly under the channel and the current production rate is reduced under the BPP land. That is attributed by the fact that the inhomogeneous compression is much more severe when RH increases as shown in Fig. 4.7. Thus GDL porosity unevenness becomes more significant. It is more difficult for the gases to transport into the GDL 
under the land; hence the GDL under the land is in the starvation of reactant gases and generate less current.

\section{Current Production Rate in CL along the thickness direction}

Fig. 4.11shows the distributions of current production rate in the thickness

direction of the $C L$ at the cell voltage of $0.5 \mathrm{~V}$ and $Z=2 \mathrm{~mm}$. The same trends in Fig. 4.10 can be observed.

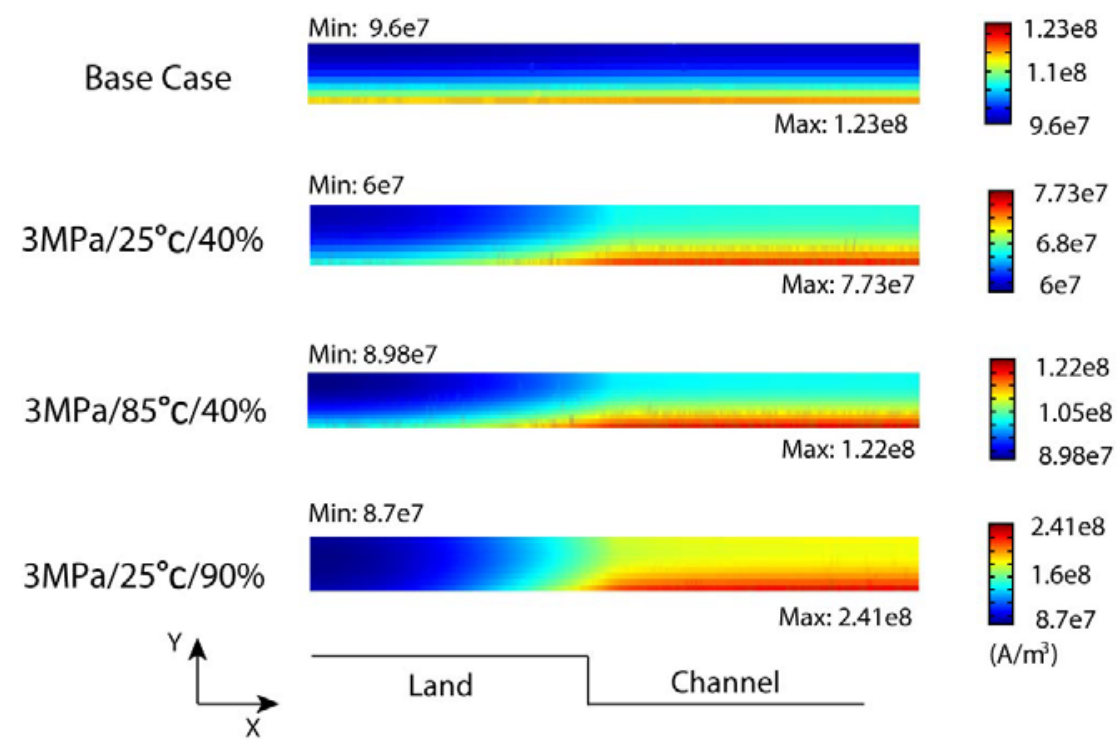

\section{Figure 4.11 Current production rate profiles in the CL for different cases at $0.5 \mathrm{~V}$}

Both compression and elevated temperature and $\mathrm{RH}$ cause significant variation along the CL thickness and width direction. Less current is produced under the land area, because of the reduced oxygen diffusion in compressed region. More current is generated under the channel area which is caused by the combined effects including the dependence of diffusion parameters and kinetic parameters on temperature and $\mathrm{RH}$, GDL protrusion and porosity variation. As shown in Fig. 4.7, GDL is expanded under the channel area so 
that the porosity is increased. Thus the gas transfer is facilitated and more current is generated.

\subsection{Conclusions}

A comprehensive analysis of the influence of elevated temperature and relative humidity on fuel cell stack deformation, contact resistance and performance was presented. Elevated temperature and humidity, especially humidity, caused severe GDL protrusion and stress-redistribution, which lead to the reduction of contact resistance. Even though elevated temperature and RH improved fuel cell performance, significant variation of current production rate was observed along all directions in the cell when assembly pressure was applied and temperature and $\mathrm{RH}$ were increased close to the operation conditions. The stack would be more prone to degradation with such significant variation. One of the future research topics is the assembly optimization at various operating conditions to improve performance as well as mitigate the current variation. 


\section{References}

Bernardi, D.M., Verbrugge, M.W., (1991), "Mathematical model of a gas diffusion electrode bonded to a polymer electrolyte," AICHE Journal, Vol. 37, pp. 11511163

Berning, T., Lu,D., Djilali, N., (2002), “Three-dimensional computational analysis of transport phenomena in a PEM fuel cell," Journal of Power Sources, Vol. 106, pp.284-294.

Bevers, D., Wohr, M. W., (1997), "Simulation of a polymer electrolyte fuel cell electrode," Journal of Applied Electrochemistry, Vol. 27, pp. 1254-1264.

Coppo, M., Siegel, N.P., Spakovsky, M. R., (2006), “On the influence of temperature on PEM fuel cell operation,” Journal of Power Sources, Vol. 159, pp. 560-569.

Cussler, E. L., (1984), Diffusion-Mass Transfer in Fluid Systems, Cambridge University Pressure, Cambridge, UK.

Escribanoa, S., Blachota, J., Ethèvea, J., Morina, A, and Mosdaleb, R., (2006), "Characterization of PEMFCs gas diffusion layers properties," Journal of Power Sources, Vol. 156, pp. 8-13.

Fischer, A., Jindraz, J., Wendt, H., (1998), "Porosity and catalyst utilization of thin layer cathodes in air operated PEM-fuel cells," Journal of Applied Electrochemistry, Vol. 28, pp. 277-282.

Ge, J., Higier, A., and Liu, H., (2006), "Effect of Gas Diffusion Layer Compression on PEM Fuel Cell Performance,” Journal of Power Sources, Vol. 159, pp. 922-927.

Gurau, V., Liu, H., and Kakac, S., (1998), "Two-Dimensional Model for Proton Exchange Membrane Fuel Cells," AIChE Journal, Vol. 44, pp. 2410-2422.

Hottinen, T., Himanen, O., Karvonen, S., Nitta, I., (2007), "Inhomogeneous compression of PEMFC gas diffusion layer Part II. Modeling the effect," Journal of Power Sources, Vol. 171, pp. 113-121.

Ihonen, J., Lindbergh, G., Sundholm, G., (2001), "A novel polymer electrolyte fuel cell for laboratory investigations and in-situ contact resistance measurements," Electrochimica Acta, Vol. 46, pp. 2899-2911

Inoue, G., Matsukuma, Y., Minemoto, M., (2006), "Effect of gas channel depth on current density distribution of polymer electrolyte fuel cell by numerical analysis including gas flow through gas diffusion layer," Journal of Power Sources, Vol. 157, pp. 136-152.

Kazim, A., Forges, P. and Liu, H. T., (2003), "Effects of cathode operating conditions on 
performance of a PEM fuel cell with interdigitated flow fields," International Journal of Energy Research, Vol. 27, pp. 401-414.

Kusoglu, A., Karlsson, M. A., Santare, M. H., Cleghorn, S. and Johnson, W. B., (2006), "Mechanical response of fuel cell membranes subjected to a hygro-thermal cycle," Journal of Power Sources, Vol. 161, pp. 987-996.

Lin, G., Nguyen, T. V., (2006), "A Two-Dimensional Two-Phase Model of a PEM Fuel Cell," Journal of the Electrochemical Society, Vol. 153, pp. A372-A382.

Mathias, M., Roth, J., Fleming, J., Lehnert, W., (2003), in: Vielstich, W., Lamm, A., Gasteiger, H.A. (Eds), Handbook of Fuel Cells - Fundamentals, Technology and Applications, V3: Fuel Cell Technology and Application, Wiley, pp. 517-538.

Mawardi, A., Yang, F., and Pitchumani, R., (2005), "Optimization of the Operating Parameters of a Proton Exchange Membrane Fuel Cell for Maximum Power Density," ASME Journal of Fuel Cell Science and Technology, Vol. 2, pp. 121135.

Natarajan, D., Nguyen, T. V., (2004), "Effect of electrode configuration and electronic conductivity on current density distribution measurements in PEM fuel cells," Journal of Power Sources, Vol. 135, pp. 95-109.

Neyerlin, K. C., Gasteiger, H. A., Mittelsteadt, C. K., Jorne, J., Gu, W., (2005), "Effect of Relative Humidity on Oxygen Reduction Kinetics in a PEMFC," Journal of the Electrochemical Society, Vol.152, pp. A1073-A1080.

Onda K., Taniuchi T., Araki T., Sunakawa D.,(2007), "Numerical Analysis of Current Distribution at Proton Exchange Membrane Fuel Cell Compared by Segmented Current Collector Cell," ASME Journal of Fuel Cell Science and Technology, Vol. 4, pp. 441-449.

Parthasarathy, A., Srinivasan, S., and Appleby, A. J., (1992), “Temperature Dependence of the Electrode Linetics of Oxygen Reduction at the Platinum/Nafion Interfacea Microelectrode Investigation," Journal of the Electrochemical Society, Vol. 139, pp. 2530-2537.

Springer, T. E., Zawodzinski, T. A., Gottesfeld, S., (1991), "Polymer electrolyte fuel cell model," Journal of the Electrochemical Society, Vol. 138, pp. 2334-2342.

Sun, W., Peppley, B., Karana. K., (2005), "Modeling the influence of GDL and flowfield plate parameters on the reaction distribution in the PEMFC cathode catalyst layer," Journal of Power Sources, Vol. 144, pp. 42-53.

Tang, Y., Santare, M. H., Karlsson, A M., Cleghorn, S., Johnson, W. B., (2006), "Stresses in proton exchange membranes due to hydro-thermal loading," ASME Journal of Fuel Cell Science and Technology, Vol. 3, pp. 119-124. 
Tang, Y., Karlsson, A., Santare, M., Gilbert, M., Cleghorn, S., Johnson, W., (2006), “An experimental investigation of humidity and temperature effects on the mechanical properties of perfluorosulfonic acid membrane," Materials Science and Engineering A, Vol. 425, pp. 297-304.

Um, S., C. Wang, Y., and Chen, K. S., (2000), "Computational Fluid Dynamics Modeling of Proton Exchange Membrane Fuel Cells," Journal of the Electrochemical Society, Vol.147 pp. 4485-4493.

Yan, W., Yang, C., SOONG, C., Chen, F., Mei, S., (2006), "Experimental studies on optimal operating conditions for different flow field designs of PEM fuel cells," Journal of Power Sources, Vol.160, pp. 284-292.

Yan, Q., Toghiani, H. Wu, J., (2006), "Investigation of water transport through membrane in a PEM fuel cell by water balance experiments," Journal of Power Sources, Vol. 158, pp. 316-325.

Yang, C., Srinivasan S., Bocarsly, A.B., Tulyani, S., Benziger, J.B., (2004), “A comparison of physical properties and fuel cell performance of Nafion and zirconium phosphate/Nafion composite membranes," Journal of Membrane Science, Vol. 237, pp. 145-161.

Zhang, Y., Mawardi, A., Pitchumani, R., (2006), "Effects of Operating Parameters on the Current Density Distribution in Proton Exchange Membrane Fuel Cells," ASME Journal of fuel cell science and technology, Vol. 3, pp. 464-476.

Zhou, Y., Lin, G., Shih, A. J., and Hu, S. J., (2008), "Multi-Physics Modeling of Assembly Pressure Effects on PEM Fuel Cell Performance," ASME Journal of Fuel Cell Science and Technology, in press.

Zhou, Y., Lin, G., Shih, A. J., and Hu, S. J., (2007), “A Micro-scale Model for Predicting Contact Resistance between Bipolar Plate and Gas Diffusion Layer in PEM Fuel Cells," Journal of Power Sources, Vol. 163, pp. 777-783. 


\section{CHAPTER 5}

\section{CONCLUSIONS AND FUTURE WORK}

\subsection{Conclusions}

The research on assembly and performance modeling of PEM fuel cells originates from the rapid development of fuel cell technology and the potential high volume assembly and manufacturing requirements. As fuel cell manufacturing scales up, it is critical to develop an understanding of the relationship between manufacturing and assembly processes and fuel cell performance and durability. Such an understanding does not currently exist, but it can play a major role in fuel cell design, and it is integral to implementing design for manufacturability. This dissertation is aimed to fill this gap and presents a comprehensive analysis of PEM fuel cell assembly and performance. The developed methodologies enable an effective and accurate prediction of fuel cell performance especially under clamping load and operating conditions. This methodology can be utilized to optimize assembly pressure and manufacturing parameters according to various operating conditions and forms a basis for design new component geometry and properties which will advance fuel cell performance and manufacturing.

The major achievements of this dissertation can be summarized in three parts; 
(1) Development of a micro-scale contact model to predict electrical contact resistance between BPP and GDL in PEM fuel cells: The contact resistance between BPP and GDL is predicted based on simulated BPP surface and GDL structure. Using this micro-scale numerical model, the contact resistance between BPP and GDL in PEM fuel cells can be predicted. It is found that contact resistance decreases monotonically with the increase of assembly pressure. Specifically, the contact resistance changes greatly as the clamping pressure increases initially and becomes almost unchanged when the assembly pressure further increases. The contact resistance also depends on BPP surface roughness parameters. Practically, the summit standard deviation has greater impact than other surface roughness parameters. This micro-scale contact model is beneficial to understand the basic mechanisms of contact behavior between the rough surface and a fibrous medium and can be integrated with other fuel cell simulations to predict the overall fuel cell performance.

(2) Development of a multi-physics approach to model PEM fuel cell performance: A multi-physics model has been developed to predict PEM fuel cell performance incorporating assembly pressure effects, contact resistance, multi-component gas flow and diffusion and chemical reactions. This model reveals that assembly pressure has significant effects on PEM fuel cell performance, which is typically neglected in existing fuel cell modeling work. Generally, high assembly pressure increases mass transfer resistance. Current density decreases dramatically with an increase of 
assembly pressure. However, by incorporating the effect of contact resistance, the overall performance first increases and then decreases with the increase of assembly pressure. There exists an optimum assembly pressure, in the lower-pressure region, at which fuel cell performance is maximized. Finally, significant variation of current density distribution and $\mathrm{O} 2$ mass fraction distribution are also observed when assembly pressure is applied. This study is able to predict fuel cell performance more realistically and could provide guidance for potential improvement of optimal assembly process.

\section{(3) Investigation of temperature and relative humidity impact on stack} deformation, contact resistance, overall performance and current distribution: A comprehensive analysis is implemented regarding the influence of elevated temperature and relative humidity on fuel cell stack deformation, contact resistance and performance. It shows that GDL is more compressed under the land area and more protruded into channel geometry when temperature and $\mathrm{RH}$ are increased. Local contact resistance are reduced due to the fact of contact pressure is increased by the re-distribution of stress field. Even though it is observed that elevated temperature and $\mathrm{RH}$ improve fuel cell overall performance, a significant variation of current production rate was found along all directions in the cell when assembly pressure is applied and temperature and $\mathrm{RH}$ are increased. The stack is more prone to degradation with such significant variation.

The original contributions of this research can be summarized as follows: 
(1) The contact resistance between BPP and GDL in PEM fuel cells is predicted theoretically, with the GDL characteristics and BPP surface topology as inputs. Guidelines are proposed for manufacturing parameters of BPP surface in order to reduce contact resistance.

(2) It is also found that elevated temperature and humidity will increase the contact pressure between BPP and GDL, hence reduce contact resistance.

(3) A finite element approach is developed to model inhomogeneous mechanical deformation induced by assembly pressure in the GDL and membrane. The significant variation and unevenness of GDL material properties are also obtained.

(4) At elevated temperature and humidity, GDL and membrane have thermal expansion and membrane swelling, which push GDL more into channel cavity and also the contact surface between GDL and membrane becomes curved.

(5) Assembly pressure is shown to have significant impacts on PEM fuel cell stack performance and more mass transfer resistance is imposed when assembly pressure increases.

(6) An optimal assembly pressure is identified, at which the fuel cell performance is maximized, by compromising the trade-offs of assembly pressure on contact resistance and mass transfer resistance.

(7) Elevated temperature and humidity can improve fuel cell power output, however, significant variations of current distribution are observed. The stack is more prone to degradation with such significant variation. 


\subsection{Future work}

The methodologies and models proposed in this research could be further improved and /or extended in the following directions:

(1) To predict contact resistance more accurately, a multi-scale approach can be developed to capture the multi-scale nature of BPP and GDL surfaces. Two or three most significant scales will be considered for contact resistance prediction, e.g., form, which represents the nominal designed land shape and waviness (due to manufacturing processes variability). In addition, stack alignment can be also considered to calculate the real assembly pressure distribution so that contact resistance can be evaluated more accurately.

(2) A three-dimensional random network model for GDL fiber structure can be developed based on the methodologies developed in Chapter 2. Porosity, diffusivity, resistivity and internal structure can be achieved from this random fiber contact model. More importantly, the change of physical properties of GDL with assembly pressure can also be obtained through this detailed structural model, which is crucial to accurately evaluating assembly pressure impact.

(3) Liquid water formation and water transport can be included into the multiphysics model to predict assembly pressure impact on performance. Liquid water transport is dramatically influenced by the inhomogeneous compression of GDL. Incorporating liquid water transport in the performance model can expose more impacts induced by assembly pressure and provides more criteria to evaluate this impact. 
(4) Innovative channel geometry can be designed to mitigate assembly pressure impact and guarantee low contact resistance. This geometry can decrease the negative impact of GDL protrusion and porosity unevenness.

(5) Optimization methods need to be developed for assembly processes under various operating conditions and for component design. 